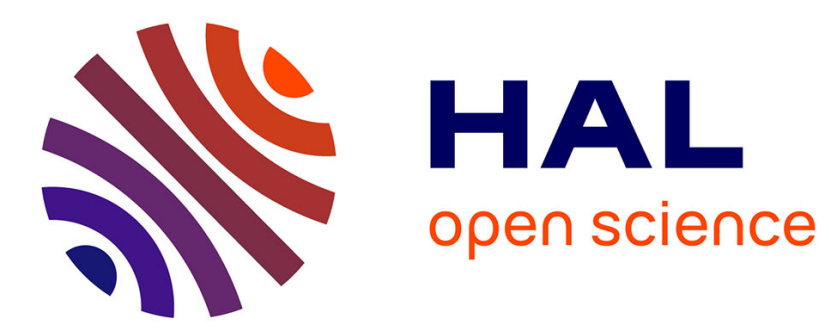

\title{
TttE ATMOSPHERIC INPUT OF TRACE SPECIES TO THE WORI• OCEAN
}

R. A Duce, P. Liss, J. Merrill, E. Atlas, P. Buat-Menard, B. Hicks, J. Miller, J. Prospero, R. Arimoto, T. Church, et al.

\section{- To cite this version:}

R. A Duce, P. Liss, J. Merrill, E. Atlas, P. Buat-Menard, et al.. TttE ATMOSPHERIC INPUT OF TRACE SPECIES TO THE WORI• OCEAN. Global Biogeochemical Cycles, 1991, 5 (3), pp.193-259. 10.1029/91GB01778. hal-03583041

\section{HAL Id: hal-03583041 https://hal.science/hal-03583041}

Submitted on 21 Feb 2022

HAL is a multi-disciplinary open access archive for the deposit and dissemination of scientific research documents, whether they are published or not. The documents may come from teaching and research institutions in France or abroad, or from public or private research centers.
L'archive ouverte pluridisciplinaire HAL, est destinée au dépôt et à la diffusion de documents scientifiques de niveau recherche, publiés ou non, émanant des établissements d'enseignement et de recherche français ou étrangers, des laboratoires publics ou privés. 
THE ATMOSPHERIC INPUT OF TRACE SPECIES TO THE WORLD OCEAN

\author{
R.A. Duce, ${ }^{1}$ P.S. Liss, ${ }^{2}$ J.T. Merrill, ${ }^{1}$ E.L. Atlas, ${ }^{3}$ \\ P. Buat-Menard, ${ }^{4}$ B.B. Hicks, ${ }^{5}$ J.M. Miller, ${ }^{5}$ \\ J.M. Prospero, ${ }^{6}$ R. Arimoto, ${ }^{1}$ T.M. Church, 7 \\ W. Ellis, ${ }^{1}$ J.N. Galloway, ${ }^{8}$ L. Hansen, ${ }^{1}$ \\ T.D. Jickells, ${ }^{2}$ A.H. Knap, ${ }^{9}$ K.H. Reinhardt, ${ }^{10}$ \\ B. Schneider, 11 A. Soudine, 12 J.J. Tokos, 1 \\ S. Tsunogai, ${ }^{13}$ R. Wollast, ${ }^{14}$ and M. Zhou 15
}

$1_{\text {Graduate School of Oceanography, University of }}$ Rhode Island, Narragansett.

2 School of Environmental Sciences, University of

East Anglia, Norwich, England.

3 National Center for Atmospheric Research, Boulder, Colorado.

${ }^{4}$ Centre des Faibles Radioactivites, Gif-Sur-

Yvette, France.

5 Air Resources Laboratory, National Oceanic and Atmospheric Administration, Silver Spring, Maryland.

$6_{\text {Rosenstiel School of Marine and Atmospheric }}$

Sciences, University of Miami, Miami, Florida.

${ }^{7}$ College of Marine Studies, University of

Delaware, Newark.

${ }^{8}$ Department of Environmental Sciences,

University of Virginia, Charlottesville.

${ }^{9}$ Bermuda Biological Station for Research, Ferry

Reach.

${ }^{10}$ GKSS Research Center, Geesthacht, Germany.

11 Institut fur Meereskunde, Universitat Kiel,

Kiel, Germany.

12World Meteorological Organization, Geneva.

13Department of Chemistry, Hokkaido

University, Hakodate, Japan.

${ }^{14}$ Laboratorie d'Oceanographie, Universite Libre

de Bruxelles, Brussels, Belgium.

15 National Research Center for Marine

Environment Forecasts, Beijing.

Copyright 1991

by the American Geophysical Union.

Paper number $91 \mathrm{~GB} 01778$.

0886-6236/91/91GB-01778 $\$ 10.00$
Abstract. Over the past decade it has become apparent that the atmosphere is a significant pathway for the transport of many natural and pollutant materials from the continents to the ocean. The atmospheric input of many of these species can have an impact (either positive or negative) on biological processes in the sea and on marine chemical cycling. For example, there is now evidence that the atmosphere may be an important transport path for such essential nutrients as iron and nitrogen in some regions. In this report we assess current data in this area, develop global scale estimates of the atmospheric fluxes of trace elements, mineral aerosol, nitrogen species, and synthetic organic compounds to the ocean; and compare the atmospheric input rates of these substances to their input via rivers. Trace elements considered were $\mathrm{Pb}, \mathrm{Cd}, \mathrm{Zn}, \mathrm{Cu}, \mathrm{Ni}, \mathrm{As}$, $\mathrm{Hg}, \mathrm{Sn}, \mathrm{Al}, \mathrm{Fe}, \mathrm{Si}$, and $\mathrm{P}$. Oxidized and reduced forms of nitrogen were considered, including nitrate and ammonium ions and the gaseous species NO, $\mathrm{NO}_{2}, \mathrm{HNO}_{3}$, and $\mathrm{NH}_{3}$. Synthetic organic compounds considered included polychlorinated biphenyls (PCBs), hexachlorocyclohexanes (HCHs), DDTs, chlordane, dieldrin, and hexachlorobenzenes (HCBs). Making this assessment was difficult because there are very few actual measurements of deposition rates of these substances to the ocean. However, there are considerably more data on the atmospheric concentrations of these species in aerosol and gaseous form, Mean concentration data for $10^{\circ} \times 10^{\circ}$ ocean areas were determined from the available concentration data or from extrapolation of these data into other regions. These concentration distributions were then combined with appropriate exchange coefficients and precipitation fields to obtain the global wet and dry deposition fluxes. Careful consideration was given to atmospheric transport processes as well as to removal mechanisms and the physical and physicochemical 
properties of aerosols and gases. Only annual values were calculated. On a global scale atmospheric inputs are generally equal to or greater than riverine inputs, and for most species atmospheric input to the ocean is significantly greater in the northern hemisphere than in the southern hemisphere. For dissolved trace metals in seawater, global atmospheric input dominates riverine input for $\mathrm{Pb}, \mathrm{Cd}$, and $\mathrm{Zn}$, and the two transport paths are roughly equal for $\mathrm{Cu}$, $\mathrm{Ni}, \mathrm{As}$, and $\mathrm{Fe}$. Fluxes and basin-wide deposition of trace metals are generally a factor of 5-10 higher in the North Atlantic and North Pacific regions than in the South Atlantic and South Pacific. Global input of oxidized and reduced nitrogen species are roughly equal to each other, although the major fraction of oxidized nitrogen enters the ocean in the northern

\section{CONTENTS}

Introduction................................. 194

Deposition Processes............................. 195

Introduction.................................. 195

Direct measurement of atmosphereocean mass fluxes....................... 195

Indirect estimates of atmosphereocean mass fluxes....................... 196

Atmospheric Transport and Precipitation

Climatology............................... 200

Introduction...................................... 200

Climatological data over the oceans........... 200

Lagrangian and Eulerian models............. 201

Framework for the calculation................ 202

Summary ................................. 204

The Atmospheric Input of Trace Elements and Mineral Aerosol to the World Ocean..... 204

Introduction..................................... 204

Methodology.............................. 206

Results...................................... 211

Comparison between global atmospheric and riverine inputs of trace elements.. 213

The Atmospheric Input of Nitrogen Species to the World Ocean........................... 214

Introduction..................................... 214

Sources of nutrient nitrogen species.......... 214

Data selection and calculation parameters... 215

Summary and discussion...................... 220

Conclusions.................................... 230

The Atmospheric Input of Synthetic Organic Compounds to the World Ocean........... 230

Introduction................................. 230

Choice of compounds....................... 231

Data selection and extrapolation............... 234

Data sources for atmospheric concentrations.......................... 235

Methods of calculation.......................... 235

Flux estimates............................. 242

Results........................................ 243

Conclusions........................................ 245 hemisphere, primarily as a result of pollution sources. Reduced nitrogen species are much more uniformly distributed, suggesting that the ocean itself may be a significant source. The global atmospheric input of such synthetic organic species as $\mathrm{HCH}$, PCBs, DDT, and HCB completely dominates their input via rivers.

\section{INTRODUCTION}

Transport of potentially harmful trace substances to the world oceans, whether it be by rivers, by bulk dumping, or via the atmosphere, has recently become a major topic of both public and scientific discussion. However, though the polluting of the oceans is not a new phenomenon, it has generally thought to have accelerated in recent years. How important a role the atmosphere plays in transporting pollutants to the oceans is a critical unknown. A first attempt to address this question was published over a decade ago [National Academy of Sciences (NAS), 1978]. Since that report a considerable amount of research and monitoring has gone on to document transport of both natural and man-made substances to the oceans via the atmosphere. SEAREX (the Sea-Air Exchange Program), WATOX (the Western Atlantic Ocean Experiment), PHYCEMED (the Physics and Chemistry of the Mediterranean), AEROCE (the Atmosphere-Ocean Chemistry Experiment), and others are examples of major research programs including such studies. These programs have produced a set of high quality atmospheric chemistry data that can be used in estimating the total deposition of many trace substances to the oceans and coastal areas. These studies showed that large quantities of continental materials are often carried great distances over the oceans.

In this report we assess the global atmosphere-toocean deposition rates of a number of trace species. Substances that can be used as nutrients are evaluated, and these include oxidized and reduced nitrogen species, both gaseous and particulate, and various trace elements including $\mathrm{Si}, \mathrm{Fe}$, and $\mathrm{P}$. We also consider potentially harmful species such as synthetic organics and such heavy metals as $\mathrm{Pb}, \mathrm{Cd}, \mathrm{Zn}, \mathrm{Ni}$, $\mathrm{As}$, and $\mathrm{Cu}$, which at high concentrations may have deleterious effects on marine organisms. We also assess Al, whose atmospheric input may have a significant impact on its chemical cycle in the oceans. Estimates of the input of these species to the major ocean basins and to the global ocean are made, and the atmospheric fluxes are compared with those fluxes entering the ocean from rivers. Atmospheric input to the coastal zone is not specifically evaluated in this paper, but the interested reader is referred to review papers on this subject by the Group of Experts on the Scientific Aspects of Marine Pollution (GESAMP) [1989] and Duce [1991].

The assessment of atmospheric fluxes to the global ocean is difficult for a number of reasons. 
First, there are very few measurements of actual deposition rates. Furthermore, most deposition studies focus only on the wet-deposited component; there are very few measurements of dry deposition of either particles or gases. However, there are relatively more data on the atmospheric concentration of various aerosol and gaseous species. As a consequence, the strategy used in this assessment is to calculate deposition rates based on atmospheric concentration data. Deposition rates are calculated for $10^{\circ} \mathrm{x}$ $10^{\circ}$ ocean areas using measured concentration data or such data extrapolated from actual concentration measurements. These concentration data are then combined with appropriate exchange coefficients for the various species. As a test, the computed fluxes for some species are compared with the more limited direct deposition measurements at certain sites. In order to carry out such computations, it is necessary to have a knowledge of atmospheric transport processes as well as removal mechanisms and physical and physico-chemical properties of aerosols and gases. Unfortunately, in many of these areas our knowledge is inadequate, and assumptions about one or more of these parameters must be made.

The organization of the paper derives from this strategy. In the deposition processes section we discuss the state of knowledge about air-sea exchange processes. These include gas exchange, dry deposition of particles, and the precipitation scavenging of both particles and gases. In that section a general description of the fundamental principles underlying the methods used to estimate the fluxes of particular classes of substances is provided. We also describe how the actual fluxes are calculated once the relevant atmospheric concentration data, exchange coefficients and precipitation scavenging ratios are available. In the next section atmospheric transport and precipitation climatology are discussed for the various ocean regions, with emphasis on the primary transport paths and with summaries of precipitation patterns and their temporal variability. The objective is to relate our knowledge of atmospheric transport paths to known atmospheric concentration distributions and to probable source areas on the continents. In this section the actual procedures used for computing the atmospheric fluxes are described in detail, and a specific example of such a computation is given.

In the succeeding sections the available atmospheric concentration data are assessed and the subsequent flux computations described. The deposition species are grouped into three categories: trace elements and mineral aerosols, nitrogen species, and synthetic organic compounds. This classification is largely based on the different physical and chemical characteristics of substances in these groups, their removal processes, and the availability of data sets. Finally, some recommendations for future research are given.

\section{DEPOSITION PROCESSES}

\section{Introduction}

The total deposition of chemicals to the ocean from the atmosphere is the sum of the amounts transferred in gas, liquid, and solid phases. The processes by which materials are transferred in gas and solid phases are collectively referred to as "dry" deposition. Liquid deposition, often referred to as "wet" deposition, will comprise water and its dissolved gases and solutes, together with any insoluble particulate material contained therein. Net upward transport from the ocean is also possible for many species and is in some cases of overriding importance. However, here the emphasis will be on net deposition, since we are principally interested in the atmosphere as a provider of material to the oceans.

\section{Direct Measurement of Atmosphere-Ocean Mass $\underline{\text { Fluxes }}$}

There are a number of direct measurements of inputs of chemicals into the oceans. Most of these measurements are for deposition via rain, since it is relatively easy to collect the samples. However, there are very real difficulties with this simple approach for determining wet deposition. Unsophisticated funnel-in-bottle precipitation samplers may collect dry deposition as well as rain. Even though it is possible to arrange for the collector to be exposed only when rain is falling, this increases the complexity of the apparatus. Another difficulty with direct measurements of wet deposition arises because of the natural variability of concentrations of trace substances in precipitation (see, for example, Jickells et al. [1984]), which means that a large number of rain events must be sampled and analyzed before meaningful average wet fluxes can be obtained. Also, great care has to be taken to ensure that the samples do not become contaminated prior to analysis; this is particularly critical for substances present in trace amounts.

Despite these complexities, direct measurements have revealed several important features of the mechanisms controlling wet deposition, most of which are consistent with the chemistry of the constituents. It is clear that the concentration of a substance in precipitation varies with its concentration (or the concentrations of its precursors) in the atmosphere and tends to be highest close to sources [Arimoto et al., 1985], although the relationship is not necessarily simple. For example, the presence of discrete layers of elevated particulate concentrations in the atmosphere can make direct comparisons of ground level aerosol concentrations and precipitation chemistry uncertain [Buat-Menard and Duce, 1986].

Soluble and reactive gaseous constituents (e.g., $\mathrm{HNO}_{3}$ and $\mathrm{SO}_{2}$ ) are readily removed from the atmosphere by rain, while relatively insoluble gaseous 
constituents (organochlorines and $\mathrm{Hg}$ vapor) are removed inefficiently by wet deposition [Slinn et al., 1978; Bidleman and Christensen, 1979; Fitzgerald et al., 1983]. The small amounts of these largely insoluble gaseous constituents found in rain probably reflect scavenging of the small proportion of the substances associated with aerosol particles.

Particulate matter is removed in wet deposition by collision with and capture by falling precipitation, or via the particles themselves acting as condensation nuclei. Some aerosol particles will readily dissolve in precipitation (e.g., sea salt, ammonium sulfate), while the extent of dissolution of less soluble particles such as fly ash or clays probably varies with the $\mathrm{pH}$ and $\mathrm{pE}$ (redox potential) of the rain. Both dissolved and particulate forms of many constituents can be expected to be present in precipitation, and the different environmental effects of these forms need to be considered [Lindberg and Harriss, 1983].

The effectiveness of wet deposition in removing atmospheric material to the oceans varies with the form of the precipitation (rain, snow, etc.) and the meteorology of the storm [Buat-Menard and Duce, 1986]. The importance of large-scale convective storms which penetrate the lower stratosphere as a removal mechanism for bomb- and cosmic-ray-produced radionuclides has been described by Burchfield et al. [1983].

Direct measurement of dry particle fluxes has been attempted using flat plate collectors having a variety of surfaces. Apart from the problems of contamination and natural inhomogeneity mentioned above, a fundamental difficulty is in knowing how well the collector surface mimics the sea surface. The direct measurement approach may be adequate only when gravitational settling of large particles is responsible for a major fraction of the dry deposition (e.g., sea salt and soil dust particles).

Similarly, direct measurements of air-sea gas fluxes are also fraught with difficulties. In this case a major problem with the use of chamber methods is that the enclosure clearly disrupts the normal aerodynamics and hydrodynamics of the interfacial transfer process. While micrometeorological methods can be applied, their use has so far been largely limited to the standard meteorological fluxes: heat, moisture, and momentum. For these reasons, it is our view that no reliable direct estimates of air-sea fluxes currently exist for gases, other than water vapor and ozone.

In view of the lack of reliable direct measurements, indirect approaches are often used to estimate air-sea fluxes. This is particularly necessary here, since the objective in the present paper is to estimate inputs to the ocean globally; by their very nature, direct measurements are local and refer only to the time and place at which the data were collected. The limited amount of directly measured deposition data is then used as a cross-check on the indirect approaches used to estimate global fluxes of nitrogen and synthetic organics.

\section{Indirect Estimates of Atmosphere-Ocean Mass Fluxes}

Basically, in indirect approaches the air-water flux is calculated from the product of a concentration term (which drives the flux) and a kinetic parameter (which quantifies the rate of mass transfer). This concept is now discussed for exchange of gases, dry particles, and precipitation.

Gases. For gases the flux $\left(F_{g}\right)$-driving term is the concentration difference between the bulk air and water phases $(\Delta \mathrm{C}$, the sign of which determines the direction of $F_{g}$ ), and the rate expression $K$ is variously known as an exchange constant/coefficient or a piston/transfer velocity (the lattermost term will be used here) and has the dimensions of a velocity. Then,

$$
\begin{aligned}
\mathrm{F}_{\mathrm{g}} & =\mathrm{K} \cdot \Delta \mathrm{C}=\mathrm{K}_{\mathrm{w}}\left[\mathrm{Cg}_{\mathrm{a}}(\mathrm{H} / \mathrm{RT})^{-1}-\mathrm{Cg}_{\mathrm{w}}\right] \\
& =\mathrm{K}_{\mathrm{a}}\left[\mathrm{Cg}_{\mathrm{a}}-\mathrm{Cg}_{\mathrm{w}}(\mathrm{H} / \mathrm{RT})\right]
\end{aligned}
$$

$K_{\mathrm{W}}$ and $\mathrm{K}_{\mathrm{a}}$ refer to whether the calculation is made with concentrations expressed on a liquid phase or a gas phase basis. $\mathrm{Cg}_{\mathfrak{a}}$ and $\mathrm{Cg}_{\mathrm{w}}$ are the gas concentrations in air and water, respectively. $\mathrm{H}$ is the dimensionless Henry's law constant, expressed as the ratio of the concentration of the gas in the air to its concentration in un-ionized form in the water, at equilibrium, and $\mathrm{R}$ and $\mathrm{T}$ are the gas constant and temperature in degrees Kelvin, respectively.

It is often more convenient to think in terms of the reciprocal of $\mathrm{K}$, which is a measure of the resistance $\mathrm{R}$ to gas exchange. On a liquid phase concentration basis the following equations show how $\mathrm{R}$ may be split into resistances in the air $\left(r_{a}\right)$ and water $\left(r_{w}\right)$ :

$$
\begin{aligned}
& 1 / \mathrm{K}_{\mathrm{w}}=1 / \alpha \mathrm{k}_{\mathrm{w}}+\mathrm{RT} / \mathrm{Hk}_{\mathrm{a}} \\
& \mathrm{R}_{\mathrm{w}}=\mathrm{r}_{\mathrm{w}}+\mathrm{RT} / \mathrm{H} \cdot \mathrm{r}_{\mathrm{a}}
\end{aligned}
$$

In (2), $k_{\mathrm{a}}$ and $\mathrm{k}_{\mathrm{w}}$ are the transfer velocities for chemically unreactive gases in the air and water, respectively. The factor $\alpha$ quantifies any enhancement in the value of $k_{w}$ due to chemical reactivity of the gas in water. In the present context it is probably safe to ignore $\alpha$, since the compounds of interest do not react rapidly with water $(\alpha=1.0)$.

On a gas phase concentration basis, (2) would be

$$
\begin{aligned}
& 1 / \mathrm{K}_{\mathrm{a}}=1 / \mathrm{k}_{\mathrm{a}}+\mathrm{H} / \mathrm{RTak}_{\mathrm{w}} \\
& \mathrm{R}_{\mathrm{a}}=\mathrm{r}_{\mathrm{a}}+\mathrm{H} / \mathrm{RT} \cdot \mathrm{r}_{\mathrm{w}}
\end{aligned}
$$

By substituting appropriate values in (2) - (5), it is possible to calculate $r_{w}$ and $r_{a}$ for particular gases and so to identify whether one of the resistances is dominant or whether both must be considered. When this substitution is done, many simple gases 
are found to fall into one of two distinct groups: (1) those for which $\mathrm{r}_{\mathrm{a}}$ » $\mathrm{r}_{\mathrm{w}}\left(\mathrm{H}_{2} \mathrm{O}, \mathrm{SO}_{2}, \mathrm{NH}_{3}\right)$ and (2) those for which $\mathrm{r}_{\mathrm{w}} \gg \mathrm{r}_{\mathrm{a}}\left(\mathrm{O}_{2}, \mathrm{~N}_{2}, \mathrm{CO}_{2}, \mathrm{CO}, \mathrm{CH}_{4}\right.$, $\left.\mathrm{CH}_{3} \mathrm{I}, \mathrm{DMS}\right)$. Gases in group 1 are those which tend to partition into the aqueous phase (low $\mathrm{H}$ ) and/or have rapid water phase chemistry; those in group 2 have high $\mathrm{H}$ values, tend to be unreactive in water, and partition into the gaseous phase. Some gases do not fit neatly into one or the other of these categories, and in their cases both $r_{a}$ and $r_{w}$ are of importance. Several of the high molecular weight organics of interest here appear to fall into this intermediate category (Mackay and Yuen [1981] and Atlas et al. [1982]; also Table 26 of this paper).

In summary, in order to use (1) to calculate $F_{g}$, both $\Delta \mathrm{C}$ and $\mathrm{K}$ must be known. The $\Delta \mathrm{C}$ term must be obtained by direct field measurements of gas concentrations in marine air and surface seawater. It will be dealt with in the sections of the paper considering specific types of trace substances, as appropriate. The value of $\mathrm{H}$ must be known for each of the gases of interest at the temperature and salinity of the water samples. $\mathrm{H}$ arises not only in the specification of $\Delta C$, but also in the solution of (2) and (4). It can be obtained either from laboratory experimental determinations or from a knowledge of the vapor pressure and solubility of the individual compounds [Mackay and Shiu, 1984].

In order to specify $K,(2)$ or (4) has to be solved. Apart from $\mathrm{H}$ (discussed above) and $\alpha$ (taken as $1.0)$, the only unknowns are $k_{\mathrm{a}}$ and $\mathrm{k}_{\mathrm{w}}$. In the following paragraphs a brief indication is given of how these individual phase transfer velocities may be formulated in terms of a widely available meteorological variable: wind speed.

The air phase transfer velocity: The air phase transfer velocity $k_{a}$ is the reciprocal of the air phase transfer resistance $r_{a}$, which is often treated in terms of two resistances in series. The first resistance corresponds to turbulent exchange in the upper part of the atmospheric boundary layer. In near-neutral atmospheric stability this resistance can be approximated as

$\mathrm{r}_{\mathrm{a} \text { (turb) }}=\mathrm{u} / \mathrm{u}_{*}{ }^{2}$

where $u$ is the wind speed and $u_{*}$ is the friction velocity (defined as the square root of the ratio of the surface drag to the air density). For the case of the open ocean, we can approximate the friction velocity using a drag coefficient,

$\mathrm{C}_{\mathrm{d}}=\left(\mathrm{u}_{*} / \mathrm{u}\right)^{2}$

The drag coefficient is known to vary with wind speed, but the variation is small, and for present purposes it will be assumed that $C_{d}$ is constant and equal to $1.3 \times 10^{-3}$. Using this value, $\mathrm{r}_{\mathrm{a} \text { (turb) }}$ can be approximated from the wind speed data alone. In doing so, the role of aerodynamic stability is neglected; when the water is warmer than the air, the atmosphere is dynamically unstable and $r_{a(t u r b)}$ will be lower than estimated above. When the water is colder than the air, $r_{a(u r b)}$ will be greater than estimated here.

The second part of the atmospheric resistance is that which applies close to the sea surface, where transfer is assumed to be by diffusion. The resistance $r_{a(d i f f)}$ associated with exchange across this boundary layer depends on both the diffusivity of the substance in air $\left(D_{a}\right)$ and $u_{*}$. Many specialized formulae have been proposed to relate $r_{a}$ (diff) to $u_{*}$ and $D_{a}$; for the present it is adequate to adapt a simplification involving the Schmidt number in air, $\mathrm{Sc}_{\mathrm{a}}=\mathrm{v}_{\mathrm{a}}$ $/ D_{a}$, where $v_{a}$ is the air viscosity. Then [after Hicks et al., 1986]

$r_{a(\text { diff })}=\left(5 / u_{*}\right) \cdot S c_{a}^{2 / 3}$

Available information indicates that (8) is most applicable over solid surfaces; over water, somewhat different forms for the role of $\mathrm{Sc}_{\mathrm{a}}$ have been suggested but are not recommended here because of lack of data and the small differences that are likely to result.

It is useful to observe that $\mathrm{Sc}_{\mathrm{a}}$ is related to the square root of the molecular weight (M.W.) of trace gases, and hence (5) - (8) can be combined to yield the following simple formula for $r_{a}$ (in mks units):

$\mathrm{r}_{\mathrm{a}}=\left(\mathrm{r}_{\mathrm{a}(\text { turb })}+\mathrm{r}_{\mathrm{a}(\text { diff })}\right)$

$=\left(770+45(\mathrm{M} . \mathrm{W} .)^{1 / 3}\right) / \mathrm{u}$

The water phase transfer velocity: The water phase transfer velocity $k_{w}$ and its formulation in terms of wind speed $u$ are discussed by Liss and Merlivat [1986]. They have used the results of various wind tunnel studies to try to specify the relationship between $k_{w}$ and $u$. The situation is more complex than that for $\mathrm{k}_{\mathrm{a}}$, since a singular relationship is not possible. Wind tunnel results show that the relationship between $\mathrm{k}_{\mathrm{w}}$ and $\mathrm{u}$ can be approximated to three linear portions, with different slopes. Up to $\mathrm{u} \sim 3.6 \mathrm{~m} \mathrm{~s}^{-1}$ the water surface is smooth; between $\mathrm{u}=3.6$ to $13 \mathrm{~m} \mathrm{~s}^{-1}$ the surface is covered with waves, but they are generally not breaking, above $u=13 \mathrm{~m} \mathrm{~s}^{-1}$, wave breaking occurs. The slopes of the straight-line segments increase as the surface becomes rougher. A further complication is that in the regime above $\mathrm{u}=13 \mathrm{~m} \mathrm{~s}^{-1}$, bubbles produced by the breaking waves act as an additional gas exchange mechanism whose magnitude varies with gas solubility in the water. This means that at higher wind speeds there is a family of curves having different slopes, with the least soluble gases showing the greatest slopes.

In order to make these laboratory results applicable in the environment, they are "tuned" using the field studies employing $\mathrm{SF}_{6}$ as a tracer carried out by 
Wanninkhof et al. [1985] in a freshwater lake. Although the applicability of lake results to the oceans, with their much longer fetch, is open to question, recent results using a purposeful dual tracer technique in the North Sea do support the validity of the extrapolation [Watson et al., 1991]. Further, the predictions made using this approach are in reasonable agreement with those open ocean results which do exist (see Figure 1). The equations derived by Liss and Merlivat describing the three portions of the $k_{w} / u$ relationship for the oceans are as follows:

$\mathrm{k}_{\mathrm{w}}=0.17 \mathrm{u}$

for $\mathrm{u} \leq 3.6 \mathrm{~m} \mathrm{~s}^{-1}$

$\mathrm{k}_{\mathrm{w}}=2.85 \mathrm{u}-9.65$ for $3.6<\mathrm{u} \leq 13 \mathrm{~m} \mathrm{~s}^{-1}$

$\mathrm{k}_{\mathrm{w}}=5.9 \mathrm{u}-49.3 \quad$ for $\mathrm{u}>13 \mathrm{~m} \mathrm{~s}^{-1}$

where $\mathrm{k}_{\mathrm{w}}$ is in centimeters per hour and $\mathrm{u}$ is in meters per second at a height of $10 \mathrm{~m}$. Equations (10) (12) apply to $\mathrm{CO}_{2}$; for other gases corrections can be

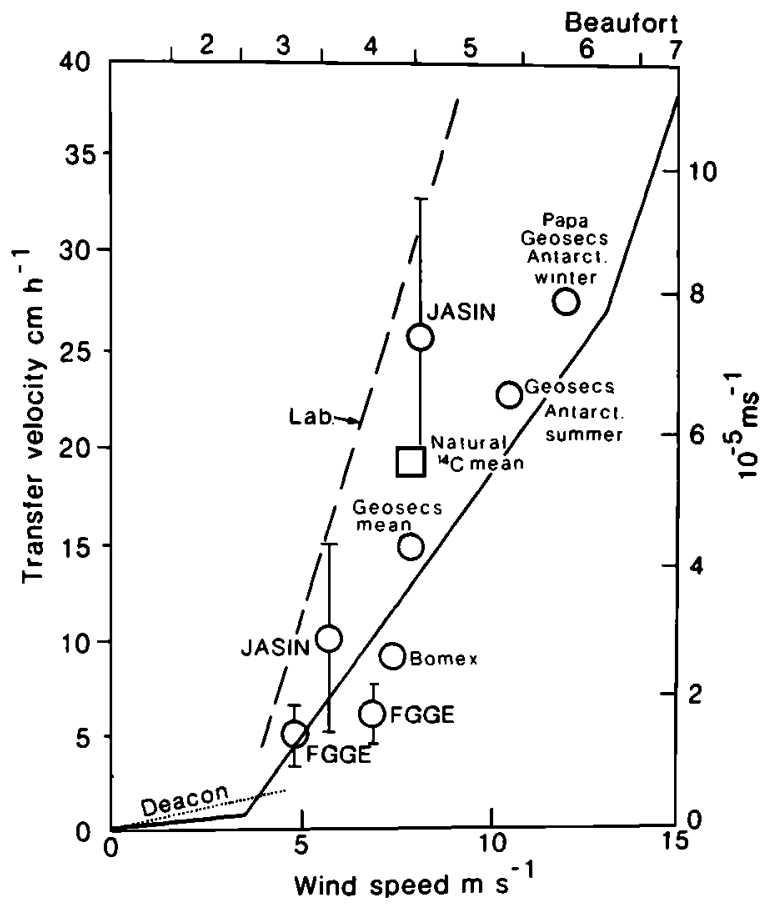

Fig. 1. Oceanic measurements of $k_{w}$ plotted as a function of wind speed measured at a height of $10 \mathrm{~m}$ and the corresponding Beaufort scale number. The dotted line represents predictions based on the Deacon [1977] smooth surface model. The dashed line represents the results for intermediate wind speeds from laboratory wind tunnel studies. All data are converted to $\mathrm{Sc}_{\mathrm{w}}=600$, corresponding to $\mathrm{CO}_{2}$ at $20^{\circ} \mathrm{C}$, by assuming that $\mathrm{k}_{\mathrm{w}} \propto \mathrm{Sc}^{-1 / 2}$ [after Roether, 1986]. The three solid lines are plots of equations 10-12 [Liss and Merlivat, 1986]. made through the water phase Schmidt number $\left(S c_{w}=v_{w} / D_{w}\right)$ as follows: for $u($ at $10 \mathrm{~m}) \leq 3.6 \mathrm{~m}$ $\mathrm{s}^{-1}, \mathrm{k}_{\mathrm{w}} \propto \mathrm{Sc}_{\mathrm{w}}{ }^{-2 / 3}$; for $\mathrm{u}>3.6 \mathrm{~m} \mathrm{~s}^{-1}, \mathrm{k}_{\mathrm{w}} \propto \mathrm{Sc}_{\mathrm{w}}{ }^{-1 / 2}$.

Particles. For deposition of particles the flux $\left(F_{p}\right)$ is given by the product of the measured concentration of the particles in air $\left(\mathrm{CP}_{\mathrm{a}}\right)$ and a deposition velocity $v_{d}$,

$F_{p}=V_{d} \cdot C p_{a}$

The term $V_{d}$ comprises all the processes of dry deposition, such as gravitational settling, impaction, and diffusion of particles to the water. It is very difficult to describe properly, since each of these processes acts simultaneously and because each of them is dependent on a number of variables (i.e., wind speed, particle size, relative humidity, air viscosity, sea surface roughness). The two-layer model outlined earlier for the prediction of the air transfer velocity for gaseous deposition $\left(\mathrm{k}_{\mathrm{a}}\right)$ can be applied to particle deposition also, but only to those particles small enough that gravitational settling is not dominant. However, it is found that even for very small particles the Schmidt number term in (9) dominates the overall atmospheric resistance computed as was outlined previously for $k_{a}$, yielding deposition velocity predictions that are unreasonably low. For small particles the simplification afforded by (8) is inadequate, and more detailed consideration of the roles of particle impaction and diffusion is then required. For present purposes, two models have been used to provide guidance on the deposition of particles too small to be strongly influenced by gravitational settling. First, the model of Slinn and Slinn [1980] has been used, with relative humidity assumed to be $98 \%$ (about the maximum that can occur in air contacting seawater, except under non equilibrium conditions). The predictions range from less than $0.01 \mathrm{~cm} \mathrm{~s}^{-1}$ to more than $0.1 \mathrm{~cm} \mathrm{~s}^{-1}$, depending on particle size (see Figure 2). The second model used is that of Hicks and Williams [1980], which yields deposition velocities ranging from $0.01 \mathrm{~cm} \mathrm{~s}^{-1}$ to more than $0.3 \mathrm{~cm} \mathrm{~s}^{-1}$, depending on wind speed.

For particles in the size range where gravitational settling is the controlling factor, both models agree and do not appear to differ greatly from values derived from direct field measurements. These various approaches indicate that the "best" values for use in the present exercise are as follows:

Submicrometer aerosol particles

$$
0.1 \mathrm{~cm} \mathrm{~s}^{-1}, \pm \text { a factor of } 3
$$

Supermicrometer crustal particles, not associated with sea salt

$1.0 \mathrm{~cm} \mathrm{~s}^{-1}, \pm$ a factor of 3 


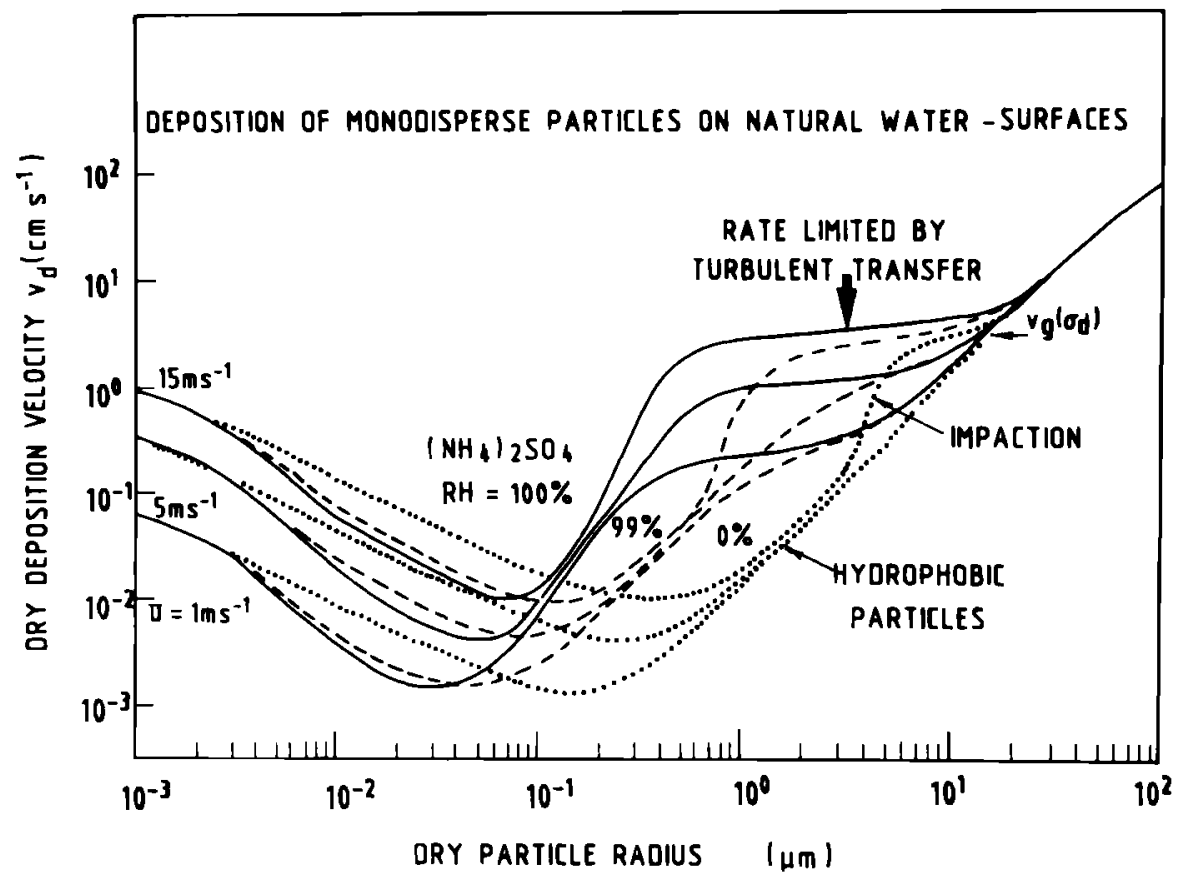

Fig. 2. Dry deposition velocity of particles in a water surface as a function of relative humidity and particle size [after Slinn and Slinn, 1980].

Large sea salt particles and materials carried by them

$$
3.0 \mathrm{~cm} \mathrm{~s}^{-1}, \pm \text { a factor of } 2
$$

Because $V_{d}$ varies with particle size, application of (13) has to be through measurements of concentration $\left(\mathrm{Cp}_{\mathbf{a}}\right)$ on aerosols size-fractionated at least into the three size classes given above. It should also be noted that in some cases corrections may need to be made for any recycled sea salt component, i.e., the measured $\mathrm{Cp}_{\mathrm{a}}$ may contain both new material entering the ocean for the first time (the net input) and "old" material recycling in sea spray.

Rain. The wet deposition flux $F_{r}$ is formally expressed as the product of the precipitation rate $(P$, discussed in the next section of the paper) and the concentration $\left(C_{T}\right)$ of the substance of interest in rain,

$\mathrm{F}_{\mathrm{r}}=\mathrm{P} \cdot \mathrm{C}_{\mathrm{r}}$

Equation (14) is often expressed not in terms of $C_{T}$, which effectively implies making a direct flux measurement, but through a scavenging ratio $S$ (also sometimes called a washout factor), which is the ratio $\mathrm{C}_{\mathrm{r}} / \mathrm{Cp}_{\mathrm{a}}$, such that

$\mathrm{F}_{\mathrm{r}}=\mathrm{P} \cdot \mathrm{S} \cdot \mathrm{Cp}_{\mathbf{a}} \cdot \mathrm{\rho}^{-1}$

In (15), $\rho$ (the density of air) appears in order to make particle concentrations, which are generally expressed as mass per unit volume of air (often micrograms per cubic meter $\left(\mu \mathrm{g} \mathrm{m}^{-3}\right)$ ), dimensionless. By analogy between (13) and (15), P $\cdot S$ is equivalent to a wet deposition velocity. The advantage of (15) over (14) is that provided $S$ is known (see later), measurement of $\mathrm{Cp}_{\mathrm{a}}$ provides the concentration driving term for both equations and hence for estimation of deposition of dry particles as well as of material in rain and other forms of wet deposit. The scavenging ratio is a dimensionless quantity, which in this report is computed from concentrations expressed as mass of substance per unit mass of rain or air. As with (13), equations (14) and (15) yield only gross fluxes, and in some cases corrections have to be applied in order to obtain the net inputs.

Factors known to affect the scavenging ratio $S$ include the size of the particles being scavenged, their physical and chemical form, and cloud properties including droplet size, temperature, and cloud type. Because of the complexity implied by the large number of processes affecting scavenging, there is no satisfactory theoretical treatment available to predict values of $S$. In view of this, resort is made to indirect, empirical approaches. The most widely used one is to measure concentrations in collected rain and simultaneously measured air concentrations at ground level; the ratio giving $S$ for the substance(s) examined. Uncertainty arises not only because this approach assumes equilibrium, or at least a constant degree of approach to equilibrium, 
but also because there is no certainty that concentrations at the ground truly reflect conditions in the cloud, where the rain acquires most of the scavenged material. In view of these substantial problems, available values of $S$ have to be treated with considerable caution. For example, at a given measurement site, $S$ can vary by an order of magnitude for any particular substance, and different substances exhibit different values of $S$. The problem is exacerbated by the small number of measurements which exist from which S can be calculated. However, there does appear to be some consistency between substances which exist on particles of similar size. Further, if a large number of separate determinations of $S$ are made, representative average values can be obtained. The most reliable values for $S$ appear to lie in the range 200 to 2000 . The values used for individual substances and particular oceans are discussed in the relevant sections of the paper. Of special interest is the case in which some (or all) of the chemical species in falling rain are derived from gas phase (rather than particulate) concentrations in air. The additional complexity of in-cloud chemical conversion must then be considered. However, expected values of $S$ appear to be in the same general range as given earlier.

\section{ATMOSPHERIC TRANSPORT AND PRECIPITATION CLIMATOLOGY}

\section{Introduction}

To make the calculations in this paper, meteorological information concerning transport and deposition must be utilized. Two approaches are considered: (1) use of climatological fields, such as those for precipitation, which can be combined with the chemical concentration data to calculate the deposition on a grid point by grid point basis, and (2) use of Lagrangian/Eulerian transport models and general circulation models (GCMs), which can be configured to calculate deposition of certain substances to the oceans and inland seas.

Before reviewing these two approaches, it should be noted that long-range atmospheric transport of trace materials to the oceans has been the subject of a number of workshop reports since the first attempts to address this question were made over a decade ago [NAS, 1978]. These include the chapters by Hasse [1983] and Merrill [1986], both of which are primarily pedagogical reviews, and those by Rodhe [1985] and Whelpdale and Moody [1990], which emphasize discussion of research results.

\section{Climatological Data Over the Oceans}

There are numerous atlases and other collections of data which contain information on the climatology of wind flow and other meteorological phenomena over the oceans, averaged by month, season, or year. In some, the vast quantities of ship-of-opportunity data have been screened by rather subjective techniques, and the final analysis made by knowledgeable marine climatologists. Included among these are the atlases for each ocean basin prepared from data compiled for the U.S. Navy [Meserve, 1977]. In others the emphasis is on a straightforward presentation of data from a limited period of time, with attention paid to making both the screening of suspect data and the analysis objective. Included among these are Oort [1983] and Slutz et al. [1985]. While these contrasting approaches tend to be complementary, the limited use of climatological data for temperature fields and mean wind speeds required for the calculations made in this report is adequately covered by either type of climatological analysis. However, the actual transport path of a substance from its source to the point of ultimate removal is typically not given by the time-averaged wind fields; i.e., the mean transport is not given by the mean winds. For example, when a large-scale wave pattern extends over a source region (south of the mean streamline position, say) and over a region of high precipitation (north of the mean streamline position), there can be sporadic transport from the source area toward the precipitating area, where removal can take place by wet deposition. As the wave pattern migrates there may later be southward flow of about the same strength; however, this may not result in significant transport to the rainy area. The mean north-south wind will be close to zero, but the transport is nonzero. However, in most cases data on the temporal and spatial variations in source and removal rate are so limited that general air flow patterns must still be used.

Attempts have been made to describe the general flow patterns that are the major atmospheric paths for such phenomena as the Saharan dust outbreaks or the transport of aerosols from the Chinese mainland. In a recent paper by Whelpdale and Moody (1990), the flow patterns and storm tracks over the six major oceans have been extensively reviewed. The authors concluded that long-range transport was indeed an important factor, especially eastward from North America, westward from Africa, eastward from southern South America, eastward from Asia, westward from northern South America, and into the polar regions. The authors made the following recommendations:

1. The major source areas should be better characterized, including temporal behavior, vertical distributions, and other parameters.

2. An intensive experimental and modeling study of the coastal zone, especially downwind of major source areas, should be made.

3. The importance of mesoscale features such as the sea breeze should be studied, especially their role in transport across land-sea boundaries.

Compiling back-trajectory flow climatologies for ocean areas is another way of summarizing flow 
conditions. When used in conjunction with standard climatological data, back trajectories calculated over periods of 5 years or longer for a given station can give some idea of the month-to-month flow patterns and hence potential deposition of the substance of interest. Such calculations have been made for sites including Hawaii, American Samoa, Amsterdam Island, Alaska, Bear Island, New Zealand, Enewetak Atoll, and Bermuda. These studies give a summary of the gross transport paths to the station of interest, and their use is discussed by Rodhe [1985], Miller [1987] and Merrill et al. [1989].

Over the last decade there has been a vigorous effort to understand transport pathways of pollutants and other substances to inland seas such as the Mediterranean, Baltic, and North seas in Europe and the Great Lakes in North America. Some initial work has also been done in the Gulf of Mexico. Much of the emphasis has been on riverine inputs and dumping. However, it was realized that because these bodies of water are so close to atmospheric pollution sources, the air pathway may also be important as a contributor to the deposition of harmful substances. For example, in the Mediterranean region, ship expeditions (PHYCEMED) and ground station measurements made over the last decade have produced a set of data that can be used to estimate trace substance inputs. A number of recent publications have used meteorological parameters either to interpret these data or to establish flow climatologies for the region (Dayan, [1986], Dulac et al. [1987], Martin et al. [1987], Maring et al. [1987, and Miller et al. [1987]; among others). Similar work has been done for the Baltic and North seas. In North America, along with the major effort to study the pollution input to the Great Lakes, transport studies to the Gulf of Mexico have begun [Parungo and Miller, 1988].

Coastal areas present a complex meteorological and chemical situation that makes it difficult to estimate deposition via the atmosphere quantitatively. For some substances in some areas the input from riverine outflow and local dumping totally mask the atmospheric contribution. The meteorological situation may be highly variable in space and time because of the land-sea breeze circulation, which exists owing to the temperature differential over the two surfaces. Even with these complications, atmospheric deposition can be estimated for some substances and may be substantial, as has been suggested for nitrate input into the Chesapeake Bay in the United States [Fisher et al., 1988]. However, in this paper we only address the atmospheric input to open ocean regions.

\section{Lagrangian and Eulerian Models}

Since the identification of possible environmental damage due to acid deposition, a considerable effort has gone into developing transport models that could be used calculate the deposition of acidic substances [Eliassen and Saltbones, 1983; Chang et al., 1988]. One recent application of such models to large water bodies is that of the use of the EMEP model to estimate sulfur and nitrogen deposition to the Baltic and North seas. For example, model calculations suggest that $138 \times 10^{9} \mathrm{~g}$ of $\mathrm{NO}_{\mathrm{x}}-\mathrm{N}$ and $634 \times 10^{9} \mathrm{~g}$ of S were deposited into the Baltic during 1985 [Eliassen et al., 1988]. Further model results for trace metals are given by Petersen et al. [1988]. However, these models are mainly regional in nature and have not yet been implemented at the global scale.

A global scale Lagrangian trace species model has been developed by the Lawrence Livermore National Laboratory in the United States [Walton et al., 1988]. Source data are used to specify the initial concentrations distributed with latitude and longitude according to best estimates from the literature. Climate model winds are used, and each mass of air is advected and deformed, allowing for continuous tracking of the concentration. At this point, the model results must be considered as preliminary because further refinements are needed, including better treatment of physical processes, such as mixing and turbulent and convective exchange.

Another approach is to use an Eulerian chemical transport model (CTM) to describe transport of a trace material. Levy and Moxim [1988, 1989] have used the Geophysical Fluid Dynamics Laboratory general circulation transport model to simulate the global spread and deposition of nitrogen emitted by fossil fuel combustion. They have allowed the nitrogen species to be transported without explicit chemistry; chemical reactions are implicitly introduced through bulk coefficients for dry and wet removal. Calculated and measured deposition values in westem Europe and over the North Pacific have been compared and agree within a factor of 2. Further tests of this approach, in which natural sources of nitrogen species will be accounted for, are planned.

Though models provide a way of estimating deposition to the oceans which is grounded in first principles, it was decided that for the purposes of this study, the climatological approach was more appropriate. This is in part because CTM results cannot be used readily in an iterative comparison with observed concentrations or fluxes. Since the models account for many processes and multiple sources, the results at a given place or time cannot be adjusted independently. Simulation of global transport and deposition is a major computational task requiring weeks of effort. For many substances the source dependencies on meteorological and other factors are presently not well known. In the near future the CTM results should provide a useful point of comparision with other estimates. Eventually, as our knowledge of source behavior and skill in parameterization increases, CTMs may become the models of choice. However, climatological techniques are more suited to the purposes of the present exercise. 


\section{Framework for the Calculation}

The method. The deposition calculations made for this report have been done for $10^{\circ} \times 10^{\circ}$ areas of the ocean using microcomputers and spreadsheet software. Working maps were prepared in advance for each ocean basin, indicating the grid areas to be used. The first step in the calculation was the annotation of these working maps with chemical concentration values, scavenging ratios, dry deposition velocities and other data needed to make the deposition estimates. When the concentration values and other chemical data were agreed upon, they were entered into the spreadsheets. On the spreadsheet, each $10^{\circ} \times 10^{\circ}$ area was represented by a cell, i.e., the intersection of a row and a column.

We used a regular longitude-latitude coordinate system represented in the illustrations via a cylindrical equidistant map of the globe, with the upper left comer representing $90^{\circ} \mathrm{N}, 30^{\circ} \mathrm{E}$. This modest spatial resolution was chosen largely because of the shortage of chemical data. Consequently, higher resolution is not justified. For the purposes of data exchange we agreed on the grid numbering scheme used in the comprehensive ocean-atmosphere data sets [Slutz et al., 1985], in which each of the grid areas is assigned a number between 1 and 648 . This system is similar to, but less cumbersome than, the Marsden square grid system.

A means of previewing the results was developed. The $10^{\circ} \times 10^{\circ}$ resolution chemical data were printed directly from the microcomputer, one page for each ocean basin and for each chemical substance or class of substances. Overlay maps were prepared for orientation; the working arrays themselves provide no explicit indication of their location on the Earth. This overlay procedure made possible interactive checking of the data fields (including possible data entry errors). It also allowed iterative modification of the parameters, given the estimated deposition results.

The deposition at any place or time depends more or less critically upon the ambient precipitation value. The precipitation fields used in the calculations are those of Jaeger (discussed by Jaeger [1983]). While the oceanic precipitation values are uncertain and need to be improved, they are not the main source of uncertainty in the discussion at hand and can be taken to be representative. Nevertheless, a brief discussion of the known problems with these data is warranted. Gridded precipitation data were obtained by interpolation of values of precipitation frequency, multiplied by the precipitation depth estimates of Geiger [1965]. The precipitation frequency data used are from the U.S. Marine Climatic Atlas, the most recent edition of which is that of Meserve [1977]. Jaeger then adjusted the oceanic values by increasing them uniformly by $6.2 \%$ to reach a global average precipitation depth of $1 \mathrm{~m}$. The latter value was indicated by independent studies of the global water balance. Only the marine areas were adjusted because they are generally less certain than those over land. The Jaeger precipitation data are available at high spatial resolution $\left(2.5^{\circ} \times 5^{\circ}\right)$ and for each month. For use in this study, seasonal total precipitation maps were prepared at the lower resolution chosen for the deposition calculations. However, only the annual total data were used in the calculations, again limited by the availability of chemical data.

Examples of the global precipitation rates contoured from these fields for the winter and summer seasons are shown in Figures 3 and 4 in millimeters of water per month. The DecemberJanuary-February averages show values over 100 mm month ${ }^{-1}$ in the midlatitude North Pacific and North Atlantic areas, with much higher values confined to the equatorial zone and to the tropical areas between $120^{\circ} \mathrm{E}$ and the date line. The June-

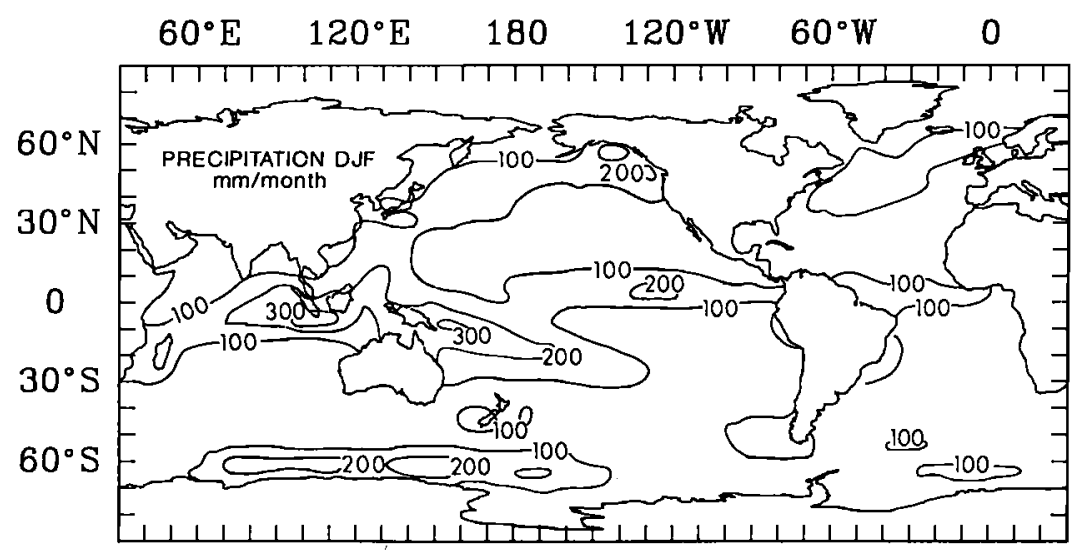

Fig. 3. Global precipitation rates for months of December, January, and February in millimeters per month. (As is discussed in the text, this figure is based on precipitation estimates of Jaeger [1983]). 
July-August averages have values higher than 100 $\mathrm{mm}$ month $^{-1}$ over wide areas of the southern hemisphere oceans, and show increased equatorial precipitation, especially west of Africa. The variation from month to month is significant, but it is suppressed in the calculations in this paper because annual average precipitation data have been used. It should be obvious that this can introduce significant errors.

The aerosol dry depositon calculation was made using the following formulation. A deposition velocity is specified for each substance or class of substances. The dry flux is then given by the concentration times the dry deposition velocity as described in the preceding section (equation (13)). Because the value of the deposition velocity is not uniform in space or time, the range of values outlined earlier has been used in the calculation.

Because the fluxes are calculated separately, a direct comparison of the relative importance of dry and wet deposition processes can be made from the calculated flux values. This is informative in those cases where separate dry and wet deposition estimates are available from field data or careful calculations.

As an example, consider a cell in the mineral aerosol calculation where the atmospheric particle concentration $\mathrm{Cp}_{\mathrm{a}}$ is $2 \mu \mathrm{g} \mathrm{m}^{-3}$ and the dry deposition velocity of the particles $V_{d}$ is $1.0 \mathrm{~cm} \mathrm{~s}^{-1}$. Then the dry deposition flux $F_{p}$ is given by

$$
\begin{aligned}
F_{p}= & C p_{a} \cdot V_{d}=\left(2 \mu \mathrm{g} \mathrm{m}^{-3}\right)\left(1.0 \mathrm{~cm} \mathrm{~s}^{-1}\right)\left(10^{-6} \mathrm{~g} \mathrm{\mu g}^{-1}\right) \\
& \left(10^{-2} \mathrm{~m} \mathrm{~cm}^{-1}\right)\left(3.15 \cdot 10^{7} \mathrm{~s} \mathrm{yr}^{-1}\right) \\
= & 0.63 \mathrm{~g} \mathrm{~m}^{-2} \mathrm{yr}^{-1}
\end{aligned}
$$

This can then be multiplied by the area of the $10^{\circ} \times 10^{\circ}$ box, which is

$$
\left(10 \cdot 111.1 \cdot 10^{3} \mathrm{~m}\right)^{2} \cdot \cos (\phi)
$$

where $\phi$ is the latitude at the middle of the box Assuming a scavenging ratio $S$ of 1000 and a precipitation rate $\mathrm{P}$ of $462 \mathrm{~mm} \mathrm{yr}^{-1}$, the corresponding wet deposition flux $F_{r}$ is given by equation (15), i.e.,

$$
\begin{aligned}
& \mathrm{F}_{\mathrm{r}}=\mathrm{P} \cdot \mathrm{S} \cdot \mathrm{Cp}_{\mathrm{a}} \cdot \rho^{-1} \\
& =\left(462 \mathrm{~mm} \mathrm{yr}^{-1}\right)(1000)\left(2 \mu \mathrm{g} \mathrm{m}^{-3}\right)
\end{aligned}
$$

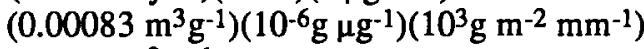

$$
\begin{aligned}
& =0.77 \mathrm{~g} \mathrm{~m}^{-2} \mathrm{yr}^{-1}
\end{aligned}
$$

where $P$ is the annual rainfall amount and the conversion from rainfall depth to mass of water per unit area is made at standard temperature and pressure. The density of air ( $\rho$ ) is taken as $1200 \mathrm{~g} \mathrm{~m}^{-3}$, within $5 \%$ of the global average surface value. The resulting flux can similarly be multiplied by the area of the box before being added in the sum for the basin-wide or global flux estimates.

The deposition process for organic substances is more complex, and a more sophisticated approach is required. This is because many of the compounds may be present in significant amounts in particulate, aqueous, and gaseous phases. The way in which these complexities have been dealt with is discussed in detail in the section on deposition of organics compounds.

Estimating concentrations using observations and transport patterns. In the open ocean there are vast areas bereft of concentration or flux data. In cases where nearshore values are relatively well known, various techniques of extrapolation were used to estimate the concentrations further from the source. The extrapolation was subjective and involved consideration of the main transport paths and areas of removal, as well as the relevant residence time or decay distance of the concentration. Often there are also data at distant offshore points. Along the main lines of transport passing such sites, judicious interpolation was used to estimate the concentration

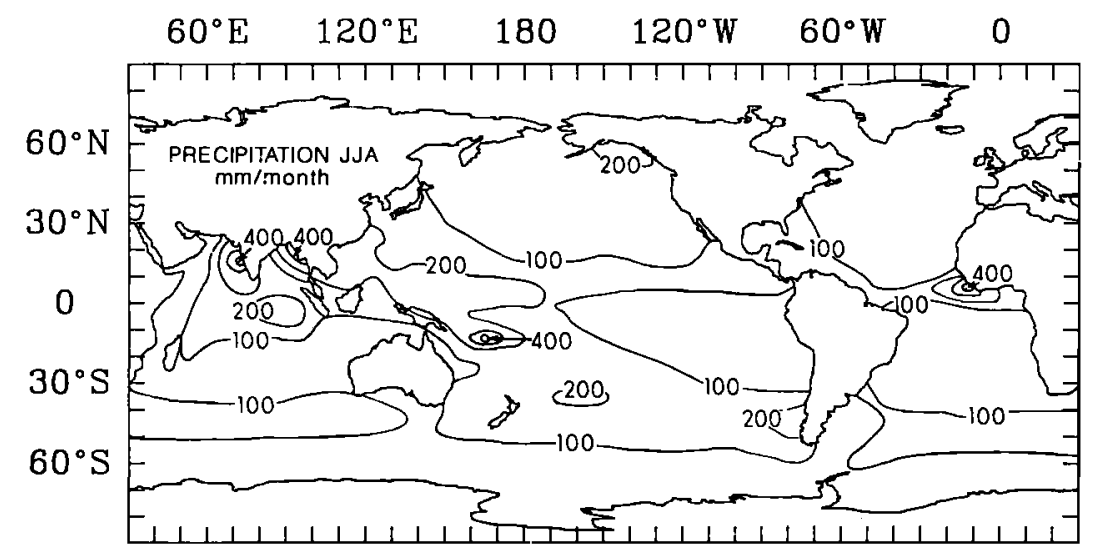

Fig. 4. Global precipitation rates for months of June, July, and August in millimeters per month. (As is discussed in the text, this figure is based on precipitation estimates of Jaeger [1983]). 
values. The interpolation procedures are discussed in the sections dealing with each particular species.

All of the calculations are based on the $10^{\circ} \times 10^{\circ}$ area estimates. Basin-total deposition, and basinaverage flux values are tabulated in the following sections. These are obtained by summing and by dividing the sum by the area of the summed boxes, respectively. The nominal basin areas for the boundaries used in the calculations are as follows (in units of $10^{12} \mathrm{~m}^{2}$ ): North Pacific, 89.6; South Pacific, 110.2; North Atlantic, 54.9; South Atlantic, 51.2; North Indian, 14.4; South Indian, 53.7; global ocean, 374.1. These values differ somewhat from atlas values. First, we arbitrarily included the area south of Australia from $120^{\circ} \mathrm{E}$ to $150^{\circ} \mathrm{E}$ in the South Pacific rather than the Indian Ocean. Second, we have not taken account of the fraction of land area in the coastal boxes; rather, we assumed they are entirely oceanic. The discrepancies are generally less than $10 \%$, and we did not choose to correct the area estimates.

\section{Summary}

Although both climatological methods and model calculations are discussed above, only the grid square technique was applied to estimate the deposition of gases and aerosols to the world oceans. Spreadsheet calculations were used to estimate the aeolian fluxes to the ocean. A serious limitation is apparent in that only annual total fluxes are estimated. While the limited availability of chemical data for each season is responsible for this, the strong variation of the precipitation distribution from winter to summer illustrates the likely importance of determining the variation of concentrations (and thus fluxes) throughout the year. A significant benefit of the microcomputer-spreadsheet approach is that the calculations can be repeated easily with revised values of the various parameters. This allows for continuing use of the spreadsheets as new chemical and meteorological data become available.

\section{THE ATMOSPHERIC INPUT OF TRACE ELEMENTS AND MINERAL AEROSOL TO THE WORLD OCEAN}

\section{Introduction}

The trace elements considered in this section are those whose distribution in oceanic systems appear to be influenced by atmospheric concentrations and fluxes. With the exception of $\mathrm{Hg}$, which occurs predominantly $(\approx 99 \%)$ in the gas phase [e.g.,

Fitzgerald, 1986], these elements are associated with aerosol particles that are produced both naturally and as a result of anthropogenic activities. The dry and wet deposition mechanisms responsible for the airto-sea transfer of trace elements may be particle size dependent, and we have therefore considered two categories of elements.

The first group of elements comprises $\mathrm{Pb}, \mathrm{Cd}$, $\mathrm{Zn}, \mathrm{Cu}, \mathrm{Ni}, \mathrm{As}, \mathrm{Hg}$, and $\mathrm{Sn}$. These elements are found primarily on particles in the accumulation $(<1$ $\mu \mathrm{m})$ mode, and a reasonable data base exists for them. It is in this size fraction that most of the aerosols exist that result from the high-temperature anthropogenic processes largely responsible for their release into the environment [e.g., Rahn, 1976]. We have considered here those elements for which there is evidence of a significant anthropogenic perturbation, at least in the northern hemisphere. These are among the so-called anomalously enriched elements (AEEs) because their atmospheric concentrations are far in excess of those expected from such natural sources as mineral aerosol and atmospheric sea salt.

The second group of elements comprises $\mathrm{Al}, \mathrm{Fe}$, $\mathrm{Si}$, and $\mathrm{P}$. These elements are present primarily in the coarse mode $(>1 \mu \mathrm{m})$, and they are derived primarily from natural mineral aerosol of terrestrial origin. The major source regions of this atmospheric dust are the arid and semi-arid areas of the world (North Africa, Central Asia, Australia, and North and South America [Prospero, 1981, 1990]. The atmospheric deposition of mineral aerosol to the ocean represents an important source of nonbiogenic material in deep-sea sediments [e.g., Duce et al., 1980]. Fractions of the elements associated with mineral aerosol are soluble in seawater, but these values are not at present well constrained. This is an important consideration because a variety of nutrients and micronutrients are associated with mineral dust, and input of this material to the oceans may affect chemical and biological processes in seawater. For example, Duce [1986] calculated that the atmosphere was the primary source of the micronutrient iron in the surface waters of the central Pacific gyre and the Sargasso Sea regions. Martin and Fitzwater [1988], Martin and Gordon [1988] and subsequent investigators suggest that phytoplankton growth is actually limited by the atmospheric iron input in certain oceanic regions.

To predict the atmospheric deposition rates of most of these trace elements, we normalized fluxes of the two groups of elements to $\mathrm{Pb}$ and the mineral aerosol data, respectively. The normalization to mineral aerosol for $\mathrm{Fe}, \mathrm{Si}, \mathrm{P}$, and $\mathrm{Al}$ was made because a considerable body of data has shown that these elements are normally in crustal abundances in both continental and oceanic areas. The data base for $\mathrm{Pb}$ is larger and more reliable than for the other AEEs (with the possible exception of $\mathrm{Hg}$ ), and the fluxes of the enriched elements were approximated by scaling the $\mathrm{Pb}$ flux by the ratio of the atmospheric concentration of the element of interest to that of $\mathrm{Pb}$.

Some elements, such as $\mathrm{Mn}, \mathrm{V}$, and $\mathrm{Cr}$, are significantly affected by both the natural and pollution sources we have considered. The fluxes of these elements could also be scaled according to their 
observed enrichments relative to mineral aerosol, but we have not done so here in view of their likely smaller effects in the oceans. Mercury and tin have been treated separately. This was necessary because $\mathrm{Hg}$ is predominantly in the gas phase, and thus gas transfer among the various environmental compartments is important. For Sn there are limited data, and these have been summarized previously [Byrd and Andreae, 1986]; we have used this summary without modification.

For the five $\propto$ cean basins considered, the mean atmospheric concentration fields of $\mathrm{Pb}$ and mineral aerosol have been generated from the available data with extrapolation for grids with missing data based on our knowledge of source regions and the dominant transport pathways [e.g., Whelpdale and Moody, 1990]. The concentration fields of ${ }^{210} \mathrm{~Pb}$, which has been used as a tracer for continental emissions [Lambert et al., 1983], were also used in our extrapolations. The selection of the data bases and details regarding the approaches used are discussed further in the following section.

The values used for the dry deposition velocities and scavenging ratios are given in Table 1. For dry deposition, the values are based on available knowledge of the particle size distribution of the elements. For pollutant elements (e.g., $\mathrm{Pb}$ ) we do not expect the dry deposition velocity to vary significantly over different oceanic regions, and a mean global ocean value of $0.1 \mathrm{~cm} \mathrm{~s}^{-1}$ [Patterson and Settle, 1987] has been adopted. This is not possible for mineral aerosol, since its size distribution varies strongly as a function of the distance from the source region. On the basis of available data over the Atlantic and the Pacific [Uematsu et al., 1985; Savoie, 1984], we have adopted a mean value of $0.4 \mathrm{~cm} \mathrm{~s}^{-1}$ for the remote open ocean (distance from the coast greater than $1000 \mathrm{~km}$ ) and a mean value of $2 \mathrm{~cm} \mathrm{~s}^{-1}$ for coastal and nearshore areas.
Based on available and reliable air and rain concentration data for lead over the North Atlantic and the Pacific Ocean [Duce et al., 1976, 1983; Church et al., 1984; Arimoto et al., 1985, 1987; Settle et al., 1982; Settle and Patterson, 1982; Patterson and Settle, 1987; Jickells et al., 1987], most values for lead scavenging ratios range from 100 to 500 . We have adopted a mean global value of 200 and have assumed that this value holds for other AEEs. This assumption seems justified on the basis of available data and the fact that pollutant elements considered here exhibit similar particle size distributions in remote marine air [Duce et al., 1976, 1983] and should therefore exhibit similar precipitation scavenging efficiencies [Buat-Menard and Duce, 1986].

On the other hand, for mineral aerosol the available data base suggests significant differences in mean scavenging ratios between the North Atlantic and Pacific oceans. The data base for the North Atlantic [Savoie, 1984; Prospero et al., 1987; Duce et al., 1976; Church et al., 1984; Jickells et al., 1987] is limited to only two sites, Miami and Bermuda, and the data tend toward a value of 200 , which has been adopted here for this basin only. The Pacific data of Uematsu et al. [1985] show little variability in the mean scavenging ratio from one site to another, and their mean value of 1000 has been used for this and all other ocean basins except the North Atlantic. The reasons for such differences are unclear. One possible explanation is that the scavenging ratio in the North Atlantic and especially at Bermuda is being calculated from temporally unmatched data sets, since the rain and air samples used to calculate the ratio were collected several years apart. Further, since scavenging ratio values are estimated from near-surface air concentrations, which can be quite different from those at the altitude of cloud scavenging, another possibility is that the vertical distribution of mineral aerosol is different

TABLE 1. Parameterizations Used for the Trace Element Calculations

\begin{tabular}{lccccc}
\hline & \multicolumn{2}{c}{$\begin{array}{c}\text { Dry Deposition } \\
\text { Velocity, } \mathrm{cm} \mathrm{s}^{-1}\end{array}$} & & \multicolumn{2}{c}{$\begin{array}{c}\text { Scavenging } \\
\text { Ratio }\end{array}$} \\
\cline { 2 - 3 } Type of Particle & Range & Mean & & Range & Mean \\
\cline { 2 - 5 } & & & & $100-500$ & 200 \\
Pollutant aerosol & $0.03-0.3$ & 0.1 & & $100-2000$ & $200^{\dagger}$ \\
Mineral aerosol & $0.3-3$ & $0.4^{*}$ & & $1000^{\S}$ \\
& & $0.2^{\ddagger}$ & & & \\
\hline
\end{tabular}

\footnotetext{
*Open ocean ( $>1000 \mathrm{~km}$ from the coast).

‡Less than $1000 \mathrm{~km}$ from the coast.

tNorth Atlantic.

\$All oceans except North Atlantic.
} 
between the North Atlantic and the Pacific Ocean. Yet again, differences in mean cloud properties and precipitation patterns between the two Atlantic sites and the Pacific sites, together with differences in mass-size distribution of mineral aerosol particles, might also explain the observed differences in scavenging ratios (see earlier and Buat-Menard and Duce [1986]). Nevertheless, though we stress that a more extensive data base is urgently needed for the North Atlantic, we have assumed that the differences in mean scavenging ratios between the North Atlantic and the Pacific Ocean are real and should be taken into account in the calculation of global wet deposition fluxes of mineral aerosol.

\section{Methodology}

Lead: North Atlantic Ocean. The concentration of lead in the atmosphere over the North Atlantic has been reliably measured over the past 15 years (see Table 2). Aerosol samples have been collected from islands over long periods and from ships over restricted periods. All these data reveal large gradi- ents in aerosol lead with concentrations decreasing away from coastal margins. In addition, there is evidence of short-term temporal variability related to seasonal changes in trans-Atlantic atmospheric transport. Longer-term changes due to the removal of lead from gasoline, primarily in the United States, require that measurements made in the early seventies be adjusted downward by roughly a factor of 2 to reflect more accurately concentrations currently expected [Shen and Boyle, 1987].

Lead was measured in aerosols at High Point, Bermuda (32 $\left.\mathrm{N} ; 62^{\circ} \mathrm{W}\right)$ from 1973 to 1974 in nonwinter months [Duce et al., 1976]. When transport was stratified into westerly, southeasterly, and easterly directions, it was found that the lead concentration in air masses coming from the west was twice that in air coming from south or east of Bermuda. Wolff et al. [1986a] made further aerosol measurements some 10 years later at ground level at the same location and obtained comparable values when corrected for decreases in leaded gasoline usage. Similar values were also obtained in the Florida easterlies in 1978 [Settle et al., 1982]. Lead concentra-

TABLE 2. Lead Aerosol Concentrations Over the Atlantic and Pacific Oceans

\begin{tabular}{|c|c|c|}
\hline Site & $\begin{array}{l}\text { Concentration* } \\
\mathrm{ng} \mathrm{m}^{-3}\end{array}$ & Reference \\
\hline \multicolumn{3}{|c|}{ Atlantic } \\
\hline Bermuda & $\begin{array}{l}3.3 \\
3.6\end{array}$ & $\begin{array}{l}\text { Duce et al. }[1976] \\
\text { Wolff et al. [1986a] }\end{array}$ \\
\hline Pigeon Key, Florida & & Settle et al. [1982] \\
\hline Weather station " $\mathrm{C}$ " & $0.6-4.4$ & Ryaboshapko et al. [1986] \\
\hline Faeroe Islands & & Kemp [1984] \\
\hline Western Atlantic & 2.4 & $\begin{array}{l}\text { Patterson and } \mathrm{Ng} \text { (unpublished } \\
\text { data, 1981) }\end{array}$ \\
\hline Northeastern Atlantic & $1.4-17.7$ & Veron [1988] \\
\hline $\begin{array}{l}\text { South Atlantic } \\
\text { Trade wind area }\end{array}$ & & \\
\hline $\begin{array}{l}\text { Trade wind area } \\
0^{\circ}-34^{\circ} \mathrm{S}\end{array}$ & $\begin{array}{r}0.27-7.5 \\
<0.17-9.2\end{array}$ & $\begin{array}{l}\text { Chester et al. [1983] } \\
\text { Volkening et al. [1988] }\end{array}$ \\
\hline $0^{\circ}-35^{\circ} \mathrm{S}$ & $<0.05-0.61$ & Volkening and Heumann [1990] \\
\hline $35^{\circ}-45^{\circ} \mathrm{S}$ & $<0.06-1.5$ & Volkening and Heumann [1990] \\
\hline $45^{\circ}-60^{\circ} \mathrm{S}$ & $0.24-0.46$ & Volkening and Heumann [1990] \\
\hline \multicolumn{3}{|c|}{$\underline{\text { Pacific }}$} \\
\hline Enewetak & $\begin{array}{l}0.088-0.26 \\
0.12\end{array}$ & Settle and Patterson [1982] \\
\hline North Pacific & $0.2-1$ & Maring et al. [1989] \\
\hline & 0.26 & Patterson [1988] \\
\hline Samoa & $0.02-0.15$ & Patterson and Settle [1987] \\
\hline & 0.016 & Arimoto et al. [1987] \\
\hline New Zealand & 0.13 & Arimoto et al. [1990] \\
\hline
\end{tabular}

\footnotetext{
${ }^{*}$ Mean or Range
} 
tions were determined for aerosol particles collected in the Canadian Arctic [Barrie et al., 1981].

Concentrations of about $1 \mathrm{ng} \mathrm{m}^{-3}$ appear to be substantially greater than global background levels and are attributed to long-range transport of pollutants to the Arctic. The value of $1 \mathrm{ng} \mathrm{m}^{-3}$ is applied to all arctic latitudes from $70^{\circ}$ to $90^{\circ} \mathrm{N}$.

Lead has also been measured in aerosols collected from ships in the North Atlantic. Veron [1988] measured aerosol lead from ships in the eastern North Atlantic. Using air mass trajectory analysis, he showed concentrations about an order of magnitude higher in those air masses coming from Europe relative to those coming from the central Atlantic. The areas to the west, near the centre of the Azores high, are characterized by some of the cleanest air in the North Atlantic, reflecting aged marine air from which much of the lead has been scavenged. Ryaboshapko et al. [1986] have made lead aerosol measurements from a weather ship stationed in the central North Atlantic $\left(52.7^{\circ} \mathrm{N}, 35.5^{\circ} \mathrm{W}\right)$ since 1976. They also stratified their data according to wind trajectory, and they estimate a relative increase of a factor 2 or more in air coming from North America. Lead was also measured in aerosols from ships on at least two occasions in conjunction with complete cruise transects from the North to South Atlantic. We used those data to extrapolate from the larger data sets mentioned above into other areas of the North Atlantic. Chester et al. [1983] measured lead over a large range of concentrations on a cruise from England to the South Atlantic. Measurements were also made recently by Volkening et al. [1988] on a cruise from Germany to the South Atlantic. Both cruises verified strong coastal gradients for lead aerosols, as well as a strong latitudinal gradient across the western and eastern sides of the Azores high. These gradients, which are typically a factor of 10 in magnitude, are attributed to transport from North America and Europe, respectively.

Extrapolating Aerosol Concentrations. The natural radionuclide ${ }^{210} \mathrm{~Pb}$, which is the product of the radioactive decay of its parent $222 \mathrm{Rn}$, provides a way of crudely estimating stable lead aerosol concentrations. This assumes some knowledge of the emission or deposition ratio of the radioactive and stable forms of lead in the area. From 1985 to 1986 , Hartman [1987] measured both stable $\mathrm{Pb}$ and ${ }^{210} \mathrm{~Pb}$ in bulk deposition at the eastern Atlantic coast near Lewes, Delaware, USA and at Bermuda. The deposition ratio of $\mathrm{Pb} / 210 \mathrm{~Pb}$ at both locations was about $400 \mathrm{ng} \mathrm{Pb} / \mathrm{dpm} 210 \mathrm{~Pb}$, with a seasonal variation of nearly $50 \%$ at the coast. This supports a value of 390 for this ratio reported by Settle et al. [1982] for the Sargasso Sea and suggests that this value might be used to estimate stable lead concentrations over parts of the North Atlantic. Using the $210 \mathrm{~Pb}$ aerosol measurements of Turekian et al.
[1977, 1983], one is able to predict stable aerosol lead concentrations near the northeast U.S. coast of $10-15 \mathrm{ng} \mathrm{Pb} \mathrm{m}^{-3}$. Likewise, using the ${ }^{210} \mathrm{~Pb}$ values of Lambert et al. [1983] across the North Atlantic, one would predict values of approximately $4 \mathrm{ng} \mathrm{Pb}$ $\mathrm{m}^{-3}$ through most of the North American plume to Europe. Similarly, the relatively high values observed for lead in the eastern Atlantic off Africa are supported by correspondingly high $210 \mathrm{~Pb}$ values. The ratio of $\mathrm{Pb} / 210 \mathrm{~Pb}$ can be quite variable geographically, however. Values for this ratio as high as $9000 \mathrm{ng} \mathrm{Pb} / \mathrm{dpm} 210 \mathrm{~Pb}$ have been observed in New Jersey [Knuth et al., 1983], and a combination of the $210 \mathrm{~Pb}$ data of Turekian et al. [1989] and the stable $\mathrm{Pb}$ data of Patterson and Settle [1987] at Samoa suggest that the ratio could be less than 10 there at times. Thus the $\mathrm{Pb} / 210 \mathrm{~Pb}$ ratio must be used very cautiously to extrapolate stable lead concentrations.

North and South Pacific Ocean. Most of the atmospheric lead concentrations over the remote Pacific Ocean were obtained by Patterson and Settle and have been summarized in a recent review paper [Patterson and Settle, 1987]. Some additional data for lead concentrations in the Pacific Ocean region have been reported by Maring et al. [1989], Duce et al. [1983], Arimoto et al. [1987], and Patterson [1988] as part of the SEAREX Program. These and the other available data are summarized in Table 2. The SEAREX data were obtained in the four major surface level wind fields over the Pacific Ocean: collections were made at Enewetak Atoll $\left(11^{\circ} \mathrm{N}, 162^{\circ} \mathrm{E}\right.$; North Pacific trade winds), American Samoa ( $14^{\circ} \mathrm{S}$, $170^{\circ} \mathrm{W}$; South Pacific trade winds), the North Island of New Zealand $\left(34^{\circ} \mathrm{S}, 172^{\circ} \mathrm{E}\right.$; South Pacific westerlies), and during two cruises in the North Pacific westerlies $\left(20^{\circ}-50^{\circ} \mathrm{N}, 155^{\circ}-170^{\circ} \mathrm{W}\right)$. The lack of data in other regions of the Pacific made it necessary for us to extrapolate from the available data to the other grid boxes over the North and South Pacific.

These extrapolations were made using three sources of information. First, we used the information on the distribution of $210 \mathrm{~Pb}$ in the Pacific atmosphere as compiled by Settle et al. [1982], Turekian et al. [1989], and by Lambert et al. [1983]. Second, trajectory information compiled by Whelpdale and Moody [1990] was used as a guideline for delineating the major transport pathways. Finally, our subjective judgment regarding sources, transport, and removal was used to predict concentrations when no other data were available.

South Atlantic and Indian oceans. Very few data are available for these oceanic regions. We have considered here lead concentrations as measured during various cruises by Chester et al. [1983] and by Volkening et al. [1988]. For the high latitudes of the southern hemisphere, we have taken as a background lead concentration a value of $10 \mathrm{pg} \mathrm{m}^{-3}$ based on the work of Wagenbach et al. [1988] at a 
coastal station in Antarctica. Extrapolation to the other grid boxes was made on the basis of the global distribution of $210 \mathrm{~Pb}$ [Lambert et al., 1983].

Mineral aerosol: North Atlantic Ocean. We have based our calculations on either total mineral aerosol data or extrapolations from $\mathrm{Al}$ concentrations by assuming that this element represents on average close to $8 \%$ by weight of mineral aerosol. Most of the data base has been obtained during several cruises and long time series measurements at Bermuda and Barbados [Duce et al., 1976; Prospero, 1979, 1981; Prospero et al., 1989; Savoie, 1984]. The highest mineral aerosol concentrations are observed in the tropical North Atlantic and reflect the long-range transport of Saharan dust, with a strong east-west decrease in near-surface concentrations. As is the case for lead, extrapolations to some grid boxes have been based on the consideration of $210 \mathrm{~Pb}$ concentration fields.

North and South Pacific Ocean. Most of the mineral aerosol concentrations and fluxes for a number of sites, both short-term and long-term (several years), in the Pacific Ocean region have been obtained as part of the SEAREX Program or related projects. Many of these data are summarized by Prospero [1979, 1981], Uematsu et al. [1983, 1985] and Prospero et al. [1989]. In addition, Tsunogai and Kondo [1982] and Tsunogai et al. [1985, 1988] have reported data from a network of aerosol sampling stations in Japan. The data for mineral dust concentrations are far more comprehensive than those for lead, but extrapolations were still needed and were made using available $210 \mathrm{~Pb}$ concentration fields, particularly those of Turekian et al. [1989], the trajectory information compiled by Whelpdale and Moody [1990], and our subjective judgement regarding sources, transport, and removal.

South Atlantic and Indian oceans. We have considered here the data obtained or compiled by Prospero [1979], Savoie [1984], Chester et al. [1983], and Volkening et al. [1988]. Also, a background value of $10 \mathrm{ng} \mathrm{m}^{-3}$ for mineral aerosol concentrations south of $50^{\circ} \mathrm{S}$ has been adopted based on the data of Wagenbach et al. [1988] at a coastal Antarctic station. Extrapolations of the existing data were made in the same way as for the Pacific Ocean.

Extrapolations to other elements. In order to estimate the inputs of some of the AEEs considered here (Cd, Cu, Ni, Zn, and As), we based our calculations on elemental ratios relative to $\mathrm{Pb}$. These ratios were determined for aerosol and precipitation samples from a wide range of environments. We considered only recent data which were thought to be representative of global patterns. These elemental ratios, which are presented in Table 3, are rather constant among sites even though the actual concentrations span more than 3 orders of magnitude. In our calculations we converted the $\mathrm{Pb}$ fluxes into fluxes of other elements based on these elemental ratios. This approach was based on our belief that the uncertainties arising from this normalization procedure would be no larger than those that would result from extrapolating from the small existing data sets for these elements to the global ocean, and would avoid bias in some areas arising from few and perhaps unrepresentative data. The calculations given here represent gross fluxes to the ocean. However, in the marine environment the gross deposition of materials such as trace metals is composed of a net input as well as a component associated with recycled sea spray. There is strong evidence that atmospheric sea salt particles produced by bubbles bursting at the sea surface contain many metals in concentrations considerably higher than would be expected on the basis of metal-to-sodium ratios of near-surface seawater [Settle and Patterson, 1982; Buat-Menard, 1986; Jickells et al., 1984; Arimoto et al., 1985; Weisel et al., 1984]. Therefore our calculated net deposition fluxes to the ocean may be upper limits or biased high, especially for very remote areas where the contribution of the recycled component is likely to be the greatest.

There have been some attempts to evaluate the importance of the recycled flux of trace metals. In most cases the approach is based on a consideration of metal-to-sodium ratios of the largest atmospheric particles, which should represent the recycled component in air [Arimoto et al., 1985]. These ratios were determined from the analysis of particles collected on the first stage of a cascade impactor. They agree reasonably well with direct measurements of sea salt particles artificially produced and collected in the North Atlantic [Weisel et al., 1984]. Although the atmospheric concentrations of trace metals associated with large sea salt particles represent only a minor fraction of the total atmospheric concentration of these elements, this fraction is likely to account for a significant, if not major, part of the gross dry deposition flux. This is because sea salt particles have much higher dry deposition velocities than materials attached to small particles. For example, using this approach for lead and other metals showed the recycled component of dry deposition to a surrogate surface to range from 12 to $100 \%$ for samples collected over the Pacific [Arimoto et al., 1985]. For some samples, essentially all the gross measured dry flux could be attributed to sea spray.

However, it is unlikely that our calculations of dry deposition for lead represent only a recycled flux. First, they are based on total atmospheric concentration data so that the contribution of the recycled component is only a small percentage of the total concentration. Second, the dry deposition velocity used here, $0.1 \mathrm{~cm} \mathrm{~s}^{-1}$, is essentially that of submicrometer aerosol particles which contain most of the atmospheric concentration of lead and other pollutant elements. Thus our calculation procedure is 


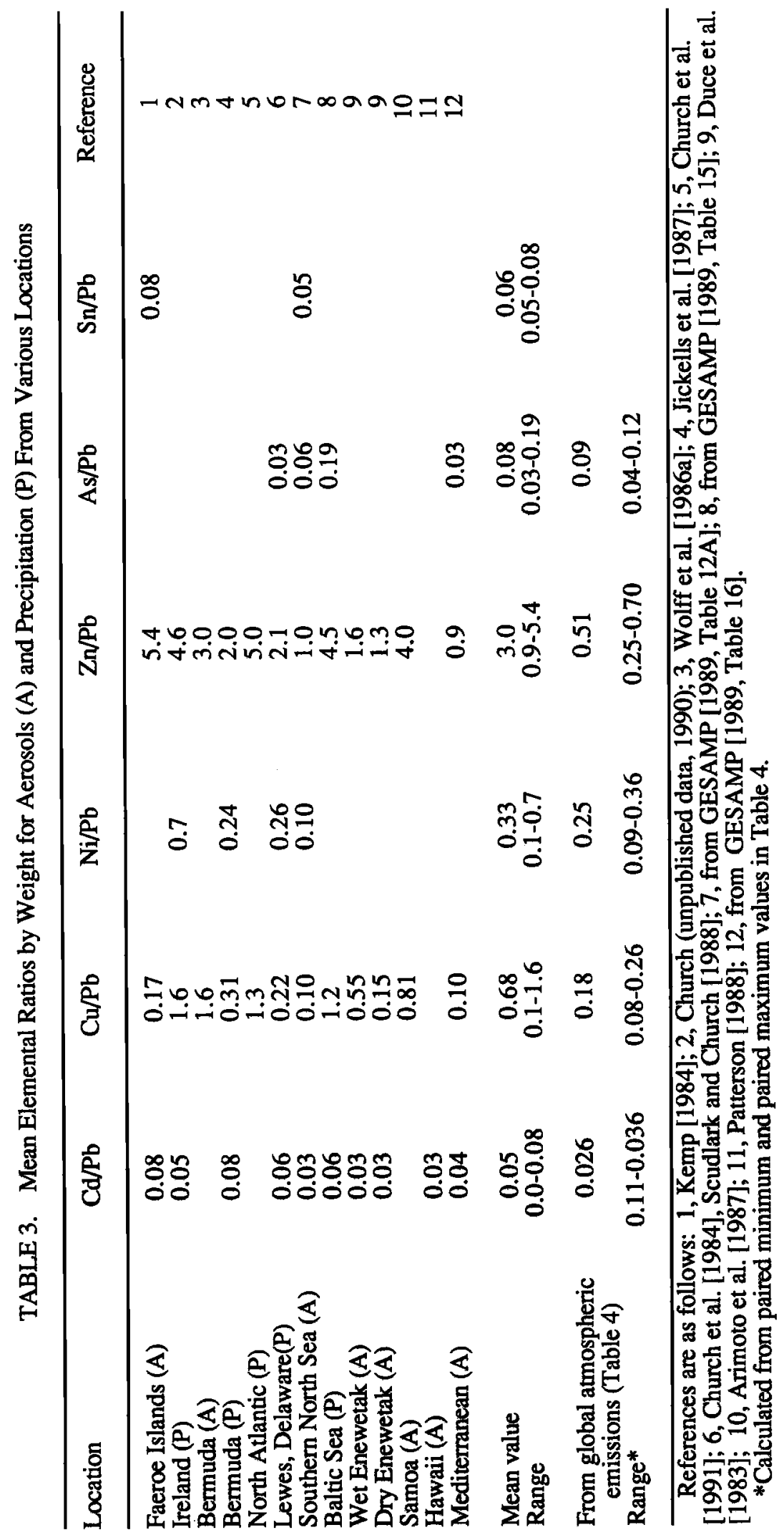


designed to minimize the recycled component, which probably represents $<50 \%$ of the calculated gross dry flux.

Recycled components for trace metals in rain collected over the North Atlantic and Pacific oceans [Jickells et al., 1984; Arimoto et al., 1985; Settle and Patterson, 1982] represent between 10 and $50 \%$ of the gross wet deposition. It can therefore be assumed that the gross wet lead fluxes calculated here may be high by similar factors for remote oceanic areas.

Overall, we expect that these calculations do not overestimate the net input of lead to the ocean by more than $50 \%$. For other elements the uncertainty may be somewhat larger, since the mean elemental ratios relative to lead in Table 3 may not give an accurate indication of the relative amount of each metal entering from nonmarine sources. We believe, however, that these ratios are probably representative of the net input to the ocean within a factor of 2 .

As a check on our assumptions, we have used an alternative approach based on the ratio of the global anthropogenic and natural atmospheric sources of a trace metal to the global anthropogenic and natural sources of lead. Estimates of these global emission fluxes are presented in Table 4, and element-to-lead ratios calculated from the global emission data in Table 4 are given at the bottom of Table 3. Despite large uncertainties (as indicated by the ranges of values shown inTable 4), the ratios calculated using the two approaches generally agree to within a factor of 2-5. Both approaches are used to calculate the global atmospheric fluxes to the ocean of these metals.

To estimate the flux of elements predominantly associated with mineral aerosol particles $(\mathrm{Al}, \mathrm{Fe}, \mathrm{Si}$, and $\mathrm{P}$ ), we have used upper continental crustal abundances [Taylor and McLennan, 1985] so that the mineral aerosol contains $8.04 \% \mathrm{Al}, 3.5 \% \mathrm{Fe}, 30.8 \%$ $\mathrm{Si}$, and $1050 \mathrm{ppm} \mathrm{P}$.

TABLE 4. Global Atmospheric Emissions of Trace Metals

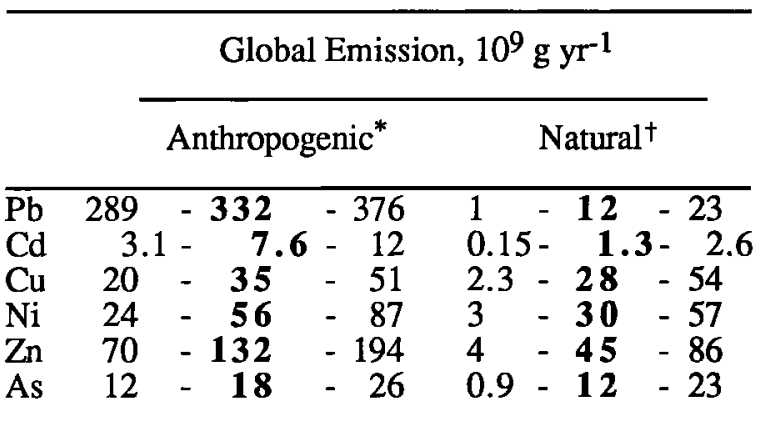

Values are given as ranges, with median values in bold type.

*Nriagu and Pacyna [1988]

†Nriagu [1989]
Solubility of trace elements in seawater. The solubility in seawater of trace elements present on atmospheric aerosols is important in determining their impact on oceanic biogeochemical cycles. The solubility of an element reflects its chemical partitioning in the aerosol and the environmental history of the particles. Crecelius [1980] and Chester et al. [1986] have demonstrated that the chemical partitioning of several elements is different in aerosols dominated by mineral dust or by anthropogenic components. Lindberg and Harriss [1983] have shown a particle size dependence of solubility which is probably caused by the different sources of different sizes of aerosols. Several authors [e.g., Moore et al., 1984; Maring and Duce, 1987; Statham and Chester, 1988; Zhuang et al., 1990] have demonstrated that $\mathrm{pH}$ significantly affects the leaching of aerosols. The possibility of oxidation or uptake of acid gases on aerosol surfaces [Andreae et al., 1986; Berresheim and Jaeschke, 1986; Graedel et al., 1985] means that atmospheric particles may be subject to low $\mathrm{pH}$ regimes during atmospheric transport that may affect their subsequent dissolution.

Although it is not possible to give unambiguous values of solubilities, the ranges observed are presented in Table 5. These data demonstrate that elements predominantly associated with mineral aerosol (e.g., $\mathrm{Al}, \mathrm{Si}$, and $\mathrm{Fe}$ ) are less soluble than those associated with accumulation mode aerosol (e.g., $\mathrm{Zn}, \mathrm{Cu}, \mathrm{Pb}$, and $\mathrm{As}$ ). For the purposes of the present calculations, it is assumed that $5 \%$ of the aluminum, $10 \%$ of the $\mathrm{Fe}, 5 \%$ of the $\mathrm{Si}, 33 \%$ of the $\mathrm{P}$,

TABLE 5. Solubility in Seawater of Elements Attached to Aerosol Particles

\begin{tabular}{lrl}
\hline Element & Solubility, $\%$ & References \\
\hline $\mathrm{Al}$ & $0.6-10$ & 1,2 \\
$\mathrm{Si}$ & $5-10$ & 3 \\
$\mathrm{P}$ & $21-51$ & 4 \\
$\mathrm{Fe}$ & $<1-50$ & $2,5,6,9$ \\
$\mathrm{Mn}$ & $25-49$ & $2,6,7$ \\
$\mathrm{~V}$ & $31-85$ & $2,6,8$ \\
$\mathrm{As}$ & $48-78$ & 5,6 \\
$\mathrm{Cd}$ & $81-84$ & 2 \\
$\mathrm{Cu}$ & $15-86$ & $2,6,10$ \\
$\mathrm{Ni}$ & $29-47$ & 2 \\
$\mathrm{~Pb}$ & $13-90$ & 2,11 \\
$\mathrm{Zn}$ & $24-76$ & 2,5 \\
\hline
\end{tabular}

References are as follows: 1, Maring and Duce [1987]; 2, Hodge, et al. [1978]; 3, Wollast and Chou [1985]; 4, Graham and Duce [1982]; 5, Crecelius [1980]; 6, Moore, et al. [1984]; 7, Statham and Chester [1988]; 8, Walsh and Duce [1976]; 9, Zhuang et al. [1990]; 10, Maring and Duce [1989]; 11, Maring and Duce [1990]. 
and $90 \%$ of the $\mathrm{Pb}$ that enters the ocean from the atmosphere is soluble.

Very few data are available on the partitioning of trace elements in rainwater between soluble and insoluble forms. This is an important area for future research, since most of the flux of the elements is associated with wet deposition. It seems that the solubility of the elements is highly variable depending on the $\mathrm{pH}$ of rainwater. For example, Losno et al. [1988] found that in Mediterranean rainwater the solubility of zinc ranged between 15 and $99 \%$ of the total zinc, with the higher percentage observed for low $\mathrm{pH}(4)$ and the lower percentage for high $\mathrm{pH}$ (7). This solubility-pH relationship can be explained by an adsorption-desorption equilibrium. There is some evidence that a similar relationship exists for $\mathrm{Pb}, \mathrm{Cu}$, and $\mathrm{Cd}$ [Elbaz-Poulichet, 1988].

Prospero et al. [1987] found that the dissolved Al concentration in rainwater containing Saharan dust was highly variable; however, the mean solubility of $5 \%$ was similar to that measured for the seawater solubility of $\mathrm{Al}$ in mineral aerosols [Maring and Duce, 1987]. Dissolution kinetics of $\mathrm{Al}$ and Si from feldspar minerals have also been investigated in the laboratory for a wide range of $\mathrm{pH}$. Such kinetics are often be described in terms of surface-complex reactions [Wollast and Chou, 1985; Carroll-Webb and Walther, 1988].

\section{Results}

The global atmospheric fluxes for lead and for mineral aerosol as calculated from the concentration fields, dry deposition velocities, precipitation scavenging ratios, and precipitation amounts for each grid are given in Tables 6 and 7 for each ocean basin. Global maps of the atmospheric fluxes of lead and mineral aerosol are presented in Figures 5 and 6.

TABLE 6. Atmospheric Flux of Lead to the Ocean

\begin{tabular}{lllllccc}
\hline & \multicolumn{3}{c}{ Flux, $10^{-3} \mathrm{~g} \mathrm{~m}^{-2} \mathrm{yr}^{-1}$} & & \multicolumn{3}{c}{ Deposition, $10^{9} \mathrm{~g} \mathrm{yr}^{-1}$} \\
\cline { 2 - 4 } \cline { 6 - 8 } \multicolumn{1}{c}{ Ocean } & Wet & Dry & Total & & Wet & Dry & Total \\
& & & & & & & \\
\hline North Pacific & 0.17 & 0.03 & 0.20 & & 16 & 2.4 & 18 \\
South Pacific & 0.02 & 0.003 & 0.02 & & 1.9 & 0.3 & 2.2 \\
North Atlantic & 0.85 & 0.18 & 1.03 & & 47 & 9.6 & 57 \\
South Atlantic & 0.06 & 0.02 & 0.08 & & 3.1 & 1.1 & 4.2 \\
North Indian & 0.27 & 0.06 & 0.33 & & 3.9 & 0.9 & 4.8 \\
South Indian & 0.04 & 0.01 & 0.05 & & 2.1 & 0.3 & 2.4 \\
Global total & 0.20 & 0.04 & 0.24 & & 74 & 15 & 89 \\
\hline
\end{tabular}

Individual estimates are uncertain by a factor of 2 to 3 .

TABLE 7. Atmospheric Flux of Mineral Aerosol to the Ocean

\begin{tabular}{|c|c|c|c|c|c|c|}
\hline \multirow[b]{2}{*}{ Ocean } & \multicolumn{3}{|c|}{ Flux, $\mathrm{g} \mathrm{m}^{-2} \mathrm{yr}^{-1}$} & \multicolumn{3}{|c|}{ Deposition, $10^{12} \mathrm{~g} \mathrm{yr}^{-1}$} \\
\hline & Wet & Dry & Total & Wet & Dry & Total \\
\hline $\begin{array}{l}\text { North Pacific } \\
\text { South Pacific }\end{array}$ & $\begin{array}{l}3.8 \\
0.23\end{array}$ & $\begin{array}{l}1.5 \\
0.13\end{array}$ & $\begin{array}{l}5.3 \\
0.35\end{array}$ & $\begin{array}{r}340 \\
25\end{array}$ & $\begin{array}{r}140 \\
14\end{array}$ & $\begin{array}{r}480 \\
39\end{array}$ \\
\hline $\begin{array}{l}\text { North Atlantic } \\
\text { South Atlantic }\end{array}$ & $\begin{array}{l}1.1 \\
0.27\end{array}$ & $\begin{array}{l}2.9 \\
0.20\end{array}$ & $\begin{array}{l}4.0 \\
0.47\end{array}$ & $\begin{array}{l}61 \\
14\end{array}$ & $\begin{array}{r}160 \\
10\end{array}$ & $\begin{array}{r}220 \\
24\end{array}$ \\
\hline $\begin{array}{l}\text { North Indian } \\
\text { South Indian }\end{array}$ & $\begin{array}{l}5.1 \\
0.60\end{array}$ & $\begin{array}{l}2.0 \\
0.22\end{array}$ & $\begin{array}{l}7.1 \\
0.82\end{array}$ & $\begin{array}{l}73 \\
32\end{array}$ & $\begin{array}{l}29 \\
12\end{array}$ & $\begin{array}{r}100 \\
44\end{array}$ \\
\hline Global total & 1.5 & 1.0 & 2.5 & 550 & 360 & 910 \\
\hline
\end{tabular}

Individual estimates are uncertain by a factor of 2 to 3 . 




Fig. 5. Global fluxes of lead to the oceans in micrograms $\mathrm{Pb}$ per square meter per year.

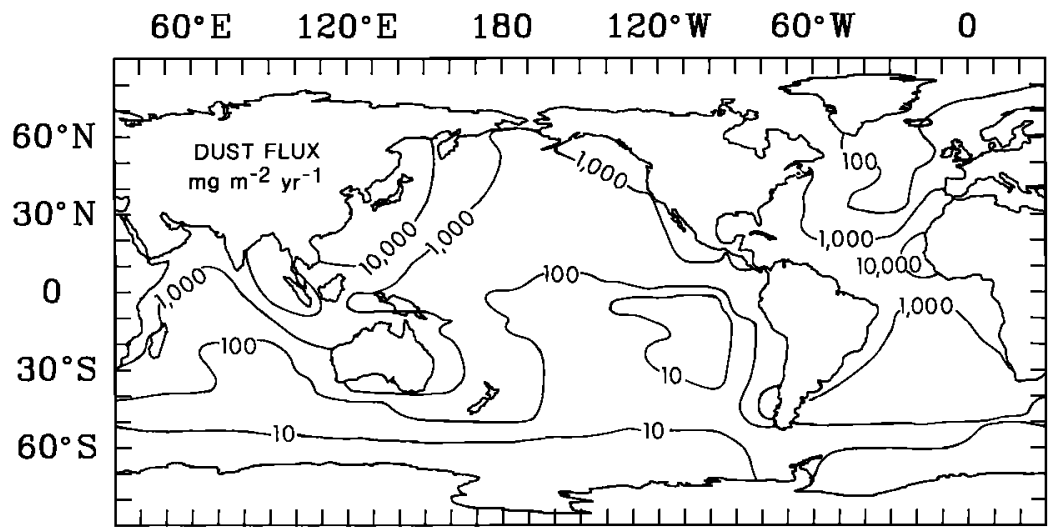

Fig. 6. Global fluxes of mineral aerosol to the oceans in milligrams per square meter per year.

The range of deposition rates for the other AEEs presented in Table 8 represents the results from the calculations using the two approaches described earlier. This represents the total deposition of these metals to the ocean, since it does not take into consideration the fraction of the metals that is soluble in the water. Note that for some elements, e.g., $\mathrm{Cu}$ and $\mathrm{Zn}$, the flux range is roughly a factor of 4 to 5 .

These large differences may result from significant marine recycling and/or large errors in the estimation of the global anthropogenic or natural atmospheric emissions for these metals. The global atmospheric depositions of $\mathrm{Al}, \mathrm{Fe}, \mathrm{Si}$, and $\mathrm{P}$ to the ocean, as calculated from the mineral aerosol input to the ocean in Table 7 and the percent crustal abundances described above, are given in Table 9.

In Tables 6-9 the depositions given are estimates of the amounts of material arriving at the sea surface. For some purposes, e.g., impact of such inputs on seawater biology, it may be more useful to know the proportion of the input which readily dissolves in the water. Such values may be obtained by multiplying the fluxes in Tables 6,8 , and 9 by the solubility factors discussed earlier (Table 5); our best estimates of the means of the solubility are given in Table 11. In order to convert from deposition to flux, the deposition values should be divided by the basin areas given in the preceding section (subsection on estimating concentrations using observations and transport patterns).

Mercury and tin. For both elements, recent global budgets have been produced. We report these without modification.

Mercury: The compilations of Gill and Fitzgerald [1987] give inputs of mercury to world oceans as shown in Table 10. This estimate of deposition to the ocean appears consistent with the lower range of estimates by Lindquist [1985] of global deposition rates (i.e., including deposition to land) of 2-17 x $10^{9} \mathrm{~g} \mathrm{yr}^{-1}$.

Tin: Byrd and Andreae [1986] report results from the North Atlantic and South Pacific which they scale to estimate inputs to the northern hemisphere oceans of $0.3 \times 10^{9} \mathrm{~g} \mathrm{yr}^{-1}$ and to Southern Hemisphere oceans of $0.023 \times 10^{9} \mathrm{~g} \mathrm{yr}^{-1}$. This leads to an estimated input to the world oceans of $0.32 \times 10^{9} \mathrm{~g} \mathrm{yr}^{-1}$. 
TABLE 8. Atmospheric Deposition to the Ocean of Primarily Anthropogenic Trace Metals

\begin{tabular}{lccccc}
\hline & \multicolumn{5}{c}{ Deposition, $10^{9} \mathrm{~g} \mathrm{yr}^{-1}$} \\
\cline { 2 - 6 } & $\mathrm{Cd}$ & $\mathrm{Cu}$ & $\mathrm{Ni}$ & $\mathrm{Zn}$ & $\mathrm{As}$ \\
\hline North Pacific & $0.47-0.90$ & $3.2-12$ & $4.5-5.9$ & $9.1-54$ & $1.6-1.4$ \\
South Pacific & $0.06-0.11$ & $0.4-1.5$ & $0.6-0.7$ & $1.1-6.6$ & $0.2-0.18$ \\
North Atlantic & $1.5-2.9$ & $10-39$ & $14-19$ & $29-170$ & $5.1-4.6$ \\
South Atlantic & $0.11-0.21$ & $0.8-2.9$ & $1.1-1.4$ & $2.1-13$ & $0.4-0.34$ \\
North Indian & $0.12-0.24$ & $0.9-3.3$ & $1.2-1.6$ & $2.4-14$ & $0.4-0.4$ \\
South Indian & $0.06-0.12$ & $0.4-1.6$ & $0.6-0.8$ & $1.2-7.2$ & $0.2-0.2$ \\
Global Total & $2.3-4.5$ & $16-60$ & $22-29$ & $44-270$ & $7.9-7.1$ \\
\hline
\end{tabular}

The first number of each pair is obtained using element to lead ratios obtained from global atmospheric emissions; the second is obtained from such ratios measured in aerosol and rain samples (Table 3 ).

TABLE 9. Atmospheric Deposition to the Ocean of Trace Elements Derived From Mineral Aerosol

\begin{tabular}{lcccr}
\hline & $\begin{array}{c}\mathrm{Al}, \\
10^{12} \mathrm{~g} \mathrm{yr}^{-1}\end{array}$ & $\begin{array}{c}\mathrm{Fe}, \\
10^{12} \mathrm{~g} \mathrm{yr}^{-1}\end{array}$ & $\begin{array}{c}\text { Si, } \\
10^{12} \mathrm{~g} \mathrm{yr}^{-1}\end{array}$ & $\begin{array}{c}\mathrm{P}, \\
10^{9} \mathrm{~g} \mathrm{yr}^{-1}\end{array}$ \\
\hline North Pacific & 38 & 17 & 150 & 500 \\
South Pacific & 3.1 & 1.4 & 12 & 41 \\
North Atlantic & 18 & 7.7 & 68 & 230 \\
South Atlantic & 1.9 & 0.8 & 7.4 & 25 \\
North Indian & 8.2 & 3.6 & 31 & 110 \\
South Indian & 3.5 & 1.5 & 14 & 46 \\
Global Total & 73 & 32 & 280 & 950 \\
\hline
\end{tabular}

Individual estimates are uncertain by a factor of 2 to 3 .

Comparison Between Global Atmospheric and Riverine Inputs of Trace Elements

Global atmospheric and riverine inputs of trace elements in the dissolved and the particulate forms are presented in Table 11. It appears that rivers are generally the major source of particulate trace elements for the ocean, with the exception of phosphorus. However, it must be stressed that particulate riverine inputs are likely to be deposited in the ocean close to the source regions, whereas inputs via the atmosphere will certainly be transported to remote oceanic areas. For example, in the case of iron, if one assumes that the particulate input is essentially refractory, the atmospheric input is likely to be the major contributor to the nonbiogenic sedimentation rate of iron in remote areas, as has been shown for the North Pacific [Arimoto et al., 1985].

Of more immediate concern for the "health" of the oceans is the soluble input which can have a direct impact on marine biological systems. Some elements (such as iron and phosphorus) are essential nutrients, and some pollutant elements enter the trophic food chain via active or passive uptake processes. From Table 11 it can be seen that atmospheric inputs of $\mathrm{Fe}$ and $P$ are similar to those from rivers. Since most of these inputs are natural, the atmospheric source must be taken into account for an accurate understanding of the biogeochemical cycling of these elements in 
the ocean, especially in open ocean areas. As was demonstrated by Duce [1986], atmospheric deposition plays a major role in the regulation of dissolved iron concentrations in the surface waters of oligotrophic marine regions, such as the Sargasso Sea and the tropical North Pacific.

For pollutant elements the global atmospheric and riverine inputs are comparable for dissolved $\mathrm{Cu}, \mathrm{Ni}$, and $\mathrm{As}$; for $\mathrm{Zn}$ and $\mathrm{Cd}$, atmospheric inputs appear to dominate. It is likely that riverine inputs dominate in pericontinental areas, especially those close to the mouths of large rivers, whereas atmospheric inputs represent the dominant contribution in open ocean areas. For lead the data presented in Table 11 confirm that at the present time, the major source of

TABLE 10. Atmospheric Hg Deposition to Ocean Basins

\begin{tabular}{lc}
\hline & $\begin{array}{c}\text { Hg Deposition, } \\
10^{9} \mathrm{~g} \mathrm{yr}^{-1}\end{array}$ \\
\hline North Atlantic & 0.42 \\
South Atlantic & 0.09 \\
North Pacific & 0.58 \\
South Pacific & 0.33 \\
North Indian & 0.07 \\
South Indian & 0.2 \\
Global Total & 1.7 \\
\hline
\end{tabular}

pollution lead to the coastal and open oceans is via atmospheric deposition. Currently, about $75 \%$ of the atmospheric deposition of pollution $\mathrm{Pb}$ is due to automotive sources. Since lead is being phased out of use in gasoline in North America and Europe, atmospheric inputs of lead to the ocean may decrease by a factor of 3 within the next few decades. Nevertheless, even if this pollution source disappears, the deposition of $\mathrm{Pb}$ from the atmosphere to the ocean due to other pollution sources [Nriagu and Pacyna, 1988] will still dominate riverine inputs.

\section{THE ATMOSPHERIC INPUT OF NITROGEN SPECIES TO THE WORLD OCEAN}

\section{Introduction}

This section focuses on those nitrogen species that can be utilized as nutrients. These fall into two classes: oxidized nitrogen species including aerosol $\mathrm{NO}_{3}{ }^{-}$and gas phase oxides of nitrogen (NO, $\mathrm{NO}_{2}$, $\mathrm{HNO}_{3}$, and related species); and reduced nitrogen species including aerosol $\mathrm{NH}_{4}{ }^{+}$and gaseous $\mathrm{NH}_{3}$ (and related organic nitrogen species).

\section{Sources of Nutrient Nitrogen Species}

Oxidized Nitrogen. There are a number of quantitative assessments of the global nitrogen cycle [Soderlund and Svensson, 1976; Anderson, 1983; Stedman and Shetter, 1983; Logan, 1983; Galloway, 1985; NAS, 1984; Ehhalt and Drummond, 1983].

TABLE 11. Global Deposition of Metals to the Ocean

\begin{tabular}{|c|c|c|c|c|c|c|c|c|}
\hline & \multicolumn{8}{|c|}{ Deposition, $10^{9} \mathrm{~g} \mathrm{yr}^{-1}$} \\
\hline & $\mathrm{Pb}$ & $\mathrm{Cd}$ & $\mathrm{Cu}$ & $\mathrm{Ni}$ & $\mathrm{Zn}$ & As & $\mathrm{Fe}$ & $\mathbf{P}$ \\
\hline \multicolumn{9}{|c|}{ Atmospheric Input ${ }^{*}$} \\
\hline Assumed \% & & & & & & & & \\
\hline Solubility ${ }^{\dagger}$ & 90 & 83 & 86 & 38 & 76 & 63 & 10 & 33 \\
\hline Dissolved & 80 & $1.9-3.3$ & $14-45$ & $8-11$ & $33-170$ & $2.3-5.0$ & $3.2 \times 10^{3}$ & 310 \\
\hline Particulate & 10 & $0.4-0.7$ & $2-7$ & $14-17$ & $11-60$ & $1.3-2.9$ & $29 \times 10^{3}$ & 640 \\
\hline \multicolumn{9}{|c|}{$\underline{\text { Riverine Input }}{ }^{\ddagger}$} \\
\hline Dissolved & 2 & 0.3 & 10 & 11 & 6 & 10 & $1.1 \times 10^{3}$ & \multirow{2}{*}{$300 \S$} \\
\hline Particulate & 1600 & 15 & 1500 & 1400 & 3900 & 801 & $10 \times 10^{3}$ & \\
\hline
\end{tabular}

\footnotetext{
${ }^{*}$ Calculated using Tables 5, 6, 8, and 9.
}

tIn selecting solubility factors from Table 5 , results from experiments in which open-ocean aerosols were used have been preferred.

ҒGESAMP [1987].

\$Total P input to marine sediment. 
These estimates and others have recently been reviewed by Warneck [1988]. Of these, the most detailed analysis is that by Logan [1983], who considers both the sources for the principal nitrogen species and their ultimate sinks. Logan obtains for the global source a range of $25-99 \times 10^{12} \mathrm{~g} \mathrm{~N} \mathrm{yr}^{-1}$ with a best estimate of about $50 \times 10^{12} \mathrm{~g} \mathrm{~N} \mathrm{yr}^{-1}$. The largest single source of $\mathrm{NO}_{\mathrm{x}}$ is fossil fuel combustion, $21 \times 10^{12} \mathrm{~g} \mathrm{~N} \mathrm{yr}^{-1}$. A recent evaluation of global fossil fuel combustion sources [Hameed and Dignon, 1988] yields a similar value, $22 \times 10^{12} \mathrm{~g} \mathrm{~N}$ $\mathrm{yr}^{-1}$ for 1980 . Of all the sources, the anthropogenic one is probably the most accurately known. The second largest source in Logan's assessment is biomass burning, $12 \times 10^{12} \mathrm{~g} \mathrm{~N} \mathrm{yr}^{-1}$, although the range of uncertainty, 4-24 $\times 10^{12} \mathrm{~g} \mathrm{~N} \mathrm{yr}^{-1}$, is rather large; recent estimates suggest a somewhat lower range, $4-7 \times 10^{12} \mathrm{~g} \mathrm{~N} \mathrm{yr}^{-1}$ [Crutzen, 1990]. Biomass burning can result from either anthropogenic activities or natural processes, but the anthropogenic portion is considered to be dominant [Seiler and Crutzen, 1980; Logan et al., 1981].

The major natural atmospheric sources of oxidized nitrogen over the oceans are believed to be NO production by lightning $\left(8 \times 10^{12} \mathrm{~g} \mathrm{~N} \mathrm{yr}^{-1}\right.$, range $2-20 \times 10^{12} \mathrm{~g} \mathrm{~N} \mathrm{yr}^{-1}$ ) and downmixing of NO from the stratosphere $\left(0.5 \times 10^{12} \mathrm{~g} \mathrm{~N} \mathrm{yr}^{-1}\right)$, where it is produced by the photolysis of $\mathrm{N}_{2} \mathrm{O}$. Both estimates have very large uncertainties. The only established oceanic source is through the photolysis of nitrite in surface waters; however, this source is generally considered to be minor [Zafiriou and McFarland, 1981]. Another potential biological source is the oxidation of marine-derived organic nitrogen compounds, e.g., amino acids and proteinaceous material, which are highly enriched in marine aerosols and rain [Mopper and Zika, 1987]. Duce [1983] estimated that the concentration of organic nitrogen is about 3 times greater than that of $\mathrm{NO}_{3}$ - nitrogen in marine aerosols over pristine oceanic areas. How much, if any, of this organic nitrogen is actually oxidized to $\mathrm{NO}_{3}$ - in the atmosphere remains to be determined. Another major source of $\mathrm{NO}_{\mathbf{x}}$ is microbial activity in soils, estimated to be $8 \times 10^{12} \mathrm{~g} \mathrm{yr}^{-1}$ but with considerable uncertainty (4-16 x $\left.10^{12} \mathrm{~g} \mathrm{yr}^{-1}\right)$ [Logan, 1983].

Taking into account all sources of oxidized nitrogen, over $80 \%$ are located on land. Consequently, the distribution and deposition of oxidized nitrogen over the oceans will be heavily influenced by the distribution of land masses in general and of anthropogenic sources in particular. Moreover, an overwhelmingly large percentage of the anthropogenic sources are located in the northern hemisphere. Of the $22 \times 10^{12} \mathrm{~g} \mathrm{~N} \mathrm{yr}^{-1}$ emitted from combustion sources to the global atmosphere, $94 \%$ is emitted in the northern hemisphere [Hameed and Dignon, 1988]. Consequently, we might expect that the impact of anthropogenic emissions on ocean deposition would be greatest there.

Reduced nitrogen. The global source budgets of ammonia are very poorly understood. There have been a number of assessments [Soderlund and Svensson, 1976; Bottger et al., 1978; Stedman and Shetter, 1983], but the estimates vary over wide ranges. The most recent estimates [Warneck, 1988] suggest that the most important sources are breakdown of urea from domestic animals $\left(22 \times 10^{12} \mathrm{~g}\right.$ $\left.\mathrm{N} \mathrm{yr}^{-1}\right)$, soil emissions $\left(15 \times 10^{12} \mathrm{~g} \mathrm{~N} \mathrm{yr}^{-1}\right)$, and biomass burning (2-8 $\left.\times 10^{12} \mathrm{~g} \mathrm{~N} \mathrm{yr}^{-1}\right)$. These sources and others yield a total of $\sim 54 \times 10^{12} \mathrm{~g} \mathrm{~N} \mathrm{yr}^{-1}$. Although Warneck discusses the possibility that the ocean could serve as a source of ammonia, the factors affecting this flux are poorly understood, and consequently, he does not include any contribution from the oceans in his budget estimates. The significance of oceanic sources for $\mathrm{NH}_{3}$ is discussed by Quinn et al. [1987, 1990].

\section{Data Selection and Calculation Parameters}

In this section the concentration data for the individual nitrogen species are reviewed, and the values that will be used for the flux calculations are selected. Also discussed are the selection of the parameters to be used in the calculations. In each case, we strive for a "best estimate" value for the deposition flux. However, for each species we also indicate what we believe to be reasonable upper and lower limits for the estimate.

Oxidized nitrogen species: Nitrate aerosol. By far the largest body of data for the oxidized species is that for $\mathrm{NO}_{3}{ }^{-}$aerosol, which is the oxidative end-member of the atmospheric nitrogen cycle. For this reason, the discussion starts with this species.

Concentration Data: The $\mathrm{NO}_{3}{ }^{-}$aerosol concentration data come mainly from two sources. The first consists of a data set of about 1000 aerosol samples gathered during the Global Weather Experiment in 1979 [Savoie, 1984]. The samples were collected aboard ships in the Atlantic, Pacific, and Indian oceans and also at a number of island stations in the North Atlantic. The data are summarized in Figure 7. In this figure Savoie also incorporates data from the literature up to the early 1980 s. The 25 regions in Figure 7 are defined on the basis of concentration trends in the data sets and on assumptions about the controlling transport conditions. Savoie made no attempt to interpolate between the measured means for the various regions.

The second major data set is that obtained in the Pacific in the SEAREX network of aerosol sampling stations [Prospero et al., 1985; Savoie et al., $1989 \mathrm{a}, \mathrm{b}]$. The network extends from Shemya in the Aleutians $\left(52^{\circ} 44^{\prime} \mathrm{N}, 174^{\circ} 06^{\prime} \mathrm{E}\right)$ to Norfolk Island $\left(29^{\circ} 05^{\prime} \mathrm{S}, 167^{\circ} 59^{\prime} \mathrm{E}\right)$. The network became operational in the North Pacific in 1981 and in the South 


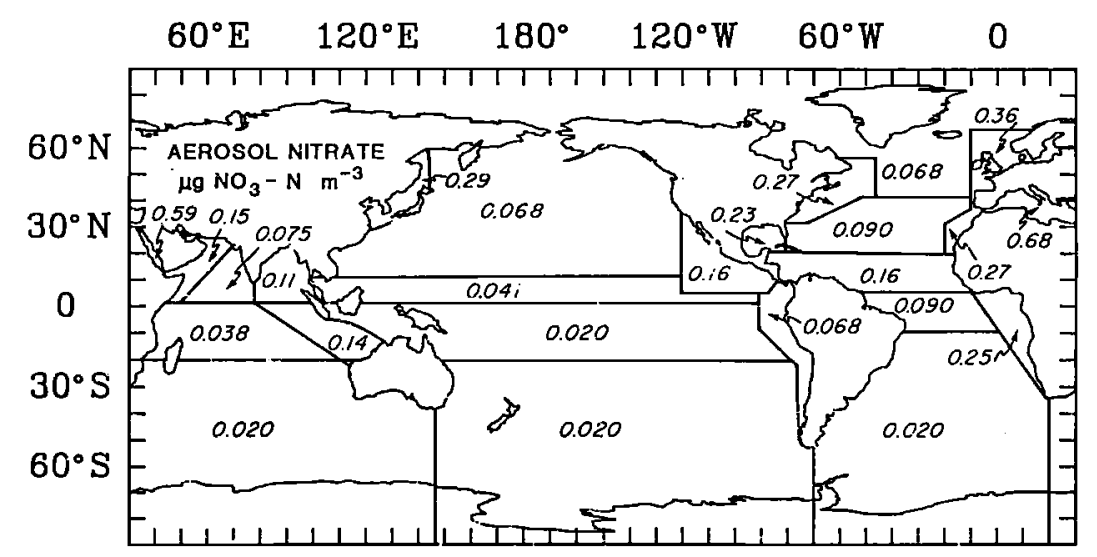

Fig. 7. Aerosol nitrate concentrations over the oceans in micrograms $\mathrm{NO}_{3}{ }^{-}$per cubic meter [after Savoie, 1984].

Pacific in 1983. This set contains data from the analysis of 2058 samples collected at 13 stations. The nitrate concentrations obtained in SEAREX fall within $20 \%$ of the values shown in Figure 7 for the Pacific; the only exception was for the region off the east coast of Australia and around New Zealand, where the mean concentrations were $0.19 \mu \mathrm{g} \mathrm{m}^{-3}$.

In assessing the data for the flux computations, we have interpolated between the coastal regions (where concentrations are usually relatively high) and the central ocean regions by assuming a half-decrease distance of $1000 \mathrm{~km}$. This selection is supported by the aerosol concentration distributions shown in Figure 7. Note that concentrations decrease by a factor of 4 from the coastal ocean region off the east coast of Asia to the more remote central North Pacific; also note the decrease by a factor of 3 in going from the ocean regions off the east coast of North America and the northwest coast of Africa to the central North Atlantic. However, it should be understood that there are few, if any, data for most ocean regions, especially along the coasts. Consequently, many of the values that we use are little more than rough estimates. Despite the uncertainties, it is clear that remote ocean areas appear to be characterized by a relatively uniform "background" $\mathrm{NO}_{3}$ - concentration of about $0.025 \mu \mathrm{g} \mathrm{N} \mathrm{m}^{-3}$ [Savoie et al., 1989a]. It is also apparent that the concentrations over the northern oceans are generally considerably higher than this background value [Prospero and Savoie, 1989].

In estimating fluxes, it is assumed that the data base for aerosol $\mathrm{NO}_{3}$ - concentrations is fairly robust for most ocean regions. It seems unlikely that the concentration fields will change greatly with the addition of new data; consequently, we only use the best estimate for the $\mathrm{NO}_{3}$ - concentrations and do not calculate a range for the calculated fluxes.

Dry deposition velocity: Nitrate aerosol over the oceans has a mass median diameter of several micrometers, the $\mathrm{NO}_{3}{ }^{-}$mass being distributed as the sur- face area of sea salt aerosol [Savoie and Prospero, 1982]. This distribution appears to result from the sorption or reaction of oxidized nitrogen species with sea salt aerosol. In the absence of measured deposition rates, we use a size-weighted deposition velocity derived from Slinn and Slinn [1980], $0.3 \mathrm{~cm} \mathrm{~s}^{-1}$, corresponding to a dry particle radius of about $1 \mu \mathrm{m}$ [Savoie and Prospero, 1982]. This same value has been used in previous budget estimates [Logan, 1983; Liu et al., 1983]. A higher value (about $1 \mathrm{~cm}$ $\mathrm{s}^{-1}$ ) might be warranted bon the basis of studies of dry deposition to flat plates [Pszenny, 1987]; however, these data are limited and the results are highly variable.

For estimating the flux range, we use 0.2 and 1.0 $\mathrm{cm} \mathrm{s}^{-1}$.

Scavenging ratio: Until recently, there were very few data on scavenging ratios measured for extended time periods over the oceans. The most extensive data set was a series of measurements made for 1 year or longer at American Samoa and Miami, Florida [Savoie et al., 1987]; these yielded values of 270 and 320 , respectively. On Bermuda, Wolff et al. [1986a] measured a value of 870 for total $\mathrm{NO}_{3}$, but this was for a relatively limited time period. More recently, a program of continuous measurements of aerosol and precipitation was initiated in a network of three stations in the North Atlantic (Barbados; Bermuda; Mace Head, Ireland) as a part of the Atmosphere-Ocean Chemistry Experiment (AEROCE). The $\mathrm{NO}_{3}$ - scavenging ratios measured over a 1 year period were identical at Barbados and Bermuda, 280, while that at Mace Head was $70 \%$ higher, 480 (J.N. Galloway and J.M. Prospero, unpublished data, 1990). The relatively narrow range obtained for all measurements (excluding Wolff et al.'s short term measurement at Bermuda) suggests that the scavenging ratio is relatively constant for a wide range of ocean environments. For the purpose of this study, a mean value of 330 is used. 
In order to assess the range of uncertainty, we simply use the range of the mean scavenging ratios measured at the five sites where the ratio was measured: 270 to 480 .

Nitrogen oxide gases. The compounds of principal interest are $\mathrm{NO}$ and $\mathrm{NO}_{2}$, photochemically linked species that are referred to collectively as $\mathrm{NO}_{\mathrm{x}}$.

Concentration data: It has proven to be very difficult to measure the atmospheric concentration of $\mathrm{NO}_{x}$ species at ambient levels in marine regions where pollutant impacts are small. Only recently have techniques become available that yield consistently reliable values. Even so, the measurement is still one of the most difficult to make. The problem of interpreting the older literature is compounded by the fact that techniques were used that purported to simultaneously measure $\mathrm{NO}$ and $\mathrm{NO}_{2}$. However, recent studies show that the instruments used were sensitive to the presence of a variety of other oxidized nitrogen species including $\mathrm{HNO}_{3}$ and peroxyacetyl nitrate (PAN). Consequently, the older data must be used with caution. Nonetheless, these data can be useful to show general concentration levels of nitrogen oxides and to indicate trends in their geographical distribution.

Among the most extensive remote ocean measurements of NO are those of Davis et al. [1987] and Ridley et al. [1987]. These were made aboard aircraft flying over the eastern North Pacific between Hawaii and the west coast of North America. Davis obtains an average midday value of $4 \mathrm{pptv}(0.0025$ $\mu \mathrm{g} \mathrm{N} \mathrm{m}^{-3}$ ) at altitudes less than $1.8 \mathrm{~km}$. Ridley et al. report a mean of $1.7 \mathrm{pptv}\left(0.0011 \mu \mathrm{g} \mathrm{N} \mathrm{m}^{-3}\right)$ with a median of $1 \mathrm{pptv}\left(0.00064 \mu \mathrm{g} \mathrm{N} \mathrm{m}^{-3}\right)$ for the region near Hawaii and $3.7 \mathrm{pptv}\left(0.0023 \mu \mathrm{g} \mathrm{N} \mathrm{m}^{-3}\right)$ with a median of $1 \mathrm{pptv}\left(0.00064 \mu \mathrm{g} \mathrm{N} \mathrm{m}^{-3}\right)$ for the open ocean off the west coast.

Recently, an extensive series of $\mathrm{NO}$ and $\mathrm{NO}_{\mathrm{x}}$ measurements were made over the North and South Atlantic on the survey flight STRATOZ (Stratospheric Ozone) III [Drummond et al., 1988; Ehhalt and Drummond, 1988]. For conditions when the winds had over-ocean trajectories, NO concentrations were generally under $10 \mathrm{pptv}(0.0062 \mu \mathrm{g} \mathrm{N}$ $\mathrm{m}^{-3}$ ) in the lower and middle troposphere over the South Atlantic and over the North Atlantic south of about $30^{\circ} \mathrm{N}$; at higher latitudes concentrations were generally in the range $20-40 \mathrm{pptv}(0.013-0.0025 \mu \mathrm{g}$ $\mathrm{N} \mathrm{m}^{-3}$ ). There are very few reliable measurements of $\mathrm{NO}_{2}$ over the oceans. In Logan's [1983] review article on global nitrogen fluxes, a world average marine boundary layer (MBL) $\mathrm{NO}_{2}$ concentration of $0.06 \mu \mathrm{g} \mathrm{m}^{-3}$ is used. However, recent measurements in the remote MBL yield values of $30 \mathrm{pptv}$ $\left(0.019 \mu \mathrm{g} \mathrm{N} \mathrm{m}^{-3}\right)$ [Warneck, 1988]. Recently, Carroll et al. [1990] report on an extensive series of $\mathrm{NO}$ and $\mathrm{NO}_{2}$ measurements that were made as a part of the NASA Chemical Instrumentation Test and Evaluation (CITE) 2 flights, some of which were made over the eastern North Pacific. Median values of $\mathrm{NO}$ and $\mathrm{NO}_{2}$ in the marine boundary layer were $4.0\left(0.0025 \mu \mathrm{g} \mathrm{N} \mathrm{m}^{-3}\right)$ and $10.4 \mathrm{pptv}(0.0065 \mu \mathrm{g} \mathrm{N}$ $\left.\mathrm{m}^{-3}\right)$, respectively, and $12.4\left(0.0077 \mu \mathrm{g} \mathrm{N} \mathrm{m}^{-3}\right)$ and $18.0 \mathrm{pptv}\left(0.011 \mu \mathrm{g} \mathrm{N} \mathrm{m}^{-3}\right)$ in the marine free troposphere.

For the purpose of this report we assume a mean NO value of $4 \mathrm{pptv}\left(0.0025 \mu \mathrm{g} \mathrm{N} \mathrm{m}^{-3}\right)$ for relatively remote ocean regions where no measurements have been made. In computing the global ocean fluxes of $\mathrm{NO}_{2}$ a background value of $0.02 \mu \mathrm{g} \mathrm{N} \mathrm{m}^{-3}$ is assumed; this value is uniformly applied to the Pacific, South Atlantic, and the Indian oceans. Higher values are found mostly over the North Atlantic; these values are used accordingly. The selection of the lower value $\left(0.02\right.$ versus $\left.0.06 \mu \mathrm{g} \mathrm{N} \mathrm{m}^{-3}\right)$ is not a critical issue because, as will be shown, the $\mathrm{NO}_{2}$ deposition flux computed with either value is quite small.

There are considerable data for the North Atlantic where the effects of continental pollution sources are quite evident. For example, the concentrations of $\mathrm{NO}_{\mathrm{x}}$ off the east coast of North America range from $0.2 \mu \mathrm{g} \mathrm{N} \mathrm{m}^{-3}$ to $7.6 \mu \mathrm{g} \mathrm{N} \mathrm{m}^{-3}$ [Galloway et al., 1984; Wolff et al., 1986a, b; Hastie et al., 1988; Misanchuk et al., 1987; Luke and Dickerson, 1987; Ryaboshapko et al., 1986]. These high concentrations result in a greatly increased rate of deposition to the western North Atlantic Ocean. The extent of the continental impact will depend upon the rate of removal of $\mathrm{NO}_{\mathbf{x}}$ during transport. For the western North Atlantic Ocean, Hastie et al. [1988] and Wolff et al. [1986a,b] estimate that the half-decrease distance is $500 \mathrm{~km}$ and $400 \mathrm{~km}$, respectively, values that are comparable to those computed from the extensive data presented by Ryaboshapko et al. [1986] for the North Atlantic. It should be noted that many of the measurements cited above were made with instruments that may have been responding to $\mathrm{NO}_{\mathrm{y}}$ (especially PAN). Consequently, the reported values of $\mathrm{NO}_{x}$ may be too high, in which case our computed fluxes will be too high. However, as we shall show in a later section, our computed fluxes for $\mathrm{NO}_{\mathrm{x}}$ are negligibly small; thus any overestimation of the $\mathrm{NO}_{\mathrm{x}}$ flux (because of erroneously high $\mathrm{NO}_{\mathrm{x}}$ data) will be of no consequence to our estimates of the total flux of nitrogen species to the ocean.

Although $\mathrm{NO}_{\mathrm{x}}$ data are lacking for most other marine regions downwind of continents, one might expect to find increased $\mathrm{NO}_{\mathrm{x}}$ concentrations over those coastal oceans as well. In regions where more extensive measurements are available, we interpolate between the high concentration regions (which are normally close to the continents) to the mid-ocean regions by using a half-decrease distance of $500 \mathrm{~km}$. The highest concentrations occur over the North and 
Baltic seas (4.4 and $1.7 \mu \mathrm{g} \mathrm{N} \mathrm{m}^{-3}$, respectively), over the Bay of Biscay $\left(2.0 \mu \mathrm{g} \mathrm{N} \mathrm{m}^{-3}\right)$, along the east coast of the United States $\left(1.5-2.5 \mu \mathrm{g} \mathrm{N} \mathrm{m}^{-3}\right)$ and over the Gulf of Mexico $\left(2.0 \mu \mathrm{g} \mathrm{N} \mathrm{m}^{-3}\right)$. In all other regions, the mean concentration is always less than $1.0 \mu \mathrm{g} \mathrm{N} \mathrm{m}^{-3}$.

Deposition fluxes: On the basis of their chemical properties (i.e., relatively insoluble and unreactive in water) the oceanic deposition velocities of NO and $\mathrm{NO}_{2}$ will be nearly identical. For the purpose of computing the deposition flux, we simply use a concentration value of $0.02 \mu \mathrm{g} \mathrm{N} \mathrm{m}^{-3}$ for combined NO and $\mathrm{NO}_{2}$ in remote ocean regions, with the exception of the North Atlantic, where we use actual values. As will be shown, these fluxes are so small that there is no reason to attempt to estimate error limits for them.

Nitric acid and volatile nitrates. There are very few data for nitric acid or volatile $\mathrm{NO}_{3}$ - Since most sampling techniques cannot distinguish between the various forms of volatile $\mathrm{NO}_{3}$ - the terms " $\mathrm{HNO}_{3}$ " and "volatile nitrate" are often used interchangeably. Volatile $\mathrm{NO}_{3}$ - could include a wide variety of low molecular weight organic species.

Concentration data: Volatile $\mathrm{NO}_{3}$ - concentrations over the oceans are often referenced to the concentration of particulate or total $\mathrm{NO}_{3}{ }^{-}$. Huebert [1980] reports a volatile nitrate/total nitrate ratio of about 0.5 for samples obtained aboard aircraft in the Pacific marine boundary layer. Huebert and Lazrus [1980a] obtain a ratio of 0.35 during a cruise in the equatorial Pacific and about 0.5 aboard aircraft in the MBL. Savoie and Prospero [1982] find that the volatile $\mathrm{NO}_{3}{ }^{-}$concentration is 0.10 or less of the total $\mathrm{NO}_{3}{ }^{-}$ in the tropical North Atlantic. Pszenny [1987] obtains essentially the same result from samples in the central and western South Pacific. Measurements in the Bermuda area [Hastie et al., 1988; Wolff et al., 1986a] yield values of 0.17 to 0.29 . During a recent cruise in the North Atlantic, ratios between 0.10 to 0.20 were found in regions not impacted by pollutants (A. Pszenny, personal communication, 1990).

Almost all the previously published data were obtained with filter packs. These have recently been shown to suffer from a number of artifacts that can give erroneously high gas phase concentrations [Talbot et al., 1990]. Recent studies with annular diffusion denuders yield consistently lower $\mathrm{HNO}_{3} /$ $\mathrm{NO}_{3}{ }^{-}$ratios, generally in the range of 0.10-0.15 (D.L. Savoie and J.M. Prospero, unpublished data, 1991). For our calculations we select a value that reflects the recent lower estimates for volatile $\mathrm{NO}_{3}$ $\left(\mathrm{HNO}_{3}\right)$, setting it equal to 0.15 of the aerosol $\mathrm{NO}_{3}{ }^{-}$.

PAN is perhaps the most important volatile $\mathrm{NO}_{3}{ }^{-}$ species after $\mathrm{HNO}_{3}$. PAN could serve as a reservoir for nitrogen oxides over the oceans [Singh et al., 1986]. However, very little is known about its distribution in marine air. The mean wintertime concen- tration in the boundary layer is $38 \mathrm{pptv}(0.024 \mu \mathrm{g} \mathrm{N}$ $\left.\mathrm{m}^{-3}\right)$ over the eastern North Pacific and $5 \mathrm{pptv}(0.003$ $\mu \mathrm{g} \mathrm{N} \mathrm{m}^{-3}$ ) over the South Pacific [Singh et al., 1986]. Thus the concentration of PAN in the South Pacific is only about $10 \%$ of the aerosol $\mathrm{NO}_{3}{ }^{-}$concentration and about the same as that for $\mathrm{HNO}_{3}$, assuming that the latter is present at $15 \%$ of the $\mathrm{NO}_{3}$ aerosol concentration. Rudolph et al. [1987] found that concentrations were less than $10 \mathrm{pptv}(0.006 \mu \mathrm{g}$ $\mathrm{N} \mathrm{m}^{-3}$ ) in the free troposphere over the South Atlantic. Recently, Singh et al. [1990] and Ridley et al. [1990] reported on an extensive series of PAN measurements that were made over the eastern North Pacific. For the middle troposphere in marine air masses, the mean value was $137 \mathrm{pptv}(0.086 \mu \mathrm{g} \mathrm{N}$ $\mathrm{m}^{-3}$ ), a value that is similar to that which we use for the mean $\mathrm{NO}_{3}{ }^{-}-\mathrm{N}$ in the central Pacific, $0.068 \mu \mathrm{g} \mathrm{N}$ $\mathrm{m}^{-3}$. However, concentrations in the marine boundary layer are much lower, the mean being $6.8 \mathrm{pptv}$ $\left(0.0043 \mu \mathrm{g} \mathrm{N} \mathrm{m}^{-3}\right)$; this is consistent with the instability of PAN at low temperatures. These data support the suggestion that PAN is an important transport species for the nitrogen cycle in the free troposphere. Given the low concentrations and the lack of knowledge about the removal properties of PAN, we have ignored its role in the deposition flux of nutrient nitrogen to the oceans. Also, we assume that any PAN that is transported to the boundary layer will ultimately be converted to nitrate and, as such, it will appear in our aerosol nitrate data base.

For the ratio of $\mathrm{HNO}_{3}$ to $\mathrm{NO}_{3}^{-}$, we use the range of mean values reported in the literature: 0.1 to 0.5 .

Dry deposition velocity: Because we ratio the concentration of $\mathrm{HNO}_{3}$ to the concentration of aerosol nitrate, we use the same dry deposition velocity as that used for aerosol nitrate, $0.3 \mathrm{~cm} \mathrm{~s}^{-1}$. We also use the same values for the range estimate, 0.2 and $1.0 \mathrm{~cm} \mathrm{~s}^{-1}$.

Scavenging ratio: The concentration of $\mathrm{HNO}_{3}$ in rainwater cannot be measured directly. We can estimate its value on the basis of ion balances. However, these estimated values are very imprecise and cannot be used for estimating the scavenging ratio for $\mathrm{HNO}_{3}$. In the absence of such information, we use the same scavenging ratio as that used for aerosol $\mathrm{NO}_{3}$-, i.e., 330. This approach is consistent with our procedure of computing the $\mathrm{HNO}_{3}$ concentration as a fixed fraction of the aerosol $\mathrm{NO}_{3}$ - concenration. If anything, this will probably be an underestimate in view of the very strong partitioning of $\mathrm{HNO}_{3}$ into water that is implied by the Henry's law constant for $\mathrm{HNO}_{3}$ [Clegg and Brimblecombe, 1988].

Since we scavenge $\mathrm{HNO}_{3}$ at the same rate as aerosol $\mathrm{NO}_{3}{ }^{-}$, we assume the same range estimate for the scavenging ratio (270 to 480 ).

Reduced nitrogen species. The decomposition and volatilization of organic materials release a number of reduced nitrogen compounds (e.g., ammonia, 
amines, amino acids) to the atmosphere. In the atmosphere these compounds can be hydrolyzed, oxidized, or removed by deposition processes. The concentrations of these compounds can be comparable to those of the oxidized nitrogen species. Consequently their contribution to the deposition of nitrogen to the oceans can be substantial.

The principal inorganic reduced nitrogen compounds are gaseous $\mathrm{NH}_{3}$ and aerosol $\mathrm{NH}_{4}{ }^{+}$. There is very little information on the concentrations of these species over the oceans [Quinn et al., 1987; Warneck, 1988]. Furthermore, the validity of much of the existing literature, especially the earlier work, is open to question. There are difficulties in distinguishing between $\mathrm{NH}_{3}$ and $\mathrm{NH}_{4}{ }^{+}$. Many of the data were obtained with filter packs, which can yield erroneously high $\mathrm{NH}_{3}$ values because of the volatilization of aerosol $\mathrm{NH}_{4}{ }^{+}$on the front filter. There are also problems with contamination, especially at the lower concentrations levels that are typical for the remote ocean. Consequently, we have not attempted to characterize the concentrations for specific ocean regions. Rather, the available data are used to broadly estimate open ocean concentration distributions.

It should be noted that in some regions the oceans may be a source of $\mathrm{NH}_{3}$ [Quinn et al., 1987, 1988; Warneck, 1988]. Because of the limited data for $\mathrm{NH}_{3}$ and $\mathrm{NH}_{4}{ }^{+}$, it is not yet possible to identify which areas are sources and which are sinks for $\mathrm{NH}_{3}$. Therefore the fluxes calculated may not be very meaningful from the standpoint of assessing the impact of continental inputs on the oceans.

Ammonium concentration data: The mean concentrations of $\mathrm{NH}_{4}{ }^{+}$aerosol over the open ocean range from 0.007 to about $0.1 \mu \mathrm{g} \mathrm{N} \mathrm{m}^{-3}$ (Table 12). For the northern oceans we choose a median value of $0.08 \mu \mathrm{g} \mathrm{N} \mathrm{m}^{-3}$. In calculating the deposition flux, the coastal ocean values are scaled in the same way as for aerosol $\mathrm{NO}_{3}{ }^{-}$.

TABLE 12. Concentrations of Reduced Nitrogen Species in the Marine Atmosphere

\begin{tabular}{|c|c|c|}
\hline Location & $\begin{array}{l}\text { Concentration } \\
\left(\mu \mathrm{g} \mathrm{N} \mathrm{m}^{-3}\right)\end{array}$ & Reference \\
\hline \multicolumn{3}{|c|}{$\mathrm{NH}_{3}$} \\
\hline $\begin{array}{l}\text { Global marine estimate } \\
\text { Global marine estimate } \\
\text { Cape Grim } \\
\text { Global estimate } \\
\text { Cape Grim } \\
\text { NW Pacific Ocean } \\
\text { North Pacific }\left(30^{\circ}-50^{\circ} \mathrm{N}\right) \\
\text { North Pacific }\left(15^{\circ}-29^{\circ} \mathrm{W}\right) \\
\text { Equatorial Pacific }\left(11^{\circ} \mathrm{S}-14^{\circ} \mathrm{N}\right)\end{array}$ & $\begin{array}{c}0.06 \\
0.01 \\
0.05 \\
0.06 \text { to } 0.6 \\
0.06 \\
0.014 \\
0.005 \\
0.004 \\
0.011\end{array}$ & $\begin{array}{l}\text { Soderlund and Svensson [1976] } \\
\text { Georgii and Gravenhorst [1977] } \\
\text { Ayers and Gras [1980] } \\
\text { Taylor et al. [1983] } \\
\text { Ayers and Gras [1983] } \\
\text { Quinn et al. [1988] } \\
\text { Quinn et al. [1990] } \\
\text { Quinn et al. [1990] } \\
\text { Quinn et al. [1990] }\end{array}$ \\
\hline \multicolumn{3}{|c|}{$\mathrm{NH}_{4}{ }^{+}$, Open Ocean } \\
\hline $\begin{array}{l}\text { Global marine estimate } \\
\text { Global marine estimate } \\
\text { Tropical Atlantic } \\
\text { Pacific Ocean } \\
\text { NW Pacific Ocean } \\
\text { Central North Atlantic } \\
\text { North Pacific }\left(30^{\circ}-50^{\circ} \mathrm{N}\right) \\
\text { North Pacific }\left(30^{\circ}-50^{\circ} \mathrm{W}\right) \\
\text { Equatorial Pacific }\left(11^{\circ} \mathrm{S}-14^{\circ} \mathrm{N}\right) \\
\text { Indian Ocean }\end{array}$ & $\begin{array}{l}0.4 \\
0.01 \text { to } 0.19 \\
0.1 \\
0.007-0.21 \\
0.084 \\
0.07 \\
0.22 \\
0.074 \\
0.078 \\
0.04\end{array}$ & $\begin{array}{l}\text { Soderlund and Svensson [1976] } \\
\text { Huebert and Lazrus [1980b] } \\
\text { Talbot et al. [1986] } \\
\text { Parungo et al. [1986] } \\
\text { Quinn et al. [1988] } \\
\text { Church et al. [1990] } \\
\text { Quinn et al. [1990] } \\
\text { Quinn et al. [1990] } \\
\text { Quinn et al. [1990] } \\
\text { Berresheim et al. [1990] }\end{array}$ \\
\hline \multicolumn{3}{|c|}{$\mathrm{NH}_{4}^{+}$, Coastal Ocean } \\
\hline $\begin{array}{l}\text { Lewes, Del., U.S.A. } \\
\text { West North Atlantic } \\
\text { West North Atlantic } \\
\text { East North Atlantic }\end{array}$ & $\begin{array}{l}1.2 \\
0.45 \\
0.42 \\
0.42\end{array}$ & $\begin{array}{l}\text { Wolff et al. [1986b] } \\
\text { Whelpdale et al. [1987] } \\
\text { Church et al. [1990] } \\
\text { Church et al. [1990] }\end{array}$ \\
\hline
\end{tabular}


Data for the southern oceans suggest that a lower value might be more appropriate. Recent aircraft data in the MBL east of Cape Grim give a mean of about $0.04 \mu \mathrm{g} \mathrm{N} \mathrm{m}^{-3}$ [Berresheim et al., 1990], while ship data in the central South Pacific yield similar values [Nagamoto et al., 1990; Parungo et al., 1986]. For the Antarctic region, Gras [1983] reports $0.05 \mu \mathrm{g} \mathrm{N}$ $\mathrm{m}^{-3}$. For our calculations a value of $0.04 \mu \mathrm{g} \mathrm{N} \mathrm{m}^{-3}$ for the remote southern oceans is used; coastal ocean concentrations are scaled in same manner as for the northern oceans. For the range estimate we arbitrarily assign an error range of a factor of 2 to the concentrations.

Dry deposition velocity: Most of the $\mathrm{NH}_{4}{ }^{+}$in aerosols is concentrated in the accumulation mode size range. Accordingly, we use a deposition velocity of $0.1 \mathrm{~cm} \mathrm{~s}^{-1}$. For the dry deposition velocity we use a range estimate of 0.05 to $0.2 \mathrm{~cm} \mathrm{~s}^{-1}$.

Scavenging ratio: There are few direct measurements of $\mathrm{NH}_{4}{ }^{+}$scavenging ratios. We can estimate a scavenging ratio for $\mathrm{NH}_{4}{ }^{+}$by using aerosol $\mathrm{NH}_{4}{ }^{+}$ data [Wolff et al., 1986a] collected at Bermuda coupled with $\mathrm{NH}_{4}{ }^{+}$data for rainfall [Galloway, 1985] which were not contemporaneous with the aerosol samples; these yield a ratio of about 100 . Recent data obtained in AEROCE at Bermuda, Mace $\mathrm{Head}$, and Barbados yield mean scavenging ratios of 160,240 , and 520, respectively, for a 1 year period (J.N. Galloway and J.M. Prospero, unpublished data, 1990). For this report we exclude the high value (which is suspect) and use a value of 200 , which is consistent with that generally used for accumulation mode aerosols.

For the lower estimate of the range we use the minimum measured value in the AEROCE North Atlantic network, 160. For the maximum estimate, 340 is used.

Ammonia concentration data: The data for $\mathrm{NH}_{3}$ are summarized in Table 12. The quality of the data for $\mathrm{NH}_{3}$ is worse than that for $\mathrm{NH}_{4}{ }^{+}$, as was previously stated. Nonetheless, the values in Table 12 range from 0.014 to $0.6 \mu \mathrm{g} \mathrm{N} \mathrm{m}^{-3}$ with most concentrations near $0.05 \mu \mathrm{g} \mathrm{N} \mathrm{m}^{-3}$. These concentrations imply a ratio of $\mathrm{NH}_{3} / \mathrm{NH}_{4}+$ that is about 0.6 (i.e., $0.05 / 0.08$ ). However, extensive data recently collected in the central Pacific [Quinn et al., 1990] suggest that $\mathrm{NH}_{3}$ concentrations are much lower, yielding an apparent $\mathrm{NH}_{3} / \mathrm{NH}_{4}{ }^{+}$ratio of less than 0.1 . For the purpose of calculating open ocean fluxes, an intermediate value for the ratio, 0.3 , is used.

For the range estimate we use the range of the means for the $\mathrm{NH}_{3} / \mathrm{NH}_{4}{ }^{+}$ratio. This is about 0.6 from the older literature and about 0.1 from more recent measurements.

Scavenging ratio: There have been no measurements of the wet scavenging ratio for $\mathrm{NH}_{3}$. One would expect that $\mathrm{NH}_{3}$ would behave as a highly soluble gas. However, since we have specified the concentration of $\mathrm{NH}_{3}$ as being a constant fraction of the aerosol $\mathrm{NH}_{4}^{+}$, the same scavenging ratio as that used for the aerosol, 200, is used. For the range estimate we use the same range as that used for the aerosol scavenging ratio, 160 to 340 .

Dry deposition velocity: There is evidence that in some regions the oceans may be a source of $\mathrm{NH}_{3}$ [Quinn et al., 1988, 1990; Warneck, 1988]. Given this uncertainty, we decided not to estimate a dry deposition flux for this species.

Other species. In addition to the inorganic forms of reduced nitrogen, there are also organic species. Examples are the amines and amino acids. Although data on their atmospheric concentrations are sparse, some measurements have been made. Mopper and Zika [1987] reported concentrations of dissolved organic nitrogen (DON) in the form of dissolved free amino acids (DFAA) and aliphatic amines in precipitation samples collected in the northwestern Atlantic Ocean and Gulf of Mexico. The DFAA concentrations ranged from 1.1 to $15.2 \mu \mathrm{M}$, with an average of about $6.5 \mu \mathrm{M}$. Aliphatic amines contributed between 0.08 and $1.36 \mu \mathrm{M}$ DON. Van Neste et al. [1987] reported vapor phase concentrations of primary, secondary, and tertiary methylamines measured in Hawaii. Together, these three amines total an average of $134 \mathrm{pmol} \mathrm{N} \mathrm{m}^{-3}$. The same authors report rainwater concentrations of these amines to range from 0.024 to $0.057 \mu \mathrm{M}$ in rain samples collected along the Rhode Island coast. Recent studies [Gorzelska and Galloway, 1990] indicate that in the summertime, dissolved free amino acids and aliphatic amines in precipitation collected over the North Atlantic contribute from 0.012 to $0.595 \mu \mathrm{M}$ DON and from 0.006 to $0.132 \mu \mathrm{M}$ DON, respectively. These compounds also add between 0.3 and 1614 pmol DON m${ }^{-3}$ to the summertime North Atlantic aerosol. Both rain and aerosol concentrations seem to be subject to pronounced seasonal and spatial variations. Thus these initial data suggest that reduced organic nitrogen compounds might make a significant contribution to the fixed nitrogen content of the atmosphere at certain times and in particular regions of the oceans. However, there are so few data for these types of compounds that it is difficult to estimate any meaningful deposition rates. Also there is no information on the sources of these compounds, and the oceans could be the dominant one; therefore they are not included in our estimates.

\section{Summary and Discussion}

Atmospheric inputs for the various nitrogen species are computed for the global ocean for each $10^{\circ} \times 10^{\circ}$ area. In order to assess the validity of the calculations, the calculated fluxes obtained for specific $10^{\circ} \times 10^{\circ}$ areas are first compared with measured values for that region. In succeeding sections, we present the results obtained for specific ocean basins and for the global ocean. 


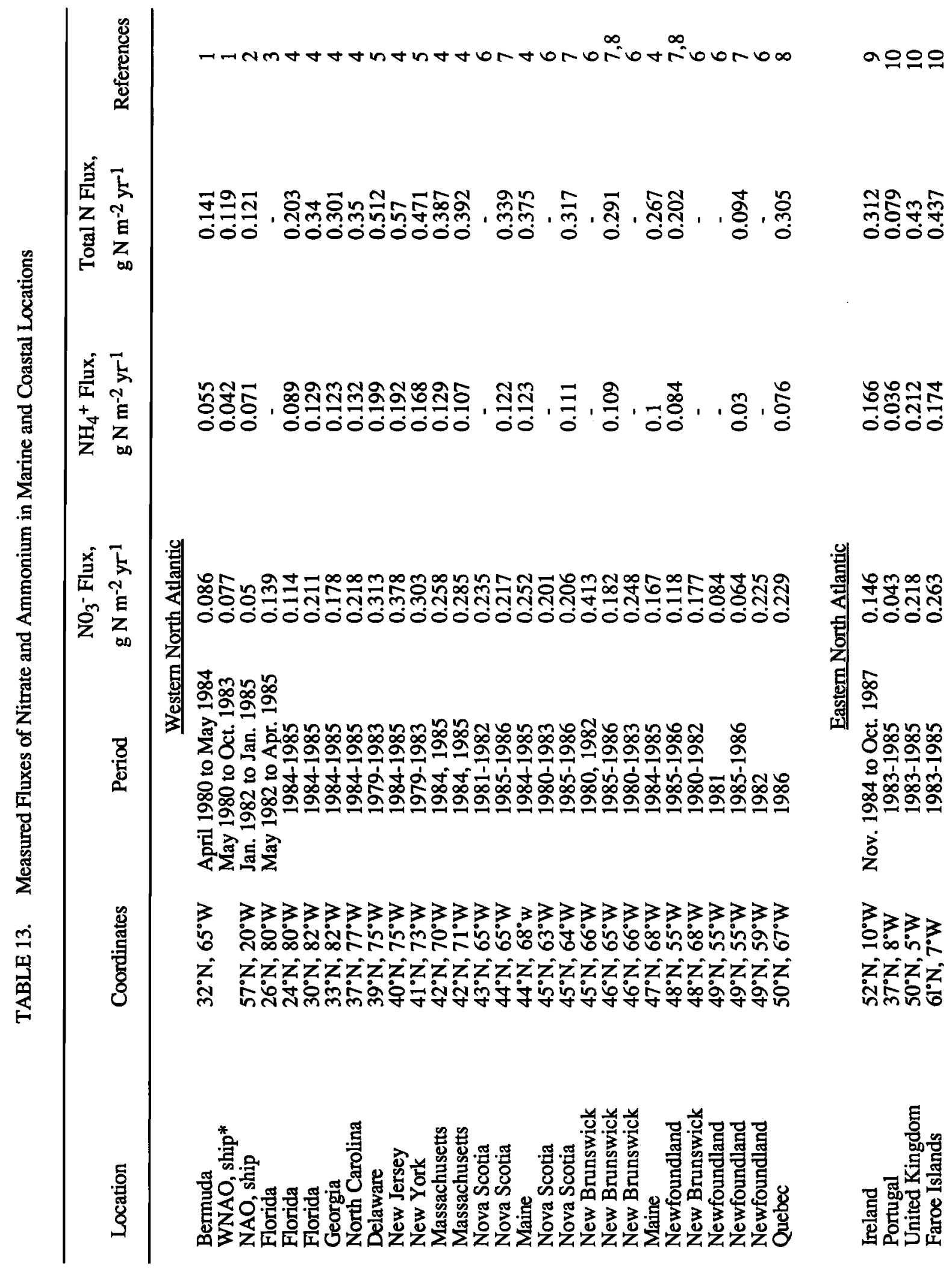




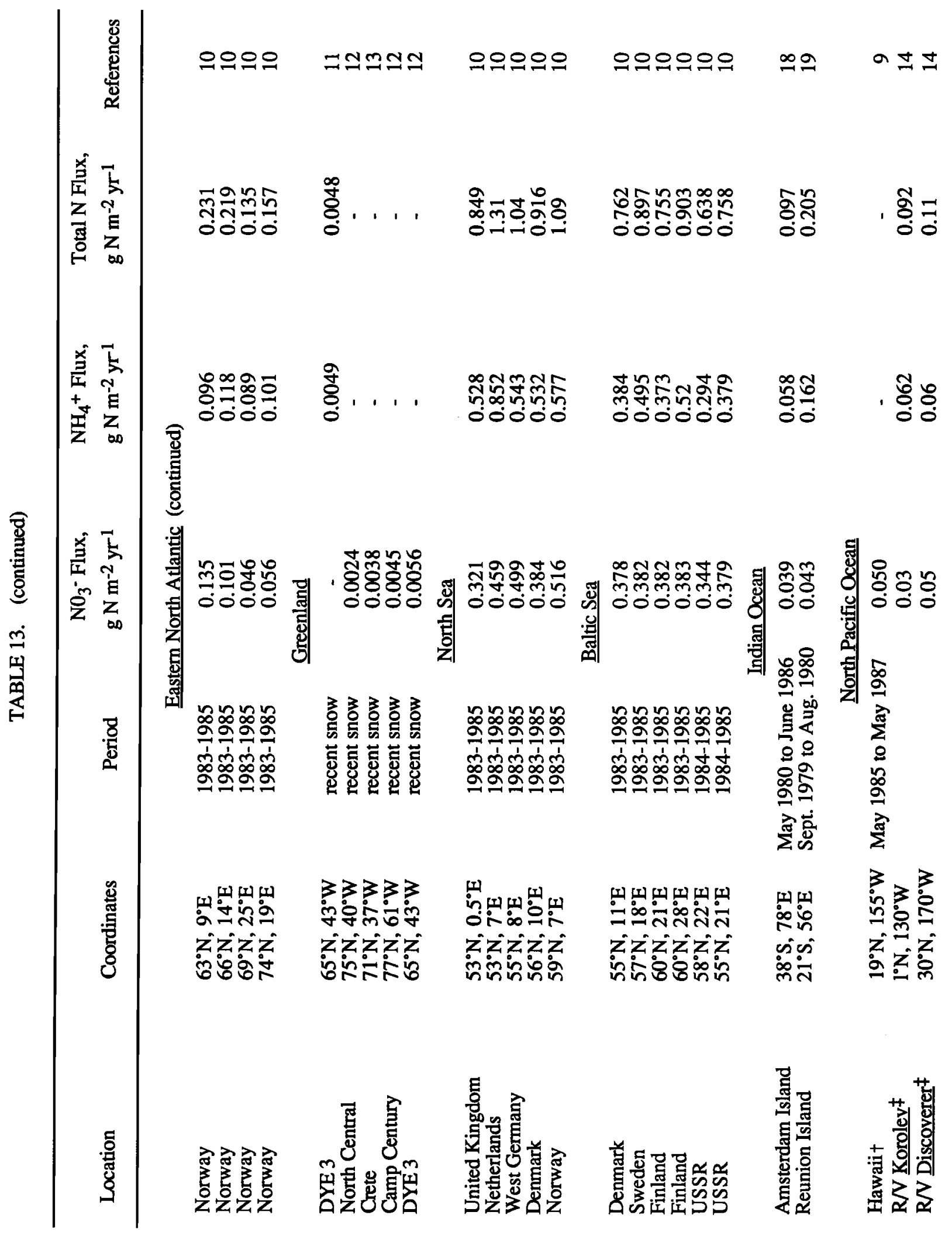




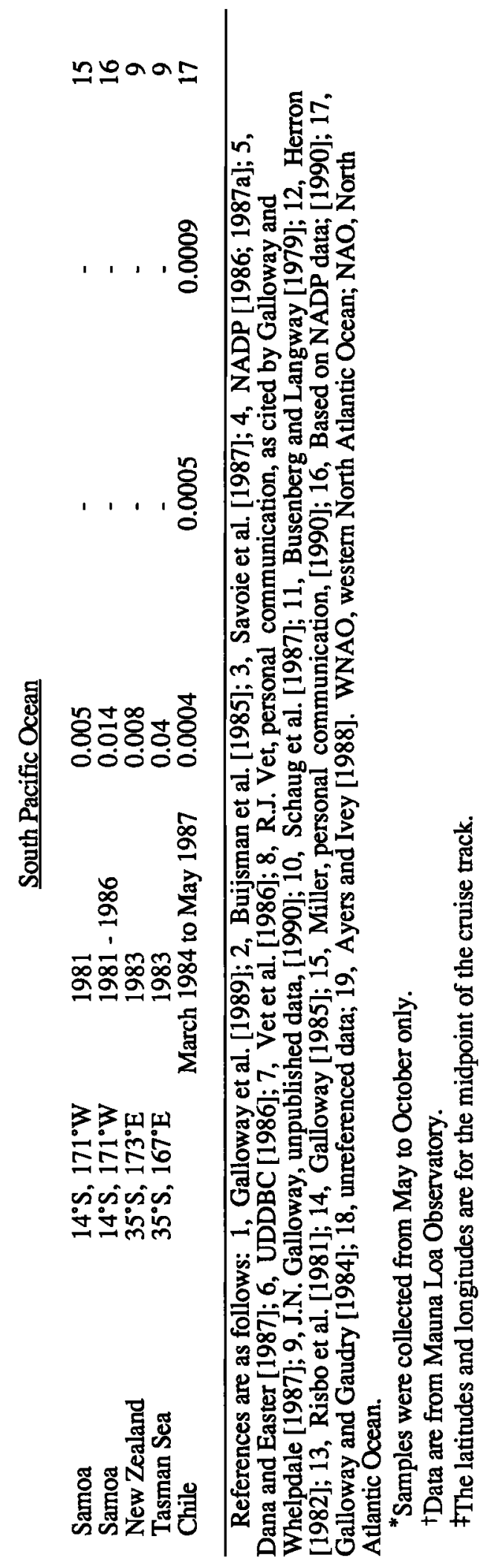

Comparison of calculated fluxes with measured values. In Table 13 a summary of measured fluxes of $\mathrm{NO}_{3}{ }^{-}$and $\mathrm{NH}_{4}{ }^{+}$in marine and coastal areas is given. In Table 14 we present a comparison of the calculated fluxes of $\mathrm{NO}_{3}$ - for specific $10^{\circ} \times 10^{\circ}$ areas with actual measured values at those locations. For this comparison, data (from Table 13) for those stations that were located on islands or on the coasts of continents adjacent to major ocean areas were chosen. Some of the measured flux values were obtained with continuously open collectors. The latter collect dry deposition as well as wet, although the dry collection efficiency is difficult to quantify. In Table 14 we also show the ratios of the calculated wet-to-measured (CW/M) flux and the computed total-to-measured (CT/M) flux.

Note that some of the stations listed in Table 13 (American Samoa, Miami, and Bermuda) were the same as those used for measuring the scavenging ratios. However, except for Miami, the measured deposition rates in Table 14 were for different time periods (and usually much longer time periods) than those used for measuring the scavenging ratios. In all cases, including the Miami case, the computed flux was based on the smoothed concentration fields and the climatological rainfall in the data base. In the case of the Ireland station, the rainfall data were obtained at Adrigole, whereas the scavenging ratio was measured at Mace Head.

For some stations, the agreement between the computed and measured values is reasonably good. In general, however, the computed values tend to be lower than the measured values. Some of these differences can be rationalized. In some cases the aerosol data were extrapolated from other regions or even other oceans; for example, the atmospheric $\mathrm{NO}_{3}-$ and $\mathrm{NO}_{x}$ data used for Amsterdam Island and Reunion (both in the Indian Ocean) were extrapolated from the South Pacific. Of special concern is the fact that the scavenging ratio, 330 , is based on measurements made in a limited number of regions. There is no reason to expect that this ratio is universally applicable to all types of rain events (for example, to both convective and frontal rains) in all regions. In particular, there are no scavenging ratio data for high latitudes. Furthermore, the scavenging ratio is computed using aerosol and gas measurements made in surface level air. The vertical concentration profile (which is invariably unknown) is implicitly incorporated in the scavenging ratio when it is measured at the sea surface. However, the profile will undoubtedly vary from region to region and especially in ocean regions adjacent to the continents.

In making the comparisons, there is a problem in deciding which concentration values are applicable for those sites that are located in regions adjacent to major source areas. For example, in Table 14 we show two computed fluxes for Ireland. In both cases, the measured flux values were obtained from a 
TABLE 14. Comparison of Computed and Measured Fluxes

\begin{tabular}{|c|c|c|c|c|c|c|}
\hline \multirow[b]{2}{*}{ Location } & \multirow[b]{2}{*}{ Coordinates } & \multicolumn{2}{|c|}{ Computed } & \multirow{2}{*}{$\begin{array}{l}\text { Measured } \\
\text { Nitrate }\end{array}$} & \multicolumn{2}{|c|}{ Ratio } \\
\hline & & $\overline{\text { Wet }}$ & Total & & $\overline{\mathrm{CW} / \mathrm{M}}$ & $\overline{\mathrm{CT} / \mathrm{M}}$ \\
\hline Bermuda & $32^{\circ} \mathrm{N}, 65^{\circ} \mathrm{W}$ & 0.081 & 0.109 & 0.086 & 0.94 & \\
\hline Novia Scotia & $44^{\circ} \mathrm{N}, 65^{\circ} \mathrm{W}$ & 0.106 & 0.142 & 0.217 & 0.49 & \\
\hline Ireland $I^{\dagger}$ & $52^{\circ} \mathrm{N}, 10^{\circ} \mathrm{W}$ & 0.037 & 0.049 & 0.146 & 0.25 & \\
\hline Ireland $\mathrm{II}^{\dagger}$ & $52^{\circ} \mathrm{N}, 10^{\circ} \mathrm{W}$ & 0.094 & 0.150 & 0.146 & 0.65 & \\
\hline Faeroe Islands $\mathrm{I}^{\ddagger}$ & $61^{\circ} \mathrm{N}, 7^{\circ} \mathrm{W}$ & 0.025 & 0.035 & 0.263 & & 0.13 \\
\hline Faeroe Islands $\Pi^{\ddagger}$ & $61^{\circ} \mathrm{N}, 7^{\circ} \mathrm{W}$ & 0.094 & 0.150 & 0.263 & & 0.57 \\
\hline Miami $\neq$ & $26^{\circ} \mathrm{N}, 80^{\circ} \mathrm{W}$ & 0.104 & 0.130 & 0.139 & 0.75 & \\
\hline Amsterdam Island & $38^{\circ} \mathrm{S}, 78^{\circ} \mathrm{E}$ & 0.007 & 0.010 & 0.039 & 0.17 & \\
\hline Reunion Island I§ & $21^{\circ} \mathrm{S}, 56^{\circ} \mathrm{E}$ & 0.011 & 0.013 & 0.043 & & 0.30 \\
\hline Reunion Island II§ & $21^{\circ} \mathrm{S}, 56^{\circ} \mathrm{E}$ & 0.017 & 0.021 & 0.043 & & 0.48 \\
\hline American Samoa & $14^{\circ} \mathrm{S}, 171^{\circ} \mathrm{W}$ & 0.020 & 0.023 & 0.014 & 1.4 & \\
\hline
\end{tabular}

Fluxes are in grams $\mathrm{NO}_{3}-\mathrm{N}$ per square meter per year.

${ }^{*}$ Ratios are CW/M computed wet-to-measured; CT/M, computed total-to-measured. CW/M is shown for total (wet + dry) deposition data.

†The Ireland station is located $10^{\circ} \mathrm{W}$ longitude. The values for Ireland I were computed using the concentrations for the $10^{\circ}$ block located to the west; the Ireland II values were computed with concentrations from the block to the east, which are much higher because of the impact of anthropogenic sources in England and Europe.

†Faeroe Islands II was computed with concentration values for the block immediately to the south.

\$Reunion Island II was computed with concentration values for the block immediately to the north.

site close to the west coast near $10^{\circ} \mathrm{W}$. The values computed for Ireland I are based on the relatively low measured concentrations for the ocean region west of $10^{\circ} \mathrm{W}$; these computed fluxes are small compared with the measured values. A second set of fluxes (Ireland II) was computed using the higher concentration values obtained for the region that includes Ireland and British Isles; these results are much closer to the measured values. Similarly, the computed fluxes for the Faeroe Islands are very low compared with the measured values. The Faeroes are located at $61^{\circ} \mathrm{N}$, just north of the square in which the British Isles fall; consequently, it might be more appropriate to compute fluxes using the higher concentrations of this region, as was done for Ireland II. Indeed the fluxes computed in this manner (Faeroe II) are in reasonable agreement with the measured Faeroe values. Similarly, Reunion Island is located immediately adjacent to a block with considerably higher concentrations; these latter values were used to compute the fluxes for Reunion II in Table 14.

The mean computed wet-to-measured ratio (using the "II" values in Table 14) is 0.68 . The ratios are reasonably consistent except for Amsterdam Island, which is unusually low; if the Amsterdam Island value is eliminated, the ratio is $\mathbf{0 . 7 5}$. Indeed, the agreement is somewhat surprising when one considers the poor quality of the input data and the often crude assumptions that had to be made in computing the flux. In any event, the fact that our computed fluxes tend to be low suggests that the wet fluxes computed for this report are conservative estimates of the true values.

Nonetheless there is some concern about the rain data from some of the remote stations. For example, a large fraction of the samples reported for American Samoa (usually between 50 to $75 \%$ ) have nitrate concentrations that are equal to, or less than, the detection limit [National Atmospheric Deposition Program (NADP), 1987b]. The annual volumeweighted deposition could range from $0.010 \mu \mathrm{g}$ $\mathrm{N} \mathrm{m}^{-2} \mathrm{yr}^{-1}$ (assuming that the samples below the detection limit have a nitrate concentration of zero) to $0.017 \mu \mathrm{g} \mathrm{N} \mathrm{m}^{-2} \mathrm{yr}^{-1}$ (assuming that the samples have a concentration equal to the detection limit). In Table 14 we used a value that was the mean of these two extreme cases. Nonetheless, this does lead to considerable uncertainty in the deposition flux. The data from Amsterdam Island also stand out because of the large difference between the computed and measured fluxes. Because American Samoa and Amsterdam Island are the only long-term remote- 
TABLE 15. Global Nitrogen Deposition Best Estimates and Estimate Ranges

\begin{tabular}{|c|c|c|c|c|}
\hline \multirow[b]{2}{*}{ Species } & \multicolumn{3}{|c|}{ Estimate, $10^{9} \mathrm{~g} \mathrm{~N} \mathrm{yr}^{-1}$} & \multirow[b]{2}{*}{ Notes* } \\
\hline & Best & Low & High & \\
\hline \multicolumn{5}{|c|}{ Oxidized Species } \\
\hline $\mathrm{NO}_{3}^{-}$, wet & 8,400 & 6,900 & 12,300 & conc. OK; S 270, 480 \\
\hline $\mathrm{NO}_{3}^{-}$, dry & 2,800 & 1,900 & 9,400 & conc. $O K ; V_{d} 0.2,1.0 \mathrm{~cm} \mathrm{~s}^{-1}$ \\
\hline $\mathrm{HNO}_{3}$, wet & 1,200 & 660 & 5,800 & $\begin{array}{l}\text { conc. varied: } 0.1 \text { and } 0.5 \text { times } \mathrm{NO}_{3} \\
\text { S } 270,480\end{array}$ \\
\hline $\begin{array}{l}\mathrm{HNO}_{3} \text {, dry } \\
\mathrm{NO}_{x} \text {, wet }\end{array}$ & $\begin{array}{r}1,000 \\
0\end{array}$ & $\begin{array}{r}660 \\
0\end{array}$ & $\begin{array}{r}3,300 \\
0\end{array}$ & $\begin{array}{l}\text { conc. varied: } 0.1 \text { and } 0.5 \text { times } \mathrm{NO}_{3}- \\
\text { not estimated }\end{array}$ \\
\hline $\mathrm{NO}_{\mathrm{x},}, \mathrm{dry}$ & 40 & 40 & 40 & not estimated \\
\hline Total & 13,400 & 10,200 & 30,800 & \\
\hline \multicolumn{5}{|c|}{ Reduced Species } \\
\hline $\mathrm{NH}_{4}^{+}$, wet & 11,400 & 4,600 & 38,900 & conc. varied: $2 x ; S 160,340$ \\
\hline $\mathrm{NH}_{4}^{+}$, dry & 1,900 & 490 & 7,800 & conc. varied: $2 \mathrm{x} ; \mathrm{V}_{\mathrm{d}} 0.05,0.2 \mathrm{~cm} \mathrm{~s}^{-1}$ \\
\hline $\mathrm{NH}_{3}$, wet & 3,400 & 510 & 10,400 & conc. varied: 0.33 and 2 times $\mathrm{NH}_{4}+$; \\
\hline Total & 16,400 & 5,600 & 57,100 & \\
\hline
\end{tabular}

${ }^{*} \mathrm{~S}$, scavenging ratio; $\mathrm{V}_{\mathrm{d}}$, deposition velocity; conc. $\mathrm{OK}$, concentrations assumed firm.

region data sites in the southern ocean, there is concern about the accuracy of our model assumptions.

Calculated deposition to the global oceans. The calculated depositions of all species to the global ocean are summarized in Table 15. The best estimate is presented along with the estimated range. In Table 16 , both flux and deposition values are presented for major ocean regions and for the oceans as a whole. Figure 8 summarizes the total deposition to each basin and Figure 9 presents fluxes. The largest total depositions are those to the North Pacific and the North Atlantic. Figure 9 shows that the fluxes for the three northern ocean regions are markedly higher than those for the southern oceans. The total deposition of all species to the northern oceans is $-22 \mathrm{x}$ $10^{12} \mathrm{~g} \mathrm{~N} \mathrm{yr}^{-1}$ and that to the southern oceans is $9 \mathrm{x}$ $10^{12} \mathrm{~g} \mathrm{~N} \mathrm{yr}^{-1}$; the fluxes are $140 \mathrm{mg} \mathrm{N} \mathrm{m}^{-2} \mathrm{yr}^{-1}$ and $46 \mathrm{mg} \mathrm{N} \mathrm{m}^{-2} \mathrm{yr}^{-1}$, respectively, while that for the global ocean is $87 \mathrm{mg} \mathrm{N} \mathrm{m}^{-2} \mathrm{yr}^{-1}$.

On a global ocean basis the depositions of oxidized and reduced nitrogen are essentially equal, $\sim 14$ and $-16 \times 10^{12} \mathrm{~g} \mathrm{~N} \mathrm{yr}^{-1}$, respectively. The fluxes for the individual ocean regions are shown in Figure 10. The global fluxes for oxidized and reduced species are 38 and $48 \mathrm{mg} \mathrm{N} \mathrm{m}^{-2} \mathrm{yr}^{-1}$, respectively. For all ocean regions except the Indian Ocean, the fluxes for the reduced and oxidized species are essentially equal.

In Figure $10 \mathrm{it}$ is clear that the fluxes to the northern oceans are much higher than those to the southern oceans. The flux of oxidized species to the North Atlantic is 5 times greater than that to the South Atlantic, while for the Pacific the ratio is about 2. For reduced species the N/S ratio for both oceans is about 2 to 3 .

There are a number of reasons for the higher fluxes in the northem hemisphere. First, as was previously pointed out, the strongest sources for most species appear to be located on the continents; since the ratio of land to ocean is larger in the northern hemisphere, we would expect a correspondingly greater impact on oceanic deposition. Second, over $90 \%$ of the anthropogenic sources of $\mathrm{NO}_{2}$ are located in the northern hemisphere. These factors explain the fluxes to the northern Indian Ocean: the ocean is relatively small and a much larger fraction is "coastal" compared with other ocean areas. The contrast between the northern and southern Indian Ocean is particularly striking in this regard; this large differ- 
TABLE 16. Estimated Atmospheric Input of Certain Nutrient Nitrogen Species to the Oceans

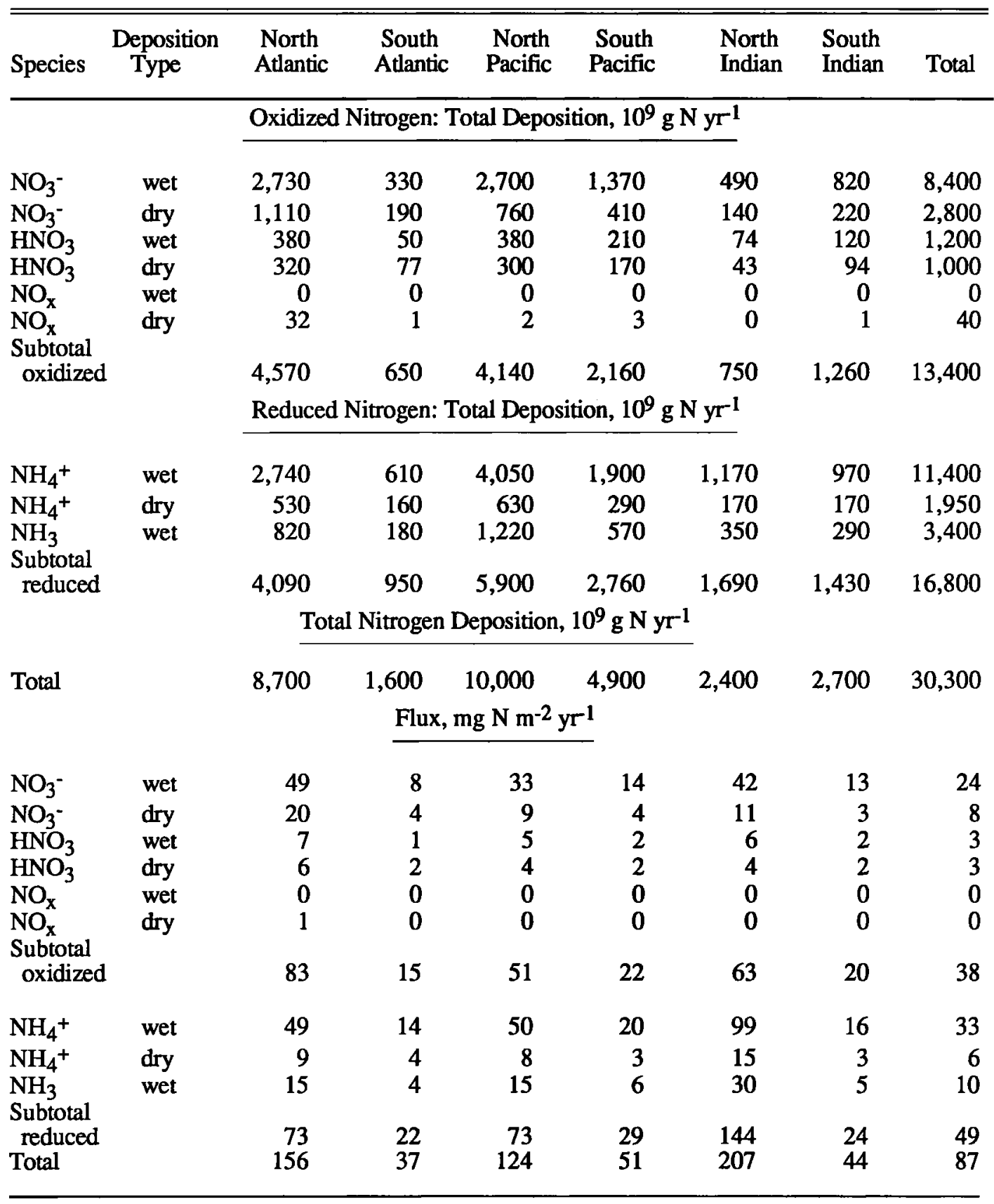

Nutrient Nitrogen Deposition, $10^{9} \mathrm{~g} \mathrm{~N} \mathrm{yr}^{-1}$

\begin{tabular}{lrrr} 
Hemisphere & Oxidized & Reduced & Total \\
\hline Northern & 9,500 & 12,000 & 22,000 \\
Southern & 4,100 & 5,100 & 9,000 \\
Global & 14,000 & 17,000 & 31,000 \\
\hline
\end{tabular}




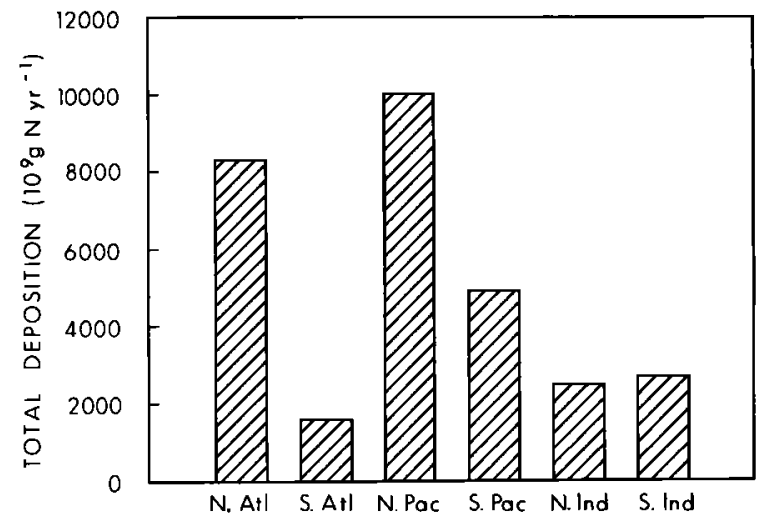

Fig. 8. Total deposition of all species to each ocean basin in $10^{9}$ grams $\mathrm{N}$ per year.

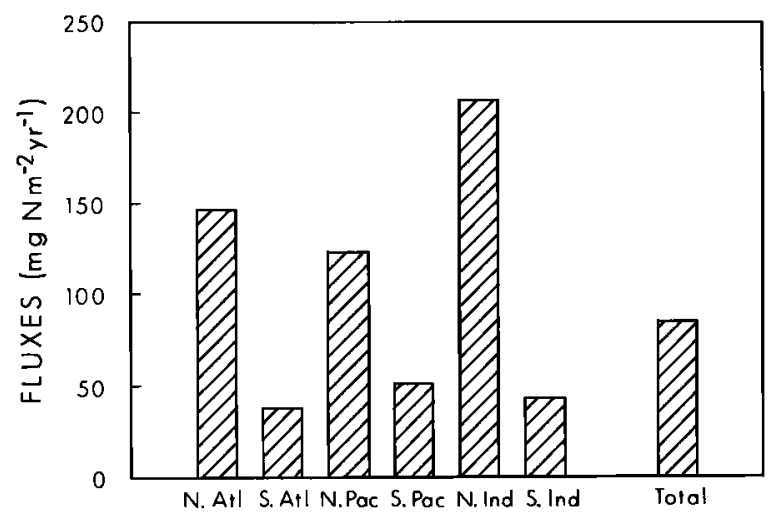

Fig. 9. Fluxes of all species to each ocean basin in milligrams $\mathrm{N}$ per square meter per year.

ence is partially due to the fact that the rainfall rates in the southern Indian Ocean are relatively low compared with those in the northern region.

The global mean fluxes for the individual species are shown in Figure 11 for wet removal and dry removal processes. The wet removal of $\mathrm{NH}_{4}{ }^{+}$ accounts for the largest flux. However, it should be emphasized that the concentration data for $\mathrm{NH}_{4}{ }^{+}$and $\mathrm{NH}_{3}$ (especially the latter) are rather poor from the standpoint of both the quality of the data and their temporal and areal distribution. The situation is further complicated by the possibility that the ocean may be serving as a source of $\mathrm{NH}_{3}$ [Quinn et al., 1988; Warneck, 1988]. Consequently, much of our computed flux of $\mathrm{NH}_{3}$ and $\mathrm{NH}_{4}{ }^{+}$could consist of recycled oceanic material. Therefore the reduced nitrogen results should be used with caution. Nonetheless, the data do suggest that these species might play a significant role in nitrogen species cycling in the marine atmosphere. Also, to the extent that the data are valid and to the degree that these species are derived from the continents, they could serve as a significant source of nutrient supply to the oceans.

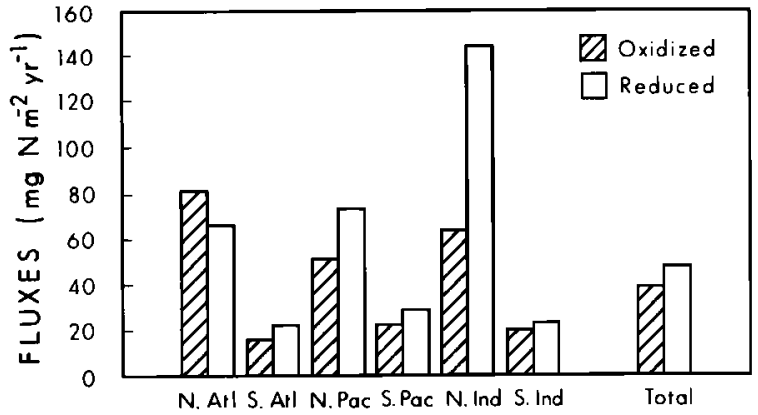

Fig. 10. Fluxes of oxidized and reduced species to each ocean basin in milligrams $\mathbf{N}$ per square meter per year.

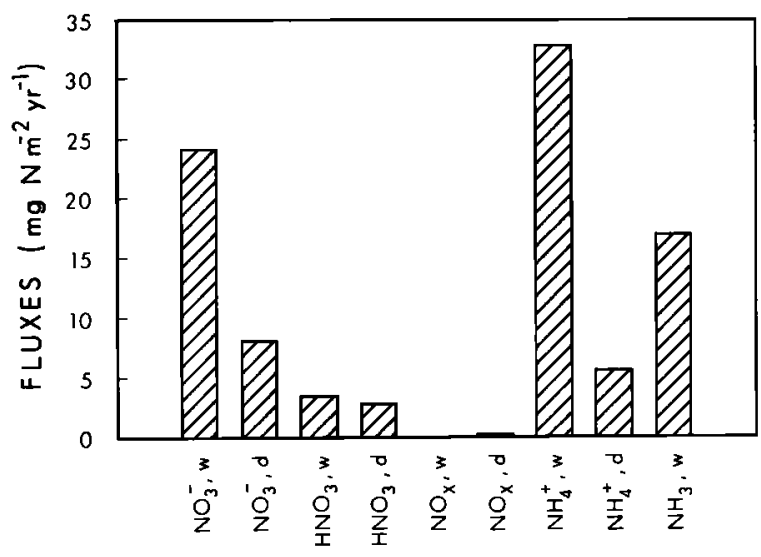

Fig. 11. Mean fluxes for each species to the global ocean in milligrams $\mathbf{N}$ per square meter per year.

Among the oxidized species, the input of $\mathrm{NO}_{\mathrm{x}}$ is insignificant as a consequence of the very low solubility in precipitation and sea water. Indeed, the removal rates are effectively zero in Table 16 . The dry fluxes are also extremely small, even in the North Atlantic where the dry deposition is greatest, and they can be ignored in budget estimates.

The deposition of oxidized species is primarily dependent on the wet and dry removal rates of aerosol $\mathrm{NO}_{3}$ - and of $\mathrm{HNO}_{3}$ (which is directly linked to the aerosol $\mathrm{NO}_{3}$ - concentrations in our calculations). In Figure 12 the total wet and dry deposition for aerosol $\mathrm{NO}_{3}$ - in each ocean region is shown. Note in particular the very large difference in total aerosol $\mathrm{NO}_{3}$ - deposition to the North and South Atlantic, a factor of 7; this difference is due to the larger fluxes to the North Atlantic (Figure 10). For the Pacific, this ratio is 2 .

The southern oceans are relatively unimpacted by anthropogenic nitrogen sources in general or by northern hemisphere sources in particular. The large difference between North and South Pacific $\mathrm{NO}_{3}^{-}$ concentrations [Prospero and Savoie, 1989] is taken 
as evidence that cross equatorial transport is suppressed by the intertropical convergence zone (ITCZ). ITCZ precipitation processes efficiently remove aerosol $\mathrm{NO}_{3}$ - and its gaseous precursors [Levy and Moxim, 1989]. Northem hemisphere air parcels (as indicated by sharply increased concentrations of gaseous pollutants such as $\mathrm{CO}_{2}$ and methylchloroform [Halter, 1984]) are often observed at American Samoa during March and April; in contrast, $\mathrm{NO}_{3}$ - concentrations at this time of year are actually at a minimum [Savoie et al., 1989a]. Southern hemisphere combustion sources can only account for about $10 \%$ of the observed $\mathrm{NO}_{3}$ - concentrations over the central South Pacific [Levy and Moxim, 1989; Penner et al., 1991].

Recently, Prospero and Savoie [1989] estimated the impact of continental $\mathrm{NO}_{3}$ - over the central North Pacific on the assumption that the $\mathrm{NO}_{3}$ - values measured in the equatorial and central South Pacific $\left(0.025 \mu \mathrm{g} \mathrm{N} \mathrm{m}^{-3}\right)$ are representative of the oceanic

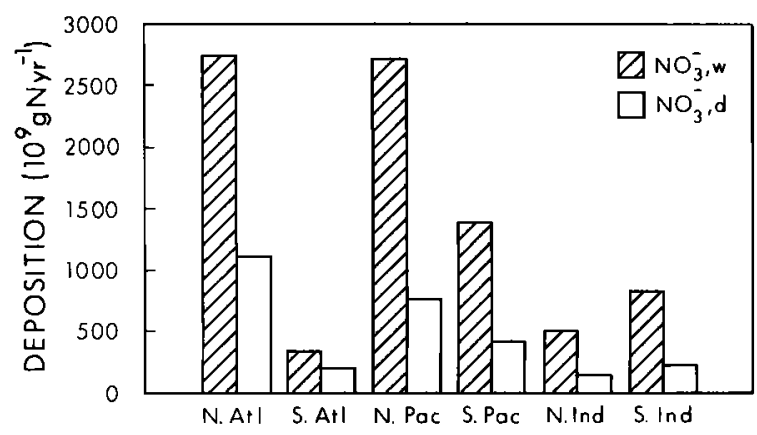

Fig. 12. Total wet and dry deposition of $\mathrm{NO}_{3}{ }^{-}$for each ocean region in $10^{9}$ grams $\mathrm{N}$ per year. "background" and these values are applicable to the central North Pacific. On this basis they estimate that about $40-70 \%$ of the $\mathrm{NO}_{3}$ - over the central North Pacific is derived from continental sources. The impacts will be much greater closer to the continents.

Comparisons with other estimates of global ocean deposition of nitrogen species. In this section our estimated depositions are compared with previously published estimates.

Oxidized nitrogen: In Table 17 the previously published estimates of the deposition of oxidized $\mathrm{N}$ species to the ocean are summarized. Also included in Table 17 are the results obtained in this work. Our deposition numbers are within the range of the previous estimates but they tend to be toward the high end of the published values. Some possible reasons for these differences can be illustrated by comparing our values with those of Logan [1983]. Logan's estimate of wet deposition to the oceans is $4-12 \mathrm{x}$ $10^{12} \mathrm{~g} \mathrm{~N} \mathrm{yr}^{-1}$. Her estimate is based on the very few measurements of $\mathrm{NO}_{3}$ - in rainfall that were available at that time for remote regions, principally Samoa, Hawaii, and Amsterdam Island. Logan used a flux range of $0.1-0.3 \mathrm{~kg} \mathrm{~N} \mathrm{ha}^{-1} \mathrm{yr}^{-1}(10-30 \mathrm{mg} \mathrm{N}$ $\mathrm{m}^{-2} \mathrm{yr}^{-1}$ ). In contrast, our computed mean flux for the global oceans is close to $40 \mathrm{mg} \mathrm{N} \mathrm{m}^{-2} \mathrm{yr}^{-1}$.

For the dry deposition velocity of $\mathrm{HNO}_{3}$, Logan simply uses a range of $0.6-1.2 \mathrm{~cm} \mathrm{~s}^{-1}$. In contrast, ours are directly computed, as described previously. For $\mathrm{NO}_{3}$ - aerosol, Logan uses a deposition velocity of 0.3 to $1.2 \mathrm{~cm} \mathrm{~s}^{-1}$. In our calculations, $0.3 \mathrm{~cm} \mathrm{~s}^{-1}$ is used. As for the dry deposition velocity of $\mathrm{NO}_{\mathrm{x}}$ over the oceans, Logan simply says that it should be small, less than $0.1-0.2 \mathrm{~cm} \mathrm{~s}^{-1}$. As we have shown, this flux is indeed negligible.

Our calculated fluxes can be used to estimate anthropogenic deposition to the northern oceans. To

TABLE 17. Summary of Published Estimates of Atmospheric Oxidized-Nitrogen Deposition to the Global Ocean

\begin{tabular}{lccl}
\hline Wet Deposition & Dry Deposition & Total & \multicolumn{1}{c}{ Reference } \\
\hline 18 & 4 & 22 & Burns and Hardy [1975] \\
$5-16$ & $6-17$ & $11-33$ & Soderlund and Svensson [1976] \\
$5-16$ & $2-13$ & $7-29$ & Anderson [1983] \\
$6-17$ & $1-7$ & $7-24$ & Stedman and Shetter [1983] \\
$4-12$ & $1-5$ & $5-17$ & Logan [1983] \\
$2-36(10)^{*}$ & 5 & $7-41$ & Galloway [1985] \\
$4-8$ & $1-6$ & $5-14$ & $\begin{array}{l}\text { Pszenny [1987] } \\
10\end{array}$ \\
$(8-18)$ & 4 & 14 & this work (best estimate) \\
& $(3-13)$ & $(10-31)$ & this work (range) \\
\hline
\end{tabular}

Units are $10^{12} \mathrm{~g} \mathrm{~N} \mathrm{yr}^{-1}$.

*Value is Galloway's [1985] "best" estimate. 
do this, we assume that the flux of oxidized species to the southern oceans, $20 \mathrm{mg} \mathrm{N} \mathrm{m}^{-2} \mathrm{yr}^{-1}$, is representative of natural sources. The difference between this flux and that for the northern oceans, $63 \mathrm{mg} \mathrm{N}$ $\mathrm{m}^{-2} \mathrm{yr}^{-1}$, is $43 \mathrm{mg} \mathrm{N} \mathrm{m}^{-2} \mathrm{yr}^{-1}$; we assume that this flux approximates the anthropogenic contribution. This assumption yields a total anthropogenic deposition of $6.4 \times 10^{12} \mathrm{~g} \mathrm{~N} \mathrm{yr}^{-1}$ to the northern oceans. This value amounts to $-30 \%$ of the $21 \times 10^{12} \mathrm{~g}$ $\mathrm{N} \mathrm{yr}^{-1}$ of anthropogenic emissions in the northern hemisphere, much of which is deposited on land. This result suggests that our deposition calculations yield reasonable results despite the many rough estimates that went into making them and that the upper range of the error limits shown in Table 15 may be too large, at least for the oxidized species.

Our calculated depositions can be compared with pollution transport estimates. Levy and Moxim [1989] used a general circulation model to simulate the global transport and deposition of reactive $\mathbf{N}$ species emitted by fossil fuel combustion sources. Their estimates indicate that about $25 \%$ of the emitted nitrogen oxides (i.e., $25 \%$ of $21.3 \times 10^{12} \mathrm{~g} \mathrm{~N} \mathrm{yr}^{-1}$, or $5.4 \times 10^{12} \mathrm{~g} \mathrm{~N} \mathrm{yr}^{-1}$ ) is transported to the oceans, of which about $5 \times 10^{12} \mathrm{~g} \mathrm{~N} \mathrm{yr}^{-1}$ should go into the northern oceans. Their estimate is comparable to our estimated northem hemisphere anthropogenic deposition, $6.4 \times 10^{12} \mathrm{~g} \mathrm{~N} \mathrm{yr}^{-1}$. If these estimates are reasonably correct, then $50-70 \%$ of the oceanic deposition flux of $\mathrm{NO}_{3}{ }^{-}$to the northern hemisphere, $9.4 \times 10^{12} \mathrm{~g} \mathrm{~N} \mathrm{yr}^{-1}$, is derived from anthropogenic combustion sources. This is consistent with recent estimates that Asian emissions account for $40-70 \%$ of the $\mathrm{NO}_{3}$ - in aerosols over the North Pacific [Prospero and Savoie, 1989].

Reduced nitrogen: There have been a number of earlier estimates of $\mathrm{NH}_{3}$ deposition to the oceans. However, because of the inadequate data base, these earlier estimates cover rather wide ranges: $8-26 \mathrm{x}$ $10^{12} \mathrm{~g} \mathrm{~N} \mathrm{yr}^{-1}$ [Soderlund and Svensson, 1976]; 0-12 $\mathrm{x} 10^{12} \mathrm{~g} \mathrm{~N} \mathrm{yr}^{-1}$ [Bottger et al., 1978]; and $10 \times 10^{12}$ $\mathrm{g} \mathrm{N} \mathrm{yr}^{-1}$ [Stedman and Shetter, 1983].

Warneck [1988] calculated the global budgets for $\mathrm{NH}_{3}$ and $\mathrm{NH}_{4}{ }^{+}$using an entirely different procedure. He computes removal rates based on the mean concentrations for these species and the mean atmospheric residence times for $\mathrm{NH}_{3}$ and $\mathrm{NH}_{4}{ }^{+}$. For ocean regions, he specifies a mean $\mathrm{NH}_{3}$ concentration of $0.14 \mu \mathrm{g} \mathrm{N} \mathrm{m}^{3}$ for the MBL and $0.06 \mu \mathrm{g} \mathrm{N}$ $\mathrm{m}^{-3}$ for the free troposphere (FT). Using a mean residence time of 5.7 days for $\mathrm{NH}_{3}$, he obtains depositions of 3.2 and $10.3 \times 10^{12} \mathrm{~g} \mathrm{~N} \mathrm{yr}^{-1}$, for the MBL and FT sources respectively (total, $13.5 \times 10^{12}$ $\mathrm{g} \mathrm{N}$ ). For $\mathrm{NH}_{4}{ }^{+}$he uses concentrations of 0.05 and $0.06 \mu \mathrm{g} \mathrm{N} \mathrm{m}^{-3}$ for the MBL and FT, respectively; for a residence time of 5.0 days he obtains depositions of 1.3 and $11.7 \times 10^{12} \mathrm{~g} \mathrm{~N} \mathrm{yr}^{-1}$ (total, 13.0). His total deposition for $\mathrm{NH}_{3}$ and $\mathrm{NH}_{4}^{+}, 26.5 \times 10^{12} \mathrm{~g} \mathrm{~N}$ $\mathrm{yr}^{-1}$, is somewhat larger than our computed deposition $17 \times 10^{12} \mathrm{~g} \mathrm{~N} \mathrm{yr}^{-1}$. Although our estimate and Warneck's are still somewhat uncertain, they seem to suggest higher depositions than those obtained in the earlier estimates.

Comparison of global atmospheric and reverine inputs of dissolved nitrogen. In this section our computed deposition inputs of the various nitrogen compounds are compared with those estimated for rivers. For river inflows we use the estimates of natural inputs presented by GESAMP [1987], as summarized in Table 18. Also included in Table 18 are our estimates for the global ocean nitrogen deposition. The atmospheric input of $\mathrm{NO}_{3}{ }^{-}$is 2 to 4 times greater than the natural riverine input, while that for $\mathrm{NH}_{4}{ }^{+}$is about 20 times larger. Indeed, the atmospheric deposition of nitrogen species is 2 times that of the total riverine input $\left(14 \times 10^{12} \mathrm{~g} \mathrm{~N} \mathrm{yr}^{-1}\right)$ for all natural nitrogen species including dissolved organic nitrogen.

However, there is also a substantial flow of pollutant nitrogen in rivers. Estimates [GESAMP, 1987] range from 7 to $35 \times 10^{12} \mathrm{~g} \mathrm{~N} \mathrm{yr}^{-1}$ (see Table 18). The total riverine flux (natural and anthropogenic) ranges from 21 to $49 \times 10^{12} \mathrm{~g} \mathrm{~N} \mathrm{yr}^{-1}$. Thus the total river inflow is essentially identical to the total atmospheric deposition.

The river inputs presented in Table 18 are gross values. That is, they show the amount of nitrogen being delivered into the estuaries. However, very little of the river input will ever reach the open ocean because these species are important nutrients that are extensively involved in the biological and chemical processes which occur in estuaries and coastal waters. As a result, most of the dissolved nutrients are removed from the water column and deposited to the shelf sediments. A large fraction of the nitrogen may also be lost to the atmosphere by denitrification processes.

The assessment of net riverine inputs to the ocean is made more difficult by the fact that coastal areas are often upwelling zones. These constitute another source of nutrient supply which greatly complicates mass balance calculations. Nonetheless, it is clear that only a small fraction of the river input reaches the open oceans. Thus the relative importance of the atmospheric input is further enhanced.

It is interesting to compare the atmospheric deposition of nitrogen compounds to the burial rate of nitrogen in the sediments. The burial rate is estimated by GESAMP [1987] on the basis of the accumulation rate of organic $C$ in pelagic sediments, 5.7 $x 10^{12} \mathrm{~g} \mathrm{C} \mathrm{yr}^{-1}$ [Berner, 1982]. Assuming a molar $\mathrm{C} / \mathrm{N}$ ratio of 15 for organic matter preserved in those sediments [Wollast, 1981], the GESAMP authors obtain a rate of accumulation of organic nitrogen of $0.44 \times 10^{12} \mathrm{~g} \mathrm{~N} \mathrm{yr}^{-1}$. This represents only $3 \%$ of the gross natural dissolved river input (of which, as was 
TABLE 18. Gross River Flows of Dissolved Nitrogen and Estimated Global Atmospheric Deposition

\begin{tabular}{|c|c|c|c|c|c|c|}
\hline $\mathrm{NO}_{3}^{-}$ & $\mathrm{NO}_{2}$ & $\mathrm{NH}_{4}^{+}$ & DIN & DON & Total & Reference \\
\hline & \multicolumn{6}{|c|}{$\underline{\text { River Fluxes: Natural }}^{*}$} \\
\hline \multirow[t]{4}{*}{3.7} & neg & 0.6 & $\begin{array}{l}7 \\
4.3\end{array}$ & $\begin{array}{l}8 \\
9.7\end{array}$ & $\begin{array}{l}15 \\
14\end{array}$ & $\begin{array}{l}\text { Livingston [1963] } \\
\text { Van Bennekom and Salomons [1981] } \\
\text { Meybeck [1982] }\end{array}$ \\
\hline & \multicolumn{6}{|c|}{ River Fluxes: Anthropogenic* } \\
\hline & & & & & $\begin{array}{r}18 \\
35 \\
32 \\
7 \\
21\end{array}$ & $\begin{array}{l}\text { Soderlund and Svensson [1976] } \\
\text { Delwiche and Likens [1977] } \\
\text { Van Bennekom and Salomons [1981] } \\
\text { Meybeck [1982] } \\
\text { Wollast [1983] }\end{array}$ \\
\hline & \multicolumn{6}{|c|}{ Atmospheric Deposition } \\
\hline 14 & neg & 16 & - & - & 30 & this work \\
\hline
\end{tabular}

said, very little reaches the open ocean). Furthermore, the nitrogen burial rate is only $1.5 \%$ of the total atmospheric nitrogen deposition $(3.3 \%$ of the total $\mathrm{NO}_{3}$ - rate).

The large difference between the atmospheric input and the burial rate suggests that the nitrogen cycle in the ocean must be balanced by a very large recycling flux of nitrogen to the atmosphere. This flux is generally assumed to consist primarily of gaseous species (mainly $\mathrm{N}_{2}, \mathrm{~N}_{2} \mathrm{O}$, and $\mathrm{NH}_{3}$ ). However, estimates of these emissions are very uncertain. Various estimates of oceanic $\mathrm{N}_{2} \mathrm{O}$ emission rates [Warneck, 1988] suggest sea-to-air transfer in the range of $10-40 \times 10^{12} \mathrm{~g} \mathrm{~N} \mathrm{yr}^{-1}$. It may be significant that these values are quite similar to our estimated rate of atmospheric deposition.

\section{Conclusions}

The gross fluxes computed in this study are generally consistent with those obtained in past studies. Our results differ from those of earlier efforts in that they clearly show that there are very large regional differences that are due to the effects of transport from continental sources which are presumed to be predominantly anthropogenic. Thus any impact that atmospheric fluxes might have on oceanic productivity could change quite dramatically from region to region. In this regard, much higher fluxes are observed for northerm hemisphere oceans compared with the southern oceans.
The comparisons with river inputs suggest that the impact of atmospheric deposition on open ocean biogeochemical cycles will be much greater than that for rivers. Although the magnitude of the fluxes are comparable, the effects of the riverine inputs will be limited primarily to estuaries and coastal waters. Finally, it must be emphasized that while the estimates made here are based on reasonable assumptions, they are subject to considerable uncertainty. There is clearly a need for more and better data. This need is especially great for remote ocean regions, and it is particularly critical for all southern oceans.

\section{THE ATMOSPHERIC INPUT OF SYNTHETIC} ORGANIC COMPOUNDS TO THE WORLD OCEAN

\section{$\underline{\text { Introduction }}$}

Synthetic organic chemicals have been observed in a variety of environmental systems from all areas of the Earth. Accumulation of certain types of synthetic species, particularly the chlorinated hydrocarbons, has been shown to occur in Arctic ecosystems [Hargrave et al., 1987; Patton et al., 1989], in the Antarctic environment [Giam et al., 1974; Risebrough and Carmignani, 1972; Tanabe and Tatsukawa, 1983; Bacci et al., 1986], in deep-sea organisms [Barber and Warlen, 1979; Ballschmiter et al., 1981], and in a variety of other areas [Tanabe et al., 1983b; Tatsukawa and Tanabe, 1990]. Even though the concentrations of synthetic chlorinated 
hydrocarbons are low in remote areas, there have been data that suggest a relationship between chlorinated hydrocarbon uptake and the decreasing concentration of reproductive hormones in marine mammals [Subramanian et al., 1987]. Other experimental evidence on the relationship between synthetic organic species and various biological effects in marine ecosystems underscores the necessity to understand and predict the inputs of potentially harmful chemical species in broad areas of the world ocean.

Most evidence available now suggests that atmospheric transport and deposition of synthetic organic compounds are significant processes for carrying organic pollutant compounds to much of the ocean surface [Atlas, 1990; Atlas and Giam, 1981, 1986, 1989; Atlas et al., 1986a, b; Knap et al., 1988; Bidleman et al., 1981; Harvey and Steinhauer, 1974]. Some measurements, modelling efforts, and calculations have been performed to estimate inputs of organic species to certain specific ocean areas [Atlas et al., 1986a; Burns et al., 1985; Tateya et al., 1988; Villeneuve and Cattini, 1986; Masclet et al., 1988 ] as well as to the Great Lakes [Eisenreich, 1981; Eisenreich et al., 1981; Rice et al; 1986; Swackhamer and Armstrong, 1986]. This chapter attempts to synthesize the available data base of synthetic organic compounds in the atmosphere and to extrapolate measurements from the marine atmosphere to obtain basin scale and global scale estimates of synthetic organic deposition to surface ocean waters.

\section{Choice of Compounds}

The compounds selected for this study have been restricted to synthetic organic species for which there is a reasonable data base. In practice, this limits the choice of compounds to several classes of chlorinated hydrocarbon pesticides or industrial compounds. The compounds to be considered are discussed below; their formulae are shown in Figure 13.
Polychlorinated biphenyls (PCBs). The PCBs have been widely recognized and studied as ubiquitous environmental pollutants. They have been used in the past as dielectric compounds and paint additives, in carbonless copy paper, and in a variety of other applications. Their open use is now restricted or banned in most areas, but the fate of existing stocks of PCB makes their distribution and transport a concern for years to come [Tanabe, 1988; Tateya et al., 1989].

The composition of PCB is quite complex, consisting of a possible 209 individual congeners. However, a much lower number of congeners $(<50)$ is found in significant concentration in the environment. Nonetheless, the chemistry of "total" PCB is determined by the combined behavior of the individual congeners. Thus a rigorous treatment of PCB deposition should consider the entire suite of congeners. Unfortunately, there are insufficient data on the environmental distribution and chemistry of the individual congeners to allow one to apply this treatment at present, and for the purposes of this report such a rigorous treatment is unwarranted. The data available in the literature are commonly reported in one of several ways: as total PCB, as Aroclor equivalents, or as "light" or "heavy" PCB. For this report, we have chosen to subdivide environmental PCB as equivalent to Aroclor 1242 or Aroclor 1254. On the basis of existing data from atmospheric samples [Atlas et al., 1986a], we have uniformly partitioned total $\mathrm{PCB}$ into $60 \%$ Aroclor $1242+40 \%$ Aroclor 1254.

Hexachlorocyclohexanes (HCHs). The $\mathrm{HCHs}$ are a pesticide mixture, commonly referred to as BHC, which has been widely used in the past and which is still used in some parts of the world. Reports suggest that $>10^{11} \mathrm{~g}$ have been used and applied throughout Asia [Food and Agriculture Organization (FAO), 1979; Colson, 1979; Tanabe et al., 1982b], and some estimates suggest that increased usage will be required in the future [Ray et al., 1985]. Because
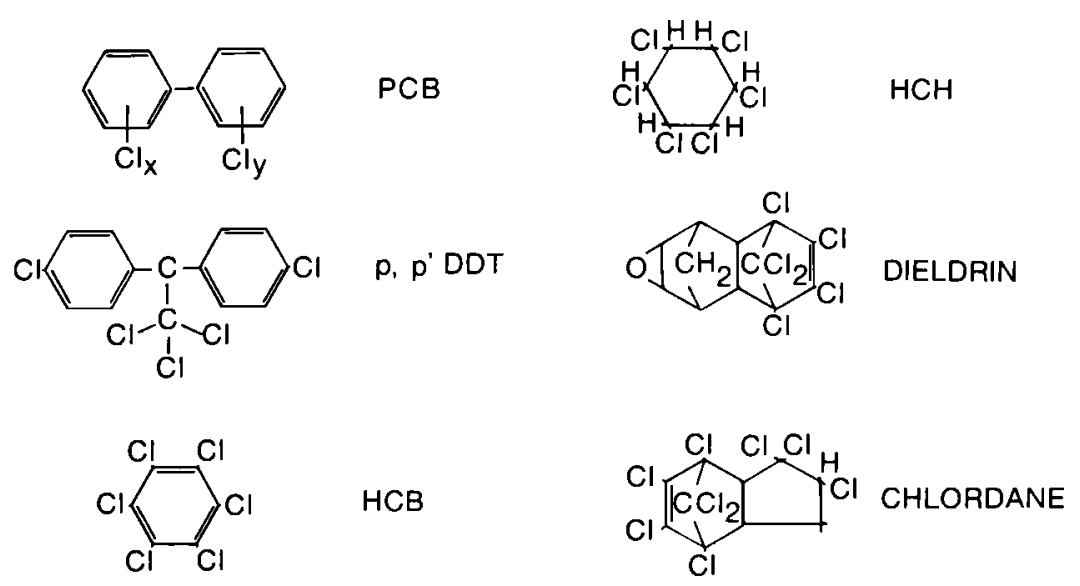

Fig. 13. Structural formulae of synthetic organic compounds considered. 
of their intensive use, HCHs are typically the most abundant chlorinated hydrocarbon pesticide observed in the marine atmosphere.

The technical HCH mixture contains several isomeric forms of hexachlorocyclohexane, as well as pentachloro- and heptachloro- components. Typically, the technical mixture is composed of $70 \%$ $\alpha-\mathrm{HCH}, 7 \% \beta-\mathrm{HCH}, 14 \% \gamma-\mathrm{HCH}$, and approximately $10 \%$ other isomers. The $\gamma$ isomer is the insecticidal component, lindane. In some areas, pure lindane or a mixture fortified with lindane is used in pesticidal applications. In this section we will evaluate deposition of $\alpha-\mathrm{HCH}$ and $\gamma-\mathrm{HCH}$. These are the main $\mathrm{HCH}$ components reported in the marine atmosphere. Usually, data are given in terms of the individual species, and these data are used directly in our calculations. In some instances, total $\mathrm{HCH}$ is reported, and an average partition between $\alpha$ - and $\gamma$ $\mathrm{HCH}$ is used for our calculations.

DDTs. The DDT (dichloro-diphenyl-trichloroethane) group of pesticides and related metabolites (DDD and DDE) have been among the most intensively studied class of chlorinated hydrocarbons in the environment. Their use is banned in most parts of the world, but there is limited use in some areas. For example, Bidleman et al. [1990] compiled data which indicate that $3 \times 10^{9} \mathrm{~g}$ of technical grade DDT was used in Mexico, Turkey, and India during 19821984. Ray et al. [1985] estimate that even larger quantities of DDT $\left(\sim 10^{10} \mathrm{~g}\right)$ may be required in India to meet food production targets. Also, traces of DDT compounds are still observed in marine, estuarine, and other organisms throughout the world [Tanabe et al., 1983; Subramanian et al., 1986; Wade et al., 1988; Sericano et al., 1990], although there is evidence of declining concentrations over the last decade [Addison and Zinck, 1986; Olsson and Reutergardh, 1986].

For this section, we will estimate the deposition of two major species most often reported in the atmosphere, p,p'-DDE and p,p'-DDT.

Chlordane and dieldrin. Among the other chlorinated pesticides used throughout the world, the two compounds chlordane and dieldrin are most often reported in remote atmospheres [Atlas and Giam, 1981; Bidleman and Leonard, 1982; Bidleman et al., 1981]. Past usage of these compounds is in the range of $10^{9}$ to $10^{10} \mathrm{~g} \mathrm{yr}^{-1}$, though detailed information on the global pattern of usage is unavailable.

Technical grade chlordane used for pesticidal application contains several individual components, primarily cis- and trans-chlordane, and cis- and trans-nonachlor [Sovocool et al., 1977]. Unless otherwise specified in the data base we have assumed that the chlordane reported is the sum of cis- and trans-chlordane, and we have treated this sum as a single compound. Data available on the chemistry of these two isomers suggests that this assumption will

TABLE 19. Summary of Data Used to Construct Distribution of Chlorinated Hydrocarbons in the Marine Atmosphere.

\begin{tabular}{|c|c|c|c|c|c|c|c|}
\hline \multirow[b]{2}{*}{ Location } & \multicolumn{6}{|c|}{ Concentration, $\mathrm{pg} \mathrm{m}^{-3}$} & \multirow[b]{2}{*}{ References } \\
\hline & $\mathrm{HCB}$ & $\Sigma \mathrm{HCH}$ & $\Sigma D D T$ & Chlordane & Dieldrin & PCBs & \\
\hline & \multicolumn{6}{|c|}{ Atlantic and Arctic Oceans } & \\
\hline North Atlantic & 133 & 386 & --- & 8* & 8 & -- & 1 \\
\hline North Atlantic & - & 230 & -- & 18 & 18 & 332 & 2 \\
\hline Barbados & 150 & 390 & 4 & 9 & 5 & 57 & 3 \\
\hline Bermuda & 111 & 240 & $2.6^{\dagger}$ & 10 & 8 & -- & 2 \\
\hline Baltic Sea & 291 & 553 & -- & -- & -- & -- & 4 \\
\hline North Sea & 125 & 130 & -- & -- & -- & -- & 4 \\
\hline Gulf of Mexico & 126 & 439 & 28 & 36 & 17 & $58 \ddagger$ & 5 \\
\hline South Atlantic & -- & 59 & $<105$ & -- & -- & $<230$ & 6 \\
\hline Brazilian coast & -- & $<41$ & $<15 \S$ & -- & $<7$ & $<84$ & 6 \\
\hline Arctic Ice Island & 32 & 177 & $<1$ & $<1.7$ & $<6$ & $<5$ & 7 \\
\hline Norwegian Arctic & 109 & 407 & --- & $1.3^{*}$ & -- & .. & 8 \\
\hline Ellesmere Island & 189 & 577 & 1.0 & 3.9 & 1.9 & 14 & 9 \\
\hline Ellesmere Island & 147 & 385 & 5.2 & 6.3 & 0.6 & 17 & 9 \\
\hline Bear Island & 40 & 390 & --- & -- & -- & 17 & 10 \\
\hline Bear Island & 111 & 237 & --- & $1^{*}$ & -- & -- & 10 \\
\hline Canadian Arctic & -- & -- & --- & 3.9 & -- & -- & 11 \\
\hline Sweden & 64 & 489 & 7.2 & 8.4 & -- & 165 & 12 \\
\hline
\end{tabular}


TABLE 19. (continued)

\begin{tabular}{|c|c|c|c|c|c|c|c|}
\hline \multirow[b]{2}{*}{ Location } & \multicolumn{6}{|c|}{ Concentration, $\mathrm{pg} \mathrm{m}^{-3}$} & \multirow[b]{2}{*}{ References } \\
\hline & HCB & $\Sigma \mathrm{HCH}$ & $\Sigma D D T$ & Chlordane & Dieldrin & PCBs & \\
\hline \multicolumn{8}{|c|}{$\underline{\text { Pacific and Indian Oceans }}$} \\
\hline $\begin{array}{l}\text { Enewetak Atoll } \\
\text { North Pacific (40N) } \\
\text { Central North Pacific } \\
\text { North Pacific } \\
\text { NW Pacific } \\
\text { Bering Sea } \\
\text { Southern ocean } \\
\text { American Samoa } \\
\text { Coastal Peru } \\
\text { New Zealand }\end{array}$ & $\begin{array}{l}100 \\
108 \\
-- \\
97 \\
-- \\
- \\
- \\
55 \\
63 \\
61\end{array}$ & $\begin{array}{r}260 \\
365 \\
-\overline{2} \\
424 \\
1014 \\
-- \\
34 \\
11 \\
26\end{array}$ & $\begin{array}{c}<6 \\
0.4 \S \\
-- \\
-- \\
257 \\
8 \\
9 \\
1.9 \\
2 \\
<2.8\end{array}$ & $\begin{array}{l}13 \\
6.8 \\
-- \\
<4 \\
-- \\
- \\
6 \\
<1 \\
1 \\
1.3\end{array}$ & $\begin{array}{l}7.9 \\
1.9 \\
-- \\
<2 \\
-- \\
-- \\
-- \\
1.1 \\
4 \\
1.9\end{array}$ & $\begin{array}{r}110 \\
32 \\
43 \\
-\overline{-} \\
<500 \\
41 \\
-- \\
11 \\
12 \\
6\end{array}$ & $\begin{array}{r}13 \\
13 \\
14 \\
15 \\
16 \\
16,14 \\
17 \\
13 \\
13 \\
13\end{array}$ \\
\hline $\begin{array}{l}\text { NW Pacific/Indian Ocean } \\
\text { SW Pacific/Indian Ocean }\end{array}$ & $\begin{array}{ll}n & - \\
1 & -\end{array}$ & $\begin{array}{r}1195 \\
320\end{array}$ & $\begin{array}{l}320 \\
262\end{array}$ & $\begin{array}{l}- \\
-\end{array}$ & $\begin{array}{l}-- \\
--\end{array}$ & $\begin{array}{l}-- \\
-\end{array}$ & $\begin{array}{l}18 \\
18\end{array}$ \\
\hline $\begin{array}{l}\text { Indian Ocean } \\
\text { Indian Ocean } \\
\text { Arabian Sea } \\
\text { East Indian Ocean } \\
\text { West Indian Ocean } \\
\text { Arabian Sea } \\
\text { Red Sea }\end{array}$ & $\begin{array}{l}-- \\
-- \\
- \\
-- \\
- \\
-- \\
--\end{array}$ & $\begin{array}{r}350 \\
-- \\
-- \\
-- \\
3200 \\
--\end{array}$ & $\begin{array}{c}60 \\
-- \\
75^{\dagger} \\
-- \\
-- \\
\ddot{132^{\dagger}}\end{array}$ & $\begin{array}{l}18 \\
-- \\
7.8 \\
-- \\
-- \\
-- \\
16\end{array}$ & $\begin{array}{l}-- \\
-- \\
3.9 \\
-- \\
-- \\
-\ddot{13}\end{array}$ & $\begin{array}{r}-- \\
-- \\
-- \\
150 \\
160 \\
-- \\
--\end{array}$ & $\begin{array}{r}17 \\
19 \\
19 \\
14,18 \\
20 \\
21 \\
19\end{array}$ \\
\hline $\begin{array}{l}\text { Antarctic } \\
\text { Antarctic } \\
\text { (Showa Station) }\end{array}$ & $\begin{array}{l}-- \\
--\end{array}$ & $\overline{80}$ & $\overline{20}$ & $\begin{array}{l}-- \\
--\end{array}$ & $\begin{array}{l}-- \\
--\end{array}$ & $\begin{array}{l}91 \\
61\end{array}$ & $\begin{array}{l}14,20 \\
14,20\end{array}$ \\
\hline
\end{tabular}

Data listed here are average concentrations. For data obtained on cruises, individual measurements at sample mid-points were used in the grid. References are as follows: 1, E.L. Atlas (unplushed data, 1989); 2, A.H. Knap (unpublished data, 1989); 3, Bidleman et al. [1981]; 4, Reinhardt and Wodarg [1988a, b]; 5, Chang et al. [1985]; 6, R. Weber, (unpublished data, 1989); 7, Hargrave et al. [1987]; 8, Pacyna and Oehme [1988]; 9, Patton et al. [1989]; 10, Oehme and Stray [1982]; 11, Hoff and Chan [1986]; 12, Bidleman et al. [1987]; 13, Atlas and Giam [1989]; 14, Tanabe and Tatsukawa [1986]; 15, D.A. Kurtz and E.L. Atlas (unpublished data, 1988); 16, Tanabe and Tatsukawa [1980]; 17, Kawano et al. [1985]; 18, Tanabe et al. [1982a]; 19, Bidleman and Leonard [1982]; 20, Tanabe et al. [1983a].

*Concentration of alpha chlordane only.

tConcentraton of p,p' DDT only.

¥Concentration of Aroclor 1254 only.

\$Concentraton of $\mathrm{p}, \mathrm{p}^{\prime}$ DDE only.

not introduce significant error in the deposition calculation. Nonachlor isomers are not included in the calculation.

Chlorobenzenes. Chlorobenzenes containing 2-6 chlorine atoms per molecule have been measured in the atmosphere [Atlas and Giam, 1989]. These compounds have a wide variety of uses, depending on the chlorine composition. Some chlorobenzenes are used in pigment synthesis and as intermediates in herbicide production [Guicherit and Schulting, 1985], while the more highly chlorinated benzenes are produced as fungicides but are also byproducts of solvent manufacture.

One of these chlorobenzenes, hexachlorobenzene (HCB), has been found to be one of the more abundant chlorinated hydrocarbons in the marine atmosphere. It is chemically stable in the atmosphere and it is widely distributed throughout the global tropo- 
sphere. Only limited data are available on the concentration and distribution of the other chlorobenzenes. Thus in this paper, we will consider only the deposition of HCB.

Other compounds. There are other compounds and classes of organic chemicals whose deposition to the ocean is of interest, but which are not being considered in this section. These include several chlorinated hydrocarbons, e.g., toxaphene, endosulfan, and halogenated dibenzodioxins and furans, as well as "soot" carbon and petroleum and polynuclear aromatic hydrocarbons. For the chlorinated hydrocarbons mentioned, we feel that there are insufficient data to estimate global or basin scale deposition rates. The same is true for polynuclear aromatic hydrocarbons (PAH) and soot carbon. There may be some relationship between $>4$ ring PAH (primarily found on particles), soot carbon, and "pollutant" aerosol (e.g., lead), at least in urban areas, but there are insufficient data to show that such a relationship is applicable to remote ocean areas. Degradation of PAH in the atmosphere may also confound such a relationship far from source areas. Furthermore, biomass burning can produce substantial quantities of PAH and soot carbon, but only negligible quantities of lead. No attention is paid here to low molecular weight $\left(\mathrm{C}_{1}-\mathrm{C}_{3}\right)$ organo-halogen compounds (e.g., chlorofluoromethanes, di- and perchlorethenes, carbon tetrachloride) used as refrigerants, propellants, and solvents.

There are somewhat more data available on high molecular weight alkanes in the marine atmosphere, but these data have already been evaluated by Duce and Gagosian [1982] to produce an estimate of atmospheric deposition of $>C_{10}$ alkanes to the global ocean. Further work, however, is necessary to evaluate inputs of the full range of petroleum-derived hydrocarbon compounds, but such an evaluation is beyond the scope of the present paper.

\section{Data Selection and Extrapolation}

We were struck by the paucity of data on which to base reasonable average concentrations of synthetic organic compounds over basin-wide scales and over time. To obtain the necessary spatial coverage, practically all data collected over the last decade were used (Table 19). This necessarily includes single measurements taken along cruise tracks as well as longer term measurements. Only in a few cases, for example, at Bermuda during SEAREX experiments and at several Arctic sites, were there more than a few measurements taken over a season at a single location. This method of data utilization inevitably has problems. It is known, for example, that the source function for chlorinated hydrocarbons has varied in time and space over the last several decades because of restrictions on production and application. Also, analytical methodology has advanced so that more recent data may not be directly comparable to older data. In cases where more than one data set was available for a given location, the most recent data set was used for our calculation. Another problem associated with using all available data is that there are only a handful of research groups in the world making measurements of synthetic organic compounds in the remote atmosphere, and intercomparability of results between investigators has not been demonstrated. Thus data from one group can skew the distribution of a particular compound over large ocean regions. Such a discrepancy was observed, for example, between the South Pacific and Indian Oceans for DDT compounds. In most cases, one data set has not been chosen over the other, but an attempt was made to smooth abrupt concentration gradients. In the case of DDT, calculations were also performed on a revised data set which was based on estimation of lower concentrations of DDTs in areas far from continental sources. This data set is referred to as DDT (rev). Certain other areas contained virtually no data (the South Atlantic was notably devoid of measurements), and best estimates for these areas are obtained by extrapolating or imposing data from adjacent ocean areas.

The data available suggested that except near large sources, the concentrations of some compounds were relatively uniform within an ocean basin. Also, somewhat higher concentrations are observed along continental margins. This type of distribution is expected for the relatively long-lived, gas phase chlorinated hydrocarbons examined in this report. Such an expected distribution allows reasonable extrapolation of concentrations over relatively large geographic areas.

Examples of data handling for specific compounds are given below

HCHs. Most of the data were taken as reported and linearly interpolated. The concentration of HCHs over the Arctic Ocean was taken from recent measurements in the Canadian Arctic [Patton et al., 1989; Hargrave et al., 1987], and these were extrapolated into areas of the North Atlantic. The South Atlantic data were based on the South Pacific data of Atlas et al. [1986a], Atlas and Giam [1986], and Atlas and Giam [1989], and recent unpublished data from coastal Brazil (R. Weber, personal communication, 1989) suggest that this is a reasonable approximation. Adequate coverage of the Indian Ocean and the central and western Pacific is obtained from cruise data of Tanabe et al., Bidleman and coworkers, and the SEAREX experiments of Atlas et al. (see Table 19).

DDTs. Many of the data used for these compounds are based on collections in the late 1970s. There are only limited numbers of measurements obtained in the last few years, and these more recent measurements suggest lower concentrations of DDTs than observed earlier. Most of the DDT concentrations for the western Pacific and Indian oceans are based on reports of total DDT by Tanabe et al. 
[1982b]. These authors suggest that of the total, $60 \%$ was $\mathrm{p}, \mathrm{p}^{\prime}$ DDT and $15 \%$ was $\mathrm{p}, \mathrm{p}^{\prime}$ DDE. This proportion was used to obtain individual species concentrations from the reported data. It is interesting to note that others have found higher DDE:DDT ratios in air samples away from sources of "fresh" DDT [Atlas et al., 1988]. It is expected that as technical grade DDT degrades in the environment the volatilized pesticide will be more enriched in DDE [Rapaport et al., 1985]. Thus it may be that the older observations of Tanabe et al. [1982b] reflected fresher sources of DDT to those ocean areas he was studying.

PCBS. The North Atlantic area had the best coverage for PCB concentrations. Most data were taken from Bidleman et al. [1981] and A.H. Knap (unpublished data, 1990). Only near-coastal measurements of PCBs were available for the South Atlantic. For the open ocean areas of the South Atlantic we used concentrations reported by Atlas and Giam [1989] for the South Pacific. Higher concentrations were used in grid boxes adjacent to a coastline. In the Pacific Ocean, data of Tanabe et al. [1982b], Atlas et al. [1986a] and Atlas and Giam [1989] were used to determine the concentration field.

Chlordane and dieldrin. The majority of data reported for chlordane and dieldrin applies to the North Atlantic and adjacent areas. Both compounds show the highest concentrations near the North American coast, and dieldrin concentrations are relatively high along the European coast. There are only a few reports of these compounds in the southern hemisphere [Atlas et al., 1986a; Atlas and Giam, 1989]. Concentrations from three South Pacific sites were fairly uniform, and these concentrations $\left(1 \mathrm{pg} \mathrm{m}^{-3}\right)$ were extrapolated to other areas of the southern hemisphere.

HCB. Available measurements of HCB suggest that its concentration is relatively uniform within the northern or southern hemisphere. Even urban areas have concentrations of $\mathrm{HCB}$ that are within a factor of 2 - 3 of values in remote ocean regions. Thus we felt comfortable in extrapolating HCB concentrations uniformly within ocean basins.

\section{Data Sources for Atmospheric Concentrations}

Table 19 summarizes data used for this paper, reporting average concentrations. However, when samples were collected along a cruise track, individual measurements were assigned to the appropriate data grid locations. Table 20 presents basin-wide averages of organochlorine concentrations calculated from the measured and extrapolated data. The data used here are assumed to represent gas phase concentrations of organochlorines, since most reports indicate that $>95 \%$ of these compounds are measured as a gas in typical regions of the marine atmosphere.

\section{Methods of Calculation}

Deposition processes for atmospheric organic compounds and their flux to the ocean have been discussed by Atlas et al. [1986a], Atlas and Giam [1986, 1989], Bidleman [1988], Bidleman et al. [1990], and Tateya et al. [1988]. These studies emphasize the complexities and uncertainties involved in modelling the air-sea flux of synthetic organic species. Because the organic compounds discussed here have a particle and gas phase component in the atmosphere, an estimate of the air-sea flux necessarily incorporates all the uncertainties of dry and wet deposition of particles and gases. Still, it is useful to examine the specific deposition processes involved to determine the primary mechanisms of deposition and to estimate the magnitude of the air-sea flux. In a previous section, the theoretical background and equations necessary for computing air-sea exchange

TABLE 20. Mean Concentrations of Organic Compounds Calculated From Measured and Extrapolated Data Assigned to $10^{\circ} \times 10^{\circ}$ Grids

\begin{tabular}{lrrrrrr}
\hline & \multicolumn{2}{c}{ Atlantic } & & \multicolumn{2}{c}{ Pacific } & \\
\cline { 2 - 3 } Compound & North & South & & North & South & Indian \\
\hline$\alpha-$ HCH & 260 & 26 & & 420 & 33 & 177 \\
$\gamma-$ HCH & 53 & 3 & 126 & 18 & 71 \\
HCB & 126 & 60 & 102 & 60 & 60 \\
Total PCB & 290 & 33 & 96 & 33 & 117 \\
Chlordane & 14 & 1 & 9 & 1 & 3 \\
Dieldrin & 13 & 1 & 5 & 3 & 3 \\
p, p' DDE & 6 & 4 & 11 & 7 & 25 \\
p, p' DDT & 6 & 4 & 29 & 20 & 52 \\
p, p' DDT (rev) & 6 & 4 & 25 & 2 & 20 \\
\hline
\end{tabular}

Concentrations are in picograms per cubic meter. 
were discussed. The discussion that follows presents details of how the equations are applied to the specific compounds addressed here.

Particle deposition processes. The first problem in assessing particle deposition of organic compounds is to estimate the fraction of each organic compound associated with particles and that fraction present as a gas in the ambient atmosphere. Even though the bulk of organochlorines is present as a gas, partitioning between gas and particle phases is critical in determining the mechanism and rate of deposition of an organic compound from the atmosphere. Recent reviews have discussed theoretical aspects of equilibrium partitioning of organic compounds onto atmospheric particles [Bidleman, 1988; Pankow, 1987]. The theoretical partitioning has been described in terms of Langmuir adsorption isotherms or other parameterizations based on temperature, surface area, and/or total suspended matter. For present purposes, we have chosen to use the equation proposed by Yamasaki et al. [1982] and Bidleman et al. [1986], which describes the relationship of adsorbed and gas phase organic compounds based on field and laboratory observations. The equation is of the form

$\log [(\mathrm{Cg} / \mathrm{Cp})(\mathrm{TSP})]=\mathrm{m} / \mathrm{T}+\mathrm{b}$

where $\mathrm{Cg}$ is the concentration of compound in the gas phase, $\mathrm{Cp}$ is the concentration of compound in the particle phase, TSP is the total suspended particle concentraion, $m$ and $b$ are constants specific for each compound, and $\mathrm{T}$ is temperature (degrees Kelvin). The measured and extrapolated constants for each compound are given in Table 21. Even though the relationship was developed during field experiments from different geographical locations, Bidleman [1988] cautions that (16) should be considered valid only for urban areas, until tests can demonstrate the applicability to clean continental or marine atmospheres. Pankow [1987], however, reformulates equation (16) in terms of vapor pressure, sorption sites on the aerosol, and the specific surface area of the aerosol particles. Thus it appears that the relationship described by equation (16) may be useful for our calculation if differences in particle size (surface area) of an urban aerosol and the marine aerosol can be accommodated. In extending this relationship to other areas, we also recognize that we assume no specific or nonequilibrium partitioning between the chlorinated hydrocarbons and particular solid phases in the urban or marine aerosol.

To do this calculation, we assume that the marine aerosol consists of three basic components: sea salt aerosol, mineral aerosol, and "background" aerosol consisting mainly of small-particle sulfate aerosol from gas particle conversion processes. Global distributions of sea salt aerosol have been computed by Erickson et al. [1986], and mineral aerosol estimates were generated in an earlier section of this paper. The background aerosol is assumed constant at $0.5 \mu \mathrm{g} \mathrm{m}^{-3}$ [Ayers et al., 1986; D.L. Savoie, personal communication, 1991]. The estimated size and area distributions for these three particle groups are given in Table 22. On the basis of particle characteristics given in this table, one can "normalize" the marine aerosol to obtain a total suspended particulate (TSP) concentration which can be applied to equation (16). The normalization is performed with the following equation:

$$
\begin{aligned}
\text { Corrected TSP }= & {\left[\mathrm{SO}_{4}\right] \cdot 1.35+[\mathrm{MA}] \cdot 0.27 } \\
& +[\mathrm{SS}] \cdot 0.08
\end{aligned}
$$

TABLE 21. Slope and Intercept Values for Calculation of Gas/Particle Partitioning of Atmospheric Organic Compounds According to Equation (16) [from Bidleman et al., 1986]

\begin{tabular}{lcc}
\hline \multicolumn{1}{c}{ Compound } & Slope $\mathrm{m}$ & Intercept b \\
\hline$\alpha-$ HCH & -2755 & 14.29 \\
$\gamma$ - HCH (lindane) & -2755 & 14.29 \\
Chlordane & -4995 & 21.01 \\
p, p' DDE & -5114 & 21.05 \\
p, p' DDT & -5870 & 22.83 \\
PCB (Aroclor 1254) & -4686 & 19.43 \\
Dieldrin* & -5114 & 21.05 \\
PCB (Aroclor 1242) & assume $=0.2 \times \Phi_{\mathrm{p}}$ calculated for PCB 1254
\end{tabular}

The fraction of the compound, $\Phi_{\mathrm{p}}$, associated with particulate matter is calculated from the equation: $\Phi_{\mathrm{p}}=1 /\left\{1+\left[10^{(\mathrm{m} / \mathrm{T}+\mathrm{b})}\right] / \mathrm{TSP}\right\}$, where TSP $=$ total suspended matter (or equivalent) in milligrams per cubic meter.

*Values are estimated on the basis of comparison to suitable reference compound. Other values are reported on the basis of observations in field and laboratory studies. 
where $\mathrm{SO}_{4}$ is the background sulfate aerosol (nonsea salt) concentration, MA is the mineral aerosol concentration, and SS is the sea salt concentration. When this equation is applied to the model data grids, a distribution of aerosol concentrations is calculated which corresponds to aerosols with a uniform surface area of $11.2 \mathrm{~m}^{2} \mathrm{~g}^{-1}$, equivalent to an average urban aerosol [Bidleman, 1988]. The total concentrations of "corrected" TSP are in the range of 1 - $3 \mu \mathrm{g} \mathrm{m}^{-3}$, compared with $>10 \mu \mathrm{g} \mathrm{m}^{-3}$ for uncorrected TSP.

This calculation is strictly a practical method for obtaining a reasonable estimate of gas particle partitioning over different conditions of temperature and particle loading over the marine atmosphere. More ideally, one would have directly measured particle size information specifically related to organic pollutants. Given current technology and the trace concentrations of most species over the oceans, this type of data is not practically obtainable. However, some preliminary results from the Florida Keys (E.L. Atlas and C.S. Giam, unpublished data, 1989) and data on particle size distribution of hydrocarbons [Ohta and Handa, 1985; Schneider et al., 1983; Sicre et al., 1987] suggest that most of the mass of the compounds will be associated with submicrometer particles.

The calculations of particle-gas partitioning were combined with the array of atmospheric concentration for each compound to obtain a concentration field of particle-bound organic species. These particles were then assumed to be scavenged by precipitation and deposited as dry deposition at rates equivalent to other compounds present on submicrometer particles (e.g., Pb). Actual data to evaluate particle scavenging and dry deposition are rare. Particle scavenging rates can vary depending on a number of meteorological and particle-dependent processes. Data summarized by Bidleman [1988] for wet deposition of particle-bound organic compounds are given in Table 23.

In Table 23 the very low scavenging ratios of organic compounds in Portland (and probably Kiel] are likely related to a strong gradient in concentration between polluted surface-level air and air at rainforming altitudes [Ligocki et al., 1985a, b]. Other available data from rural or more remote areas suggest that a reasonable range for particle scavenging of organic species may fall between 200 and 500 . Once again, however, it needs to be emphasized that this scavenging ratio is a practical device to relate mean concentrations in rainfall to mean concentrations in surface level air. Any individual events or locations may show scavinging ratios far different from those described here. However, it is at least satisfying that the few measurements of particle scavenging of organic compounds are at least consistent with scavenging ratios of inorganic particulate species. (Certainly, any large differences between organic and inorganic particles would need considerable explanation.)

There are fewer data available to evaluate dry deposition velocities of organochlorine compounds. Field measurements are often confounded by the potential for adsorption of gas phase material, and there is the general difficulty of executing and interpreting measurements obtained in the field. Typical deposition velocities for a variety of semivolatile organic

TABLE 22. Parameters Used to Normalize Marine Aerosol Distribution Based on Surface Area Characteristics

\begin{tabular}{|c|c|c|c|}
\hline & \multicolumn{3}{|c|}{ Aerosol Type } \\
\hline & Sulfate & Mineral & Sea Salt \\
\hline \multicolumn{4}{|l|}{ Median diameter, $\mu \mathrm{m}$} \\
\hline $\begin{array}{l}\text { Mass } \\
\text { Surface } \\
\text { Number }\end{array}$ & $\begin{array}{l}0.4 \\
0.2 \\
0.05\end{array}$ & $\begin{array}{l}2.0 \\
1.0 \\
0.25\end{array}$ & $\begin{array}{l}7.0 \\
3.5 \\
0.87\end{array}$ \\
\hline Geometric s.d. & 2.3 & 2.3 & 2.3 \\
\hline Surface area, $\mathrm{m}^{2} \mathrm{~g}^{-1}$ & 15.2 & 3.0 & 0.9 \\
\hline Correction factor ${ }^{*}$ & 1.35 & 0.27 & 0.08 \\
\hline
\end{tabular}


TABLE 23. Measured Scavenging Ratios for Particle-Associated Organic Compounds

\begin{tabular}{llcc}
\hline Compound Class & \multicolumn{1}{c}{ Location } & Scavenging Ratio & Reference \\
\hline n-alkanes & College Station, Tex. & $330-580$ & 1 \\
n-alkanes & Portland, Oreg. & $13-22$ & 2 \\
n-alkanes & Enewetak Atoll & 1000 & 3 \\
n-Alkanes & Norfolk, Va. & $400-1600$ & 4 \\
PAH & Portland, Oreg. & $2-11$ & 2 \\
PAH & Isle Royale, Mich. & $140-250$ & 5 \\
Phthalate esters & Portland, Oreg. & $13-36$ & 2 \\
PCB & Kiel, Germany & 30,37 & 6 \\
PCB, CHC & College Station, Tex. & 500 (estimated) & 1 \\
\hline
\end{tabular}

References are as follows: 1, Atlas et al. [1988]; 2, Ligocki et al. [1985b]; 3, Zafiriou et al. [1985]; 4, Farmer and Wade [1986]; 5, McVeety and Hites [1988]; 6, Duinker and Bouchertall [1989].

compounds in continental areas range from 0.05 to 1 $\mathrm{cm} \mathrm{s}^{-1}$ [Bidleman and Christensen, 1979; Bidleman, 1988], with a central tendency in the range of 0.1 $0.2 \mathrm{~cm} \mathrm{~s}^{-1}$. Data of Murphy et al. [1981] from lakes Michigan and Huron suggest, however, that measurements of deposition velocities on the lake margin may be dominated by large-particle fluxes. Actual deposition rates in the center of the lake are smaller. Uncertainties in the actual size distribution of organic compounds adsorbed to the marine aerosol make extrapolation of particle dry deposition rates to open ocean areas just as problematical. Given the present state of knowledge, it seems reasonable to assume that the dry deposition rate of particle-associated organic matter in the marine atmosphere follows that of other "pollutant" aerosol (e.g., Pb). Since there may be some influence of larger mineral and sea salt particles on the deposition of organic matter, and since these larger particles have higher deposition rates, it is also reasonable to extend the possible range of deposition rates for organic particles up to $0.5 \mathrm{~cm} \mathrm{~s}^{-1}$.

Gas phase exchange processes. The basic equations which are applicable to modelling gas exchange processes were discussed earlier. It was shown that the flux of any gas is the product of the overall transfer velocity $K$ and the disequilibrium between air and surface water concentrations. If a compound in the ocean is undersaturated with respect to the atmosphere, a net transfer of the gas phase compound into the ocean will occur at a rate proportional to the degree of undersaturation. This simple relationship masks a highly complex phenomenon. For example, the transfer velocity for any particular compound is a function of its temperature-dependent Henry's law constant, Schmidt number, and water temperature.
Wind speed, wave formation, and bubble penetration are other factors affecting gas transfer in a complex way. To simplify the calculations here, the nonlinear effects of wind speed on the exchange process have been eliminated. For all calculations in this section we assume a uniform wind speed over the ocean of 8 $\mathrm{m} \mathrm{s}^{-1}$. This assumption also allows one to use a uniform square root Schmidt number dependence for the liquid phase transfer velocity. Still, even with these simplifications, there are a number of uncertainties in the basic physical properties of the individual organic compounds and on their temperature dependent behavior (see Table 24).

First we will examine the equations used to calculate the gas exchange flux and identify the assumptions and uncertainties in the different terms. Equation (2) is used to calculate the overall transfer velocity:

$$
1 / K_{w}=1 / \alpha k_{w}+R T / H k_{a}
$$

The overall transfer velocity $\mathrm{K}$ is calculated from the individual water and air transfer velocities $\left(\mathrm{k}_{\mathrm{w}}\right.$ and $k_{\mathfrak{a}}$ ), the Henry's law constant $H$, the gas constant $\left(\mathrm{R}=8.2 \times 10^{-5} \mathrm{~m}^{3} \mathrm{~atm} \mathrm{deg}-1 \mathrm{~mol}^{-1}\right)$, and the water temperature $T$ in degrees Kelvin. The first term, $\mathrm{k}_{\mathrm{w}}$, is based on the exchange of $\mathrm{CO}_{2}$ and needs to be corrected for temperature and diffusivity of the organic compound. This is done with the following relationship:

$$
\begin{aligned}
& \mathrm{k}_{\mathrm{W}}(\text { organic })=\mathrm{k}_{\mathrm{W}}\left(\mathrm{CO}_{2}\right) \\
& \quad\left[\mathrm{Sc}\left(\mathrm{CO}_{2}\right) / \mathrm{Sc}(\text { organic })\right]^{0.5}
\end{aligned}
$$


TABLE 24. Summary of Physical Properties of Organic Compounds at $20-25^{\circ} \mathrm{C}$ : Vapor Pressure (Solid, $\left(\mathrm{p}^{\circ} \mathrm{S}\right)$; Subcooled Liquid, $\left(\mathrm{p}^{\circ} \mathrm{L}\right)$ ), Solubility (S), and Henry's Law Constants $(\mathrm{H})$ Both Reported in the Literature and Adopted Here

\begin{tabular}{|c|c|c|c|c|c|}
\hline \multirow[t]{2}{*}{ Compound } & \multirow{2}{*}{$\begin{array}{c}\mathrm{p}^{\circ} \mathrm{S} \\
10^{-3} \mathrm{~Pa}\end{array}$} & \multirow{2}{*}{$\begin{array}{r}\mathrm{p}^{\circ} \mathrm{L} \\
10^{-3} \mathrm{~Pa}\end{array}$} & \multirow{2}{*}{$\begin{array}{c}S \\
\mu \mathrm{g} \mathrm{L}^{-1}\end{array}$} & \multicolumn{2}{|c|}{$\mathrm{H}, 10^{-5} \mathrm{~atm} \mathrm{m^{3 }} \mathrm{mol}^{-1}$} \\
\hline & & & & Reported* & Adopted \\
\hline$\alpha-\mathrm{HCH}$ & 3.3 & 84 & $\sim 2,000$ & 0.85 & 0.46 \\
\hline$\gamma-\mathrm{HCH}$ & 3.7 & 32 & $-6,500$ & $0.12-0.23$ & 0.23 \\
\hline $\mathrm{HCB}$ & 1.5 & 186 & 5 & $7-81$ & 81 \\
\hline trans-chlordane & 0.52 & 3.9 & 56 & $5.9-8.9$ & 7.5 \\
\hline cis-chlordane & 0.40 & 2.9 & --- & --- & --- \\
\hline $\mathrm{p}, \mathrm{p}^{\prime} \mathrm{DDE}$ & 0.35 & 1.7 & $1.2-120$ & 7.8 & 7.8 \\
\hline $\mathrm{p}, \mathrm{p}^{\prime}$ DDT & 0.021 & 0.17 & $<1-25$ & $1.3-2.3$ & 1.8 \\
\hline Aroclor 1254 & 10.2 & 1.9 & $45-70$ & $28-70$ & 28 \\
\hline Aroclor 1242 & & $\ldots$ & $340-730$ & $16-70$ & 34 \\
\hline Dieldrin & 0.40 & --- & 195 & $1.1-3.2$ & 2.0 \\
\hline
\end{tabular}

Literature references are from Fendinger and Glotfelty [1988], Suntio et al. [1987], Foreman and Bidleman [1987], Atlas et al. [1982, 1983], Callahan et al. [1979], Slater and Spedding [1981], Murphy et al. [1987], and T.F. Bidleman (personal communication, 1989).

*Values listed as reported are based on actual measurements or those recommended by Suntio et al. [1987].

We have information on the temperature dependence of the Schmidt number for $\mathrm{CO}_{2}$ [Liss and Merlivat, 1986] but not for the organic compounds of interest. Thus to make the calculation of $\mathrm{k}_{\mathrm{w}}$ at any temperature, we assume that the ratio of the Schmidt numbers of $\mathrm{CO}_{2}$ and the organic compound can be approximated as a constant which is equal to the ratio of their respective diffusivities in water. For the organic compounds here, the ratios of their diffusivity to that of $\mathrm{CO}_{2}$ is approximately $\mathbf{0 . 2}$ [Atlas et al., 1982]. To correct for temperature, we multiply $k_{w}$ for $\mathrm{CO}_{2}$ at $20^{\circ} \mathrm{C}$ and $8 \mathrm{~m} \mathrm{~s}^{-1}$ wind velocity $(13.2 \mathrm{~cm}$ $\mathrm{h}^{-1}$, where $\mathrm{Sc}=600$ ) as follows:

$\mathrm{k}_{\mathrm{W}}\left(\mathrm{T}^{\circ} \mathrm{C}\right)=\mathrm{k}_{\mathrm{W}}\left(20^{\circ} \mathrm{C}\right) \cdot\left(600 / \mathrm{Sc}\left(\mathrm{T}^{\circ} \mathrm{C}\right)\right)^{0.5}$

Thus the overall equation for calculating $k_{w}$ of an organic compound at any temperature $T$ is

$\mathrm{k}_{\mathrm{w}}$ (organic, $\left.\mathrm{T}^{\circ} \mathrm{C}\right)=\mathrm{k}_{\mathrm{w}}\left(\mathrm{CO}_{2}, 20^{\circ} \mathrm{C}\right) \cdot$ $\left[\mathrm{D} \text { (organic) } / \mathrm{D}\left(\mathrm{CO}_{2}\right)\right]^{0.5} \cdot\left[600 / \mathrm{Sc}\left(\mathrm{T}^{\circ} \mathrm{C}\right)\right]^{0.5}$

$\mathrm{k}_{\mathrm{W}}\left(\right.$ organic, $\left.\mathrm{T}^{\circ} \mathrm{C}\right)=13.2 \cdot(0.2)^{0.5}$ • $(600)^{0.5} \cdot\left(\mathrm{Sc}\left(\mathrm{T}^{\circ} \mathrm{C}\right)\right)^{-0.5}$

$\mathrm{k}_{\mathrm{W}}\left(\right.$ organic, $\left.\mathrm{T}^{\circ} \mathrm{C}\right)=145 \cdot\left(\mathrm{Sc}\left(\mathrm{T}^{\circ} \mathrm{C}\right)\right)^{-0.5}$

The temperature dependence of the Schmidt number of $\mathrm{CO}_{2}$ was estimated from a polynomial fit of the data given by Liss and Merlivat [1986], (from the original data of Jaehne [1980]). The Schmidt number of $\mathrm{CO}_{2}$ from $0-40^{\circ} \mathrm{C}$ is given by:

$$
\begin{gathered}
\mathrm{Sc}(\mathrm{T})=1858-108.7 \cdot \mathrm{T}\left({ }^{\circ} \mathrm{C}\right)+2.77 \cdot \mathrm{T}\left({ }^{\circ} \mathrm{C}\right)^{2} \\
-0.026 \cdot \mathrm{T}\left({ }^{\circ} \mathrm{C}\right)^{3}
\end{gathered}
$$

The second term on the right side of (2) represents the gas phase transfer resistance. The value for $\mathbf{k}_{\mathrm{a}}$ was calculated according to (9). It should be noted that the use of (9) produces less of a dependence on molecular weight than models of gas exchange reported elsewhere [Atlas et al., 1982; Smith et al., 1981]. In effect, the equation used here shows that most of the resistance to gas transport is associated with turbulent exchange away from the air-water boundary layer rather than with diffusive exchange across the interfacial zone. In numerical terms, the typical $\mathrm{k}_{\mathrm{a}}$ of an organic compound is only $10-20 \%$ less than that of water vapor. At $8 \mathrm{~m} \mathrm{~s}^{-1}, \mathrm{k}_{\mathrm{a}}$ of water molecules is $3200 \mathrm{~cm} \mathrm{~h}^{-1}$, while that of an organic compound of molecular weight 300 is $2690 \mathrm{~cm}$ $\mathrm{h}^{-1}$. Earlier equations had suggested that $\mathrm{k}_{\mathrm{a}}$ for high molecular weight organic compounds might be only $20-40 \%$ of the transfer velocity of water vapor.

More uncertainty is introduced into the calculation of transfer velocity though uncertainties in the Henry's law constant and its temperature dependence. Table 24 gives values of $\mathrm{H}$ adopted here, compared to reports in the literature relating to direct measurement of Henry's law constants and estimation of the constants based on vapor pressure and 
solubility determinations. In fact, this table represents only a fraction of the literature data judged to be the most representative. Reported or calculated values of Henry's law constants can range over orders of magnitude [e.g., Callahan et al., 1979; Suntio et al., 1987]. In choosing values for $\mathrm{H}$, we have preferred actual measurements over calculated constants. Otherwise, recommended constants or averages of Henry's law constants are used.

Given the relatively uncertain state of knowledge of Henry's law constants, it is not surprising that even less information is available on the magnitude of the temperature dependence. Some measurements and theoretical calculations are available for PCB mixtures [Burkhard et al., 1985; Murphy et al., 1987; Tateya et al., 1988], but not for other organics considered here. Often, the temperature dependence of the Henry's law constant is given in the form

$\ln \mathrm{H}=\mathrm{A}+\mathrm{B} / \mathrm{T}$

The slope of this equation, B, defines the temperature dependence. Table 25 lists data on the temperature dependence of selected organic compounds.
Based on these data, we have chosen to apply an average of $B=-7750$ (based on PCB) to other high molecular weight organic compounds. After these calculations were complete, new measurements and calculations became available on the temperature dependence of HCHs and several other high molecular weight organic compounds (D.A. Hinckley and T.F. Bidleman, personal communication, 1989). These data are shown in Table 25. From these data it appears that the temperature dependence of the Henry's law constant may be similar (within 25\%) for several different classes of high molecular weight organic compounds, and the initial value chosen for these calculations may be appropriate for the compounds being considered here. However, more direct measurements of Henry's law constants for specific compounds over the temperature range from $-2^{\circ}$ to $40^{\circ} \mathrm{C}$ are still needed.

To calculate $\mathrm{H}(\mathrm{T})$ at any temperature, we applied the following equation:

$H(T)=H\left(T_{\text {ref }}\right) \cdot e^{B}\left(1 / T-1 / T_{\text {ref }}\right)$

where $T$ is the temperature of interest, $T_{\text {ref }}$ is the

TABLE 25. Temperature Dependences of Henry's Law Constants of Selected Organic Compounds Based on Equation (22)

\begin{tabular}{|c|c|c|}
\hline Compound & Slope B & Reference \\
\hline $\begin{array}{l}\text { PCB } \\
\text { PCB } 1242 \\
\text { PCB } 1254\end{array}$ & $\begin{array}{l}-7868 \\
-7346 \\
-8060\end{array}$ & $\begin{array}{l}\text { Tateya et al. [1988] } \\
\text { Burkhard et al. [1985] } \\
\text { Burkhard et al. }[1985]\end{array}$ \\
\hline $\begin{array}{l}\text { Biphenyl } \\
2,2^{\prime}, 4,5,5^{\prime} \text { PCB } \\
2,2^{\prime}, 3,3^{\prime}, 5,5^{\prime}, 6,6^{\prime} \text { PCB } \\
\text { Decachlorobiphenyl }\end{array}$ & $\begin{array}{l}-7517 \\
-7308 \\
-6122 \\
-6629\end{array}$ & $\begin{array}{l}\text { D.A. Hinckley and T.F. Bidleman (pers. comm., 1989) } \\
\text { D.A. Hinckley and T.F. Bidleman (pers. comm., 1989) } \\
\text { D.A. Hinckley and T.F. Bidleman (pers. comm., 1989) } \\
\text { D.A. Hinckley and T.F. Bidleman (pers. comm., 1989) }\end{array}$ \\
\hline $\begin{array}{l}\mathrm{a}-\mathrm{HCH}^{*} \\
\mathrm{~g}-\mathrm{HCH}^{*}\end{array}$ & $\begin{array}{l}-7329 \\
-7329\end{array}$ & $\begin{array}{l}\text { D.A. Hinckley and T.F. Bidleman (pers. comm., 1989) } \\
\text { D.A. Hinckley and T.F. Bidleman (pers. comm., 1989) }\end{array}$ \\
\hline $\begin{array}{l}\text { Naphthalene } \\
\text { Fluorene } \\
\text { Anthracene } \\
\text { Phenanthrene } \\
\text { Fluoranthene }\end{array}$ & $\begin{array}{l}-5947 \\
-6664 \\
-5770 \\
-7242 \\
-5378\end{array}$ & $\begin{array}{l}\text { D.A. Hinckley and T.F. Bidleman (pers. comm., 1989) } \\
\text { D.A. Hinckley and T.F. Bidleman (pers. comm., 1989) } \\
\text { D.A. Hinckley and T.F. Bidleman (pers. comm., 1989) } \\
\text { D.A. Hinckley and T.F. Bidleman (pers. comm., 1989) } \\
\text { D.A. Hinckley and T.F. Bidleman (pers. comm., 1989) }\end{array}$ \\
\hline $\begin{array}{l}\mathrm{C}_{2} \mathrm{Cl}_{4} \\
\mathrm{CHCl}_{3} \\
\mathrm{CHCl}_{3} \\
\mathrm{CCl}_{4}\end{array}$ & $\begin{array}{l}-5119,-4622 \\
-4180,-4322 \\
-3649 \\
-3230\end{array}$ & $\begin{array}{l}\text { Lincoff and Gossett [1984] } \\
\text { Lincoff and Gossett [1984] } \\
\text { Hunter-Smith et al. [1983] } \\
\text { Hunter-Smith et al. [1983] }\end{array}$ \\
\hline Dimethyl sulfide & -3547 & Dacey et al. [1984] \\
\hline
\end{tabular}

D.A. Hinckley and T.F. Bidleman (personal communications, 1989) is a compilation by these authors of existing data and also includes their own experimental results.

*Measurements in seawater. 
temperature at which the Henry's law constant $\mathrm{H}$ is determined (usually 293 or $298^{\circ} \mathrm{K}$ ), and B is the slope from equation $22(=-7750)$. Approximately a factor of 2 change in Henry's law constant occurs for a temperature change of $8^{\circ} \mathrm{C}$.

Henry's law constants also enter into the calculation of gas exchange processes in the determination of the saturation state of seawater. Thus the concentration in surface seawater in equilibrium with the atmosphere, $\mathrm{C}_{\mathrm{eq}}$, is calculated from

$$
\mathrm{C}_{\mathrm{eq}}(\text { seawater })=\mathrm{C}_{\mathrm{g}}(\mathrm{air}) \cdot\left[\mathrm{RT} / \mathrm{H}\left(\mathrm{T}^{\circ} \mathrm{C}\right)\right]
$$

where $C_{g}$ (air) is the concentration of gas phase organic in the atmosphere and the Henry's law terms are defined as before. The same equation applies to calculating the equilibrium concentration of an organic compound in rainwater at temperature $\left(T^{\circ} \mathrm{C}\right)$. To correct for the salting out effect of organic compounds in seawater, we decrease $\mathrm{H}$ determined in distilled water by $20 \%$. This reduction in $\mathrm{H}$ is driven by a decreased solubility of organic compounds in seawater versus distilled water.

The factors which result from equations relating to gas exchange are summarized in Table 26. This table shows typical gas exchange constants for different compounds in the ocean basins and the estimated concentration of organic compounds in seawater at equilibrium with the atmosphere In terms of gas or liquid phase control of exchange (equation (2)), our calculations show that HCB is mostly liquid phase controlled, HCHs are mostly gas phase controlled, and all other compounds have signficant resistances to exchange in both gas and liquid phases, as is shown in Table 26. It should be realized in evaluat-

TABLE 26. Contribution of Gas and Liquid Phase Resistances to Overall Transfer Velocity of Selected Organochlorine Compounds (at $\mathrm{T}=20^{\circ} \mathrm{C}$, Wind Speed $=8 \mathrm{~m} \mathrm{~s}^{-1}$ )

\begin{tabular}{lccc}
\hline & $\begin{array}{c}\text { Transfer } \\
\text { Velocity }\end{array}$ & \multicolumn{2}{c}{ Resistance } \\
\cline { 3 - 4 } Compound & $\mathrm{cm} \mathrm{h}^{-1}$ & \% Gas & \% Liquid \\
\hline$\alpha$-HCH & 0.47 & 92 & 8 \\
$\gamma$-HCH & 0.25 & 96 & 4 \\
HCB & $5.54^{*}$ & 6 & 94 \\
PCB 1254 & $4.97 *$ & 16 & 85 \\
PCB 1242 & $5.11^{*}$ & 13 & 87 \\
trans-chlordane & 3.47 & 41 & 59 \\
Dieldrin & 1.62 & 73 & 27 \\
p,p' DDE & 3.52 & 40 & 60 \\
p,p' DDT & 1.50 & 75 & 25 \\
\hline
\end{tabular}

\footnotetext{
${ }^{*} \mathrm{At} 25^{\circ} \mathrm{C}$.
}

ing the data in Tables 26 and 27 that the gas transfer velocities and the relative importances of gas and liquid phase resistances will be a function of temperature and wind speed.

The final calculation of flux multiplies the overall transfer velocity $K_{w}$ with the difference in concentration between actual seawater concentration and that in equilibrium with the atmosphere. This seemingly simple calculation brings another level of uncertainty to the estimate of gas flux. There are extraordinarily few data on the concentration of high molecular weight organochlorines in open ocean seawater which can be used to assess the saturation state of surface seawater. Some of the few data available are listed in Table 27. These data suggest that on average, surface seawater may be near equilibrium with the atmosphere. However, there are really too few data on which to make this judgment. Also, interactions occurring between organic compounds and particulate or colloidal matter in seawater make the saturation state of seawater even more uncertain [Atlas and Giam, 1986; Caron et al., 1985; Whitehouse, 1985].

In spite of these difficulties, we will make several assumptions regarding gas exchange to allow a reasonable estimate of the magnitude of the deposition process. Given the fact that the organochlorines discussed in this report have been cycling in the environment for several decades (at least), it seems reasonable to assume that atmosphere-ocean interactions have reached some sort of quasi-steady-state situation. If organochlorines behave as inert gases, such as chloro-fluorocarbons, then certainly one would expect equilibrium with surface waters to be reached in a relatively short time. At a transfer velocity of 4 $\mathrm{cm} \mathrm{h}^{-1}$ (see Table 27), organochlorines dissolved in the upper $100 \mathrm{~m}$ of the ocean equilibrate with the atmosphere approximately three times per year. Thus the surface ocean is in a very dynamic equilibrium with the atmosphere. Transient conditions of atmospheric concentrations, temperatures, and ocean dynamics may result in local regions of gas phase disequilibrium. Under these transient conditions, the ocean may be a sink or a source of organochlorine compounds. However, when averaged over suitably long intervals (months to years), net gas deposition of organochlorines into the ocean is probably controlled by processes in the water column which remove the compounds to the deep ocean. These processes include sedimentation and mixing with undersaturated water deeper in the water column. To what extent these processes influence the magnitude of gas exchange can only be guessed now. Atlas et al. [1986a] suggested that these processes might limit gas exchange to only $5 \%$ of the maximum rate. Studies based on transient tracer species, such as tritium, indicate mixing processes which might double this rate [Broecker and Peng, 1982]. For the purposes of this report, we will use a "best" estimate of net gas deposition equal to $10 \%$ of the maximum 
TABLE 27. Calculated Gas Deposition Factors: Overall Gas Transfer Velocity $\mathbf{K}_{\mathbf{w}}$ and Seawater Concentration in Equilibrium with the Atmosphere

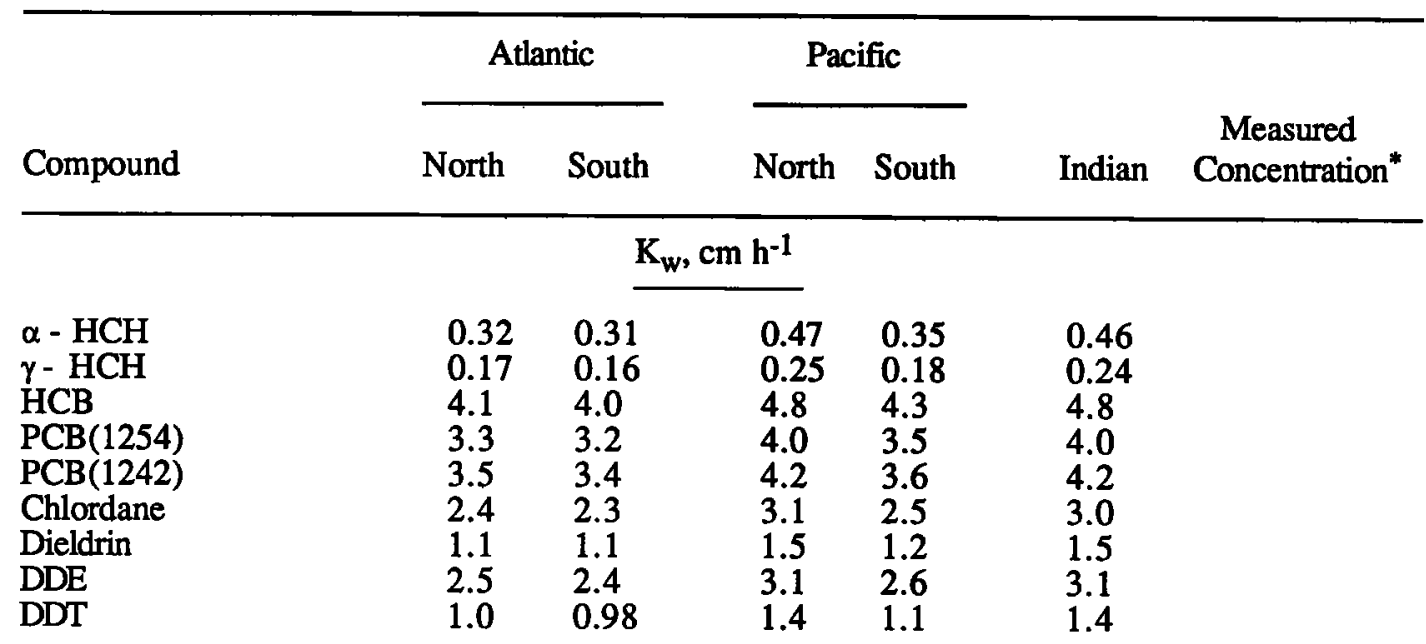

Saturated Seawater Concentration , $\mathrm{pg} \mathrm{L}^{-1}$

$\alpha-\mathrm{HCH}$
$\gamma-\mathrm{HCH}$
$\mathrm{HCB}$
PCB $(1254)$
PCB $(1242)$
Total PCB
Chlordane
Dieldrin
DDE
DDT

\begin{tabular}{rrrr}
\hline 1880 & 30 & 2600 & 310 \\
1020 & 70 & 1400 & 430 \\
9 & 6 & 6 & 6 \\
48 & 9 & 12 & 8 \\
40 & 7 & 10 & 7 \\
88 & 16 & 22 & 15 \\
7 & 1 & 4 & 1 \\
23 & 4 & 5 & 7 \\
2 & 2 & 2 & 5 \\
10 & & 11 & 19
\end{tabular}

520
561
4
16
13
29
1
5
5
6

$$
\begin{gathered}
300->2000 \\
20-600 \\
6-100 \\
-- \\
- \\
<3->200 \\
1-7 \\
<2-11 \\
32 \quad 1-30
\end{gathered}
$$

\footnotetext{
*Data from de Lappe et al. [1983]; Burns et al. [1985]; Tanabe et al. [1982a, b]; D.A. Kurtz and E.L.Atlas (unpublished data, 1990), and Hargrave et al. [1987].
}

rate. In other words, we are assuming that "average" seawater is $90 \%$ saturated with respect to organochlorines in the atmosphere. We acknowledge that there is little evidence on which to base this estimate, and we suggest that further measurement and modelling studies are urgently needed.

\section{Flux Estimates}

Calculations of deposition of organ-ochlorine compounds were performed covering a range of conditions. Dry deposition of particles was assumed to range from 0.05 to $0.5 \mathrm{~cm} \mathrm{~s}^{-1}$. A "best" estimate was $0.1 \mathrm{~cm} \mathrm{~s}^{-1}$. Because of major uncer-tainties regarding particle size distribution and extent of gasparticle partitioning, no additional refinements to deposition velocity, e.g., in pericontinental areas, were added to the calculation. Dry deposition of gas was calculated using the Henry's law constants in
Table 24, and the same temperature dependence for each compound was assumed. Annual average sea surface temperatures were used for the calculation in each grid box. Since wet deposition may be dependent on equilibration at rain-forming altitudes [Bidleman, 1988; Ligocki et al., 1985a], two different sets of assumptions were used. One assumed that rain equilibrated with particles and gases at an altitude that was $15^{\circ} \mathrm{C}$ cooler than sea surface temperature. Assuming a standard lapse rate, this corresponds to about $2 \mathrm{~km}$ altitude. At this altitude, the compound has a greater solubility in rain, and also a greater fraction of the compound is adsorbed to particles. The second assumption was that rain equilibrated with organic compounds at the temperature of the sea surface. Scavenging ratios ranged from 200 to 1000 . A "best" estimate of wet deposition used the cooler temperature with a scavenging ratio of 200. 


\section{$\underline{\text { Results }}$}

In spite of all the caveats, assumptions, and uncertainties in our estimates, we believe that the calculations performed here are a reasonable representation of the total deposition of organochlorines to the world ocean. Different observed features of the deposition of organochlorine compounds are adequately simulated in our calculations. The calculations provided a "best" estimate of the deposition of each organochlorine compound in each ocean basin. Table 28 summarizes these calculations as total deposition ( $\mathrm{x}^{106} \mathrm{~g} \mathrm{yr}^{-1}$ ) and flux (micrograms per square meter per year). The geographical mean flux distributions of the calculated fluxes of $\mathrm{\Sigma HCH}$ and $\Sigma P C B$ are shown in Figures 14 and 15.

Since major sources of organochlorine compounds are in the northern hemisphere, it is not surprising that our calculations show that a majority of the deposition of these compunds is to the North Atlantic and North Pacific oceans. Because of the different sources and transport of compounds over the ocean basins, different compounds predominate in different ocean basins. For example, $\mathrm{HCH}$ and DDT compounds have the greatest deposition rates in the North Pacific. This deposition is largely influenced by sources of these compounds on the Asian continent. PCBs and dieldrin have higher deposition rates over the North Atlantic than over the North Pacific. This difference appears to be related to proximity of sources of these compounds in Europe and North America. Chlordane and HCB have somewhat higher deposition rates over the North Atlantic,but total deposition of these two compounds is approximately the same for the North Atlantic and the North Pacific.

In this section the Indian Ocean is treated as a single basin, and no distinction is made between the northern Indian and southern Indian Ocean. How- ever, we note that high atmospheric concentrations and fluxes of HCHs, DDTs, and PCBs have been reported in the coastal region off India [Bidleman and Leonard, 1982; Tanabe and Tatsukawa, 1980; Tanabe et al., 1982a, b]. Our calculations also indicate that fluxes of organochlorine compounds in some areas adjacent to India are over an order of magnitude higher than fluxes to the interior of the southern Indian Ocean. Further, there have been reports of high concentrations of organochlorine pesticides in the rivers of Southern India (S. Tanabe, personal communication, 1990). Thus in addition to atmospheric deposition, runoff and river drainage also may be an important route for pesticide inputs to the northern Indian Ocean region.

Calculations also show that the mechanisms of exchange differ between individual organochlorine compounds, although there are some broad similarities (Table 29). In all cases, the magnitude of direct gas exchange across the sea surface is uncertain. However, given the assumptions described above, even a limited rate of gas exchange can provide an average of $25-85 \%$ of the total exchange for organochlorine compounds. Direct dry deposition of particle-bound organic material is a minor component of the deposition of all compounds considered here. There may be situations of high particle loading and low rainfall where particle dry deposition may be more important, but on average dry deposition is $<5 \%$ of the total particle deposition. The primary differences in deposition mechanisms between compounds occurs in wet deposition. Particle scavenging by precipitation is most significant for PCB and DDT compounds; gas scavenging is the predominant mechanism removing $\mathrm{HCH}$ compounds in rain. Particle scavenging accounts for $15-30 \%$ of the wet deposition of the other organochlorines.

While these estimates provide a guideline for comparing compounds and obtaining total deposition

TABLE 28. Summary of Total Deposition and Mean Flux of Organochlorine Compounds to the Oceans

\begin{tabular}{|c|c|c|c|c|c|c|c|c|c|c|c|c|}
\hline \multirow[b]{2}{*}{ Compound } & \multicolumn{2}{|c|}{$\begin{array}{l}\text { North } \\
\text { Atlantic }\end{array}$} & \multicolumn{2}{|c|}{$\begin{array}{l}\text { South } \\
\text { Atlantic }\end{array}$} & \multicolumn{2}{|c|}{$\begin{array}{l}\text { North } \\
\text { Pacific }\end{array}$} & \multicolumn{2}{|c|}{$\begin{array}{l}\text { South } \\
\text { Pacific }\end{array}$} & \multicolumn{2}{|c|}{ Indian } & \multicolumn{2}{|c|}{ Global } \\
\hline & $\mathrm{TD}$ & MF & $\mathrm{TD}$ & MF & $\mathrm{TD}$ & MF & TD 1 & MF & $\mathrm{TD}$ & MF & $\mathrm{TD}$ & MF \\
\hline $\begin{array}{l}\text { CB } \\
\text { ieldrin } \\
\text { SDT } \\
\text { hlordane } \\
\text { PCB }\end{array}$ & $\begin{array}{c}850 \\
17 \\
17 \\
16 \\
8.7 \\
100\end{array}$ & $\begin{array}{c}16 \\
0.31 \\
0.30 \\
0.28 \\
0.16 \\
1.8\end{array}$ & $\begin{array}{c}97 \\
10 \\
2.0 \\
14 \\
1.0 \\
14\end{array}$ & $\begin{array}{l}1.9 \\
0.20 \\
0.04 \\
0.27 \\
0.02 \\
0.27\end{array}$ & $\begin{array}{r}2600 \\
20 \\
8 . \\
66 \\
8 . \\
36\end{array}$ & $\begin{array}{l}30 \\
0.22 \\
90.10 \\
0.74 \\
30.09 \\
0.40\end{array}$ & $\begin{array}{c}470 \\
19 \\
9.5 \\
26 \\
1.9 \\
29\end{array}$ & $\begin{array}{ll}4.3 \\
0.17 \\
5 & 0.09 \\
0.23 \\
9 \\
0.02 \\
0.26\end{array}$ & $\begin{array}{c}700 \\
11 \\
6.0 \\
43 \\
2.4 \\
52\end{array}$ & $\begin{array}{l}10 \\
0.17 \\
0.09 \\
0.64 \\
0.04 \\
0.77\end{array}$ & $\begin{array}{r}4800 \\
77 \\
43 \\
170 \\
22 \\
240\end{array}$ & $\begin{array}{c}13 \\
0.23 \\
0.11 \\
0.44 \\
0.06 \\
0.64\end{array}$ \\
\hline
\end{tabular}

$\mathrm{TD}$, total deposition (x $10^{6} \mathrm{~g} \mathrm{yr}^{-1}$ ); MF, mean flux (micrograms per square meter per year). 


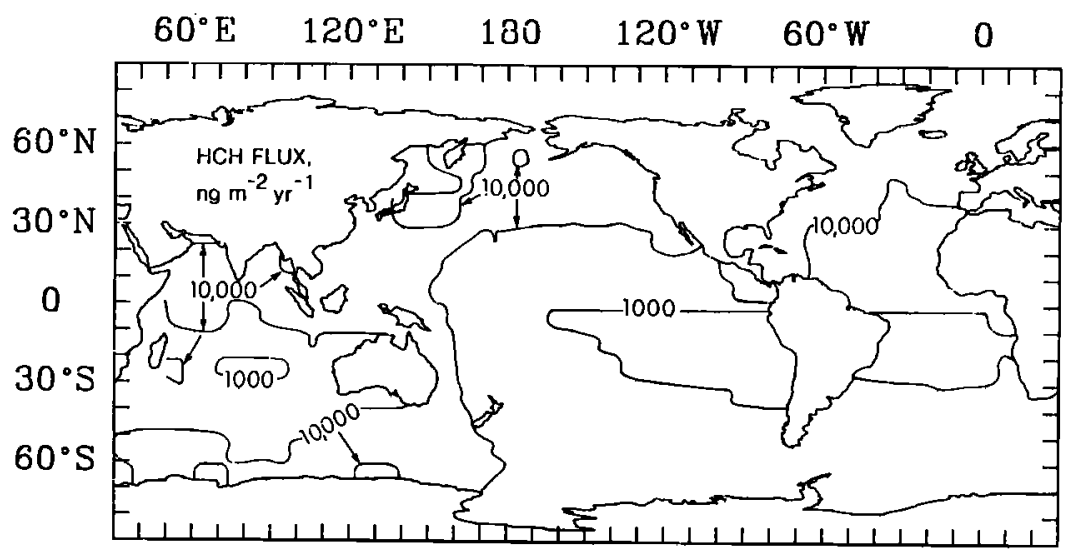

Fig. 14. Global flux of HCHs to the oceans in nanograms per square meter per year.

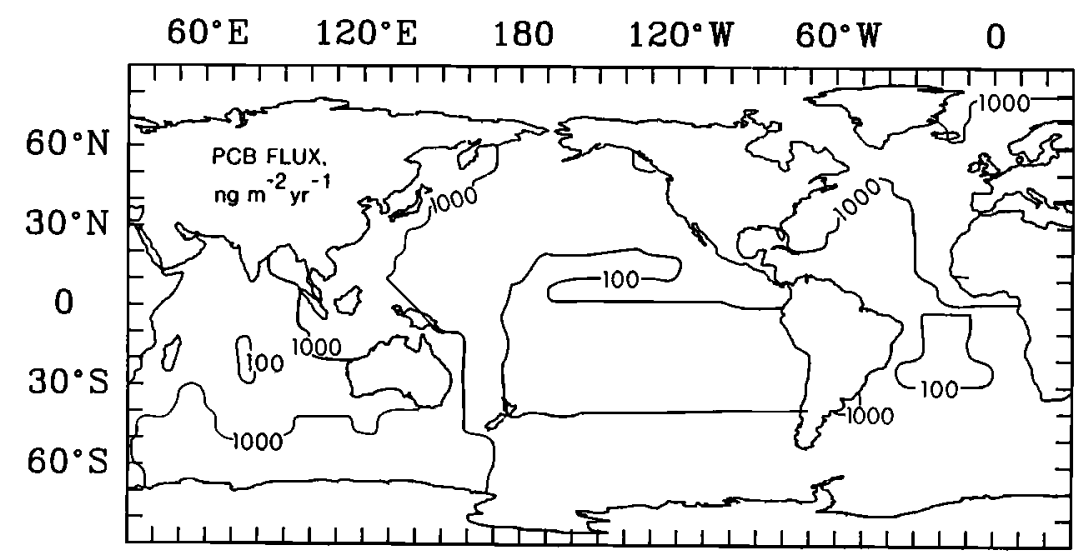

Fig. 15. Global flux of PCBs to the oceans in nanograms per square meter per year.

rates, it should be remembered that the relative importance of mechanisms described here is dependent on the various assumptions used in the calculation. A factor of 2 error in the gas-particle partition coefficient or the Henry's law constant can change the relative importance of particle versus gas scavenging. Still, there are various checks we can make on our calculations to evaluate how appropriate they are for estimating deposition to the oceans.

To check the calculations of deposition rates, we can make several comparisons with existing data. The first check compares estimates of the predicted wet deposition with actual measurements of organochlorine compounds in rainwater at specific sites in the model grid (Table 30). For this comparison we use only measurements of rain at remote marine locations. Thus there are only a few sites available for comparison. These include the four SEAREX sites in the Pacific Ocean, one site at Bermuda, and an average of several samples taken during a research cruise in the Indian Ocean. With the exception of $\mathrm{HCH}$, most organochlorine compounds are below detection in marine rain. The low levels of most organochlorines is consistent with model calcula- tions. For the more abundant $\mathrm{HCH}$, there is generally excellent agreement between observed and predicted concentrations in the Pacific and Indian Oceans. Our model calculation (based on a scavenging ratio of 200 and assuming equilibration at $15^{\circ} \mathrm{C}$ below sea surface temperature) tends to overestimate $\mathrm{HCH}$ concentration in rainfall at Bermuda but to underestimate the chlordane and dieldrin concentration there. Better agreement for $\mathrm{HCH}$ at Bermuda is obtained when we assume equilibration at sea surface temperature.

The second check we can make is to compare our estimates of deposition rates with other direct or indirect measurements of deposition to water bodies or other surfaces (Table 31). For most of the cases available for comparison, the measurement describes only net deposition rates. When applied to sedimentation, deposition rates describe only that fraction of the total deposition which becomes attached to sinking particles. Accumulation in peat bogs is probably best compared with wet deposition rates; gas exchange at peat forming layers in the bog may not be significant [Rapaport and Eisenreich, 1988]. Overall, the comparison between estimated deposition rates for the North Atlantic and deposition rates 
measured at other northern hemisphere sites is surprisingly good. There is a suggestion in the data that maximum flux rates, i.e., those assuming maximum gas exchange, will overestimate the net flux of organochlorines to the oceans. A more reasonable comparison is obtained using a limited rate of gas dry deposition.

Finally, a comparison is made between the magnitude of the atmospheric input of organochlorines to the oceans to the global amount from riverine input (Table 32). There is, however, a lack of data on organochlorine inputs to the world ocean from large river systems. The data situation for organochlorines in major rivers is much worse than for the marine atmosphere. A recent report [GESAMP, 1987] also noted the lack of data on anthropogenic organic com-

TABLE 29. Estimats of Deposition of Organochlorines to the World Oceans by Various Processes, Expressed as Percent of Total Deposition

\begin{tabular}{|c|c|c|c|c|}
\hline \multirow[b]{2}{*}{ Compound } & \multicolumn{2}{|c|}{ Particle } & \multicolumn{2}{|c|}{ Gas } \\
\hline & Dry & Wet & Dry & Wet \\
\hline $\begin{array}{l}\alpha-\mathrm{HCH} \\
\gamma-\mathrm{HCH} \\
\text { HCB } \\
\text { Dieldrin } \\
\text { p,p' DDT (rev) } \\
\text { p,p' DDE } \\
\text { Chlordane } \\
\Sigma \text { PCB }\end{array}$ & $\begin{array}{r}<0.1 \\
<0.1 \\
0.2 \\
0.3 \\
0.7 \\
0.4 \\
0.2 \\
0.6\end{array}$ & $\begin{array}{c}0.1 \\
<0.1 \\
2.2 \\
13 \\
34 \\
21 \\
9.5 \\
23\end{array}$ & $\begin{array}{l}38 \\
23 \\
85 \\
54 \\
45 \\
64 \\
72 \\
65\end{array}$ & $\begin{array}{l}62 \\
77 \\
13 \\
33 \\
20 \\
15 \\
18 \\
11\end{array}$ \\
\hline
\end{tabular}

pounds in rivers. River data in Table 32 were taken from Atlas and Giam [1986]. They assumed that upper limits for "global average" riverine concentrations were $1 \mathrm{ng} \mathrm{L}^{-1}$ for PCB and $\mathrm{HCH}$ and $0.1 \mathrm{ng}$ $\mathrm{L}^{-1}$ for other organochlorines. For these cases, atmospheric input is the dominant mechanism of input of organochlorine compounds to the world ocean. However, for the reasons already discussed, it is important to recognize that such a comparison is very crude.

\section{CONCLUSIONS}

Chemicals, both natural and human-derived, reach the open ocean by a number of routes, including rivers, direct dumping, and the atmosphere. The first two paths have been studied for several decades, but only relatively recently has it become possible to estimate the amounts of material entering the ocean from the atmosphere. As the calculations have become less crude, for some substances the atmospheric route appears to have gained importance relative to other paths. This improvement in quantifying atmospheric inputs has come about through better understanding of the transport and deposition mechanisms carrying material to the surface of the oceans, as well as the availability of an improved data base of atmospheric concentration measurements in the marine environment.

In this paper, estimates have been made of the atmospheric input to the ocean of trace metals, mineral aerosol, nitrogen species, and synthetic organic compounds. The results are of particular importance in that they provide for the first time an indication on a regional scale of the global distribution and fluxes of these substances. The calculations show clearly that the continents are a dominant source for most of

TABLE 30. Comparison of Measured Rainfall Concentrations at Specific Locations (in parentheses) With Model Predictions (Based on Sea Surface Temperature Minus $15^{\circ} \mathrm{C}$ and Scavenging Ratio of 200)

\begin{tabular}{|c|c|c|c|c|c|c|}
\hline \multirow[b]{2}{*}{ Compound } & \multicolumn{2}{|c|}{ North Pacific } & \multicolumn{2}{|c|}{ South Pacific } & \multirow[b]{2}{*}{$\begin{array}{l}\text { Indian } \\
\text { Ocean }\end{array}$} & \multirow{2}{*}{$\begin{array}{c}\text { Atlantic } \\
\text { (Bermuda) }\end{array}$} \\
\hline & $\begin{array}{l}\text { North } \\
\text { Pacific }\end{array}$ & Enewetak & Samoa & $\begin{array}{l}\text { New } \\
\text { Zealand }\end{array}$ & & \\
\hline$\alpha-\mathrm{HCH}$ & $6400(6300)$ & $2400(3100)$ & $380 \quad(320)$ & $770(450)$ & $3800(5000)$ & $4400(850)$ \\
\hline$\gamma-\mathrm{HCH}$ & $1200(1900)$ & $290(510)$ & $47 \quad(30)$ & 61 & $1300(1100)$ & $1000(130)$ \\
\hline HCB & 23 & $9(<30)$ & 7 & $19(<30)$ & 6 & 24 \\
\hline Total PCB & 47 & $66(<600)$ & $7(<200)$ & 13 & 64 & 470 \\
\hline Dieldrin & 11 & $20(<20)$ & 3 & 17 & 11 & $46(160)$ \\
\hline Chlordane & 11 & $9(<20)$ & $1(<30)$ & 3 & 3 & 17 (77) \\
\hline $\mathrm{DDE}$ & 2 & 2. $(<20)$ & 1 & 6 & 4 & 11 \\
\hline DDT (rev) & 13 & $12(<20)$ & 5 & $21(<20)$ & 30 & $40(<310)$ \\
\hline
\end{tabular}

Concentrations are in picograms per liter. 
the species evaluated, and that the primary continental sources are human-related. We see a marked northern/southern hemisphere contrast in fluxes, with the major fraction entering the ocean in the northern hemisphere. It is also apparent that the fluxes to the ocean are much higher near the continents; the same marine areas utilized most extensively by society through fishing, recreation, etc.

While these calculations represent the current "state of the art" in terms of the global input to the ocean, there are still large uncertainties in the quantitative fluxes presented. These uncertainties often result from the relatively small data sets covering short temporal and limited geographical scales. They are also related to uncertainties in modeling the fundamental processes by which material is transferred from the atmosphere to the ocean. While the uncertainties differ for the various substances, in general we assess that these estimates are accurate to at best a factor of 2 to 4 , and in some cases the uncertainty probably approaches an order of magnitude.

Atmospheric input to the global ocean appears to be approximately equivalent to riverine input for the dissolved forms of such metals as $\mathrm{Fe}, \mathrm{Cu}, \mathrm{Ni}, \mathrm{P}$, and As, while atmospheric input dominates for $\mathrm{Zn}$, $\mathrm{Cd}$, and $\mathrm{Pb}$. It should be noted that much of the riverine input of these substances probably never reaches the open ocean. Wet deposition is greater than dry deposition for these substances, and there is a significantly greater input to the ocean in the northern hemisphere than in the southern hemisphere. Mineral aerosol input shows a similar pattern, with particularly high fluxes to the oceans found downwind of major desert regions, particularly in eastern and southeastern Asia, Africa, India, and Australia.

The wet deposition of nitrate and nitric acid appears to provide a very important fraction of the total oxidized nitrogen entering the global ocean. Deposition of $\mathrm{NO}_{\mathrm{x}}$ appears to be relatively insignificant. Again, most of the oxidized nitrogen enters the ocean in the northern hemisphere. Anthropogenic sources of oxidized nitrogen are quite important, with the highest air-to-sea fluxes per unit area occurring to the North Atlantic Ocean, reflecting the strong humanderived sources in North America and Europe. While fluxes of reduced nitrogen were calculated,

TABLE 31. Comparison of Estimated Measured Fluxes of Chlorinated Hydrocarbons

\begin{tabular}{|c|c|c|c|c|}
\hline Compound & Flux, $\mu \mathrm{g} \mathrm{m}^{-}$ & $\mathrm{yr}^{-1}$ & Location & Reference \\
\hline$\Sigma \mathrm{PCB}$ & $\begin{array}{l}0.1-4.0 \\
0.8-3.1 \\
1.6 \\
0.57-13.6\end{array}$ & $(1.8)$ & $\begin{array}{l}\text { NE U.S. peat cores } \\
\text { rural Wisconsin lakes } \\
\text { N. Atlantic sediment trap } \\
\text { N. Atlantic, calculated }\end{array}$ & $\begin{array}{l}1 \\
2 \\
3 \\
\text { this work }\end{array}$ \\
\hline $\mathrm{HCB}$ & $\begin{array}{l}0.03-0.4 \\
0.24 \\
0.04-2.8\end{array}$ & $(0.31)$ & $\begin{array}{l}\text { NE U.S. peat cores } \\
\text { Mediterranean Sea rain } \\
\text { N. Atlantic, calculated }\end{array}$ & $\begin{array}{l}1 \\
4 \\
\text { this work }\end{array}$ \\
\hline$\Sigma D D T s$ & $\begin{array}{l}0.4-1.5 \\
0.33 \\
0.97 \\
1.6 \\
0.15-1.5\end{array}$ & $(0.28)$ & $\begin{array}{l}\text { NE U.S. peat cores } \\
\text { central Minnesota snow } \\
\text { Mediterranean Sea sediment trap } \\
\text { Mediterranean Sea rain } \\
\text { N. Atlantic, calculated }\end{array}$ & $\begin{array}{c}1 \\
5 \\
6 \\
4 \\
\text { this work }\end{array}$ \\
\hline Chlordane & $\begin{array}{l}0.02 \\
0.044-1.25\end{array}$ & $(0.16)$ & $\begin{array}{l}\text { N. Atlantic sediment trap } \\
\text { N. Atlantic, calculated }\end{array}$ & $\begin{array}{l}3 \\
\text { this work }\end{array}$ \\
\hline Dieldrin & $\begin{array}{l}0.04 \\
0.14-1.9\end{array}$ & $(0.32)$ & $\begin{array}{l}\text { N. Atlantic sediment trap } \\
\text { N. Atlantic, calculated }\end{array}$ & $\begin{array}{l}3 \\
\text { this work }\end{array}$ \\
\hline$\gamma$-HCH & $\begin{array}{l}0.97 \\
2.4 \\
7.5 \\
3.2-13.2\end{array}$ & $(4.2)$ & $\begin{array}{l}\text { Mediterranean Sea sediment trap } \\
\text { Mediterranean Sea dry deposition } \\
\text { Great Britain - North Sea rain } \\
\text { N. Atlantic, calculated }\end{array}$ & $\begin{array}{c}6 \\
4 \\
7 \\
\text { this work }\end{array}$ \\
\hline
\end{tabular}

References are as follows: 1, Rapaport and Eisenreich [1988]; 2, Swackhamer and Armstrong [1986]; 3, Knap et al. [1986]; 4, Villeneuve and Cattini [1986]; 5, Rapaport et al. [1985]; 6 Burns et al. [1985]; 7, Wells and Johnstone [1978]. Values calculated in this paper include the maximum range and "best" estimate (in parentheses) of the flux. 
TABLE 32. Comparison of Atmospheric and Riverine Inputs of Organochlorine Compounds to the World Oceans

\begin{tabular}{lccc}
\hline Compound & Atmospheric & $\begin{array}{l}\text { Estimated } \\
\text { Riverine }\end{array}$ & \% Atmospheric \\
\hline$\Sigma H C H$ & 4800 & $40-80$ & 99 \\
HCB & 77 & 4 & 95 \\
Dieldrin & 43 & 4 & 91 \\
$\Sigma$ DDT & 170 & 4 & 98 \\
Chlordane & 22 & 4 & 85 \\
$\Sigma$ PCB & 240 & $40-80$ & 80 \\
\hline
\end{tabular}

Units are $10^{6} \mathrm{~g} \mathrm{yr}^{-1}$.

much of that flux may be material that has been recycled through the air-sea interface. The calculations of global atmospheric input of nitrogen species to the ocean are similar to nitrogen fluxes from rivers, although, like trace metals, much of the riverine nitrogen probably never escapes the estuarine zone. Apparently only a few percent of the annual input of nitrogen species from rivers and the atmosphere reaches the marine sediments. Even though we are comparing current atmospheric and riverine input estimates with historical marine sedimentation rates, this comparison implies that there is significant recycling of nitrogen (e.g., as $\mathrm{N}_{2}, \mathrm{~N}_{2} \mathrm{O}$, or $\mathrm{NH}_{3}$ ) from the ocean back to the atmosphere.

All of the organic species considered are humanderived, and their deposition rates and pathways are complex and unique to each compound. Most of these synthetic substances appear to be deposited in the North Pacific and North Atlantic oceans. Regional differences are observed depending upon the continental area in which the substances are primarily used. For example, HCHs and DDT are mainly used in Asia, and their deposition is greatest over the North Pacific, whereas PCBs and dieldrin, which are utilized primarily in North America and Europe, have greater deposition rates to the North Atlantic. The atmosphere is by far the dominant transport path for these substances found in the ocean.

Several gaps in knowledge have become apparent during these calculations, and further work is required before we are able to reduce the large uncertainties in these global flux values. The following are significant sources of uncertainties in our present estimation of the fluxes of these trace substances:

1 . The best way to quantify atmospheric inputs top the oceans is by direct flux measurements. However, methods for measuring fluxes directly are lacking at the present, except for precipitation. The development of techniques to enable direct flux measurements to be made should be a top priority. In addition, the geographical coverage of rain sampling programs should be expanded considerably.

2. In default of direct flux methods, we must resort to indirect approaches that use measured air concentrations. The presently available concentration data fields must be improved both temporally and spatially. Areas for which concentration data are particularly lacking are the South Atlantic, South Pacific, Indian, and Arctic oceans.

3 . To convert concentrations to fluxes requires knowledge of the kinetic parameter (deposition/ transfer velocity) controlling the deposition rate. Better parameterization of this term, which can come from better understanding of the controlling processes, is required for both particles and gases.

4. Rain scavenging ratios for particular substances vary substantially both temporally at a fixed site and between different locations. There are many reasons for the existence of these ranges. Part of the problem may be that scavenging ratios often must be computed from rain and air concentrations measured in samples that were not collected contemporaneously. There is an urgent need for simultaneous collections and measurements, including vertical profiles, so that scavenging ratios can be obtained from truly paired rain and air samples.

5. An important uncertainty in flux calculations for synthetic organic compounds is the concentration of the "free" (i.e., able to exchange across the air-sea interface) compounds in the surface ocean. Although technically difficult to address, such measurements should have a high priority in future studies of these compounds.

ACKNOWLEDGMENTS. The work described in this paper was undertaken under the auspices of the Group of Experts on the Scientific Aspects of Marine Pollution (GESAMP), Working Group 14, Interchange of Pollutants Between the Atmosphere and Ocean. Financial support for the working group meetings was provided by the World Meteorological Organization, the United Nations Environment Program, and UNESCO. The extensive technical support of Mr. Van Chisholm is gratefully acknowledged. 


\section{REFERENCES}

Addison, R.F. and M.E. Zinck, PCB's have declined more than DDT-group residues in Arctic ringed seals (Phoca hispida) between 1972 and 1981, Environ. Sci. Technol., 20, 253-256, 1986.

Anderson, L.G., Fate of nitrogen oxides in urban atmospheres, in Advances in Environmental Science and Technology, vol. 12, edited by S. E. Schwartz, pp. 371-409, John Wiley, New York, 1983.

Andreae, M.O., R.J. Charlson, F. Bruynseels, H. Storms, R. Van Grieken, and W. Maenhaut, Internal mixture of sea-salt, silicates, and excess sulfate in marine aerosols, $\underline{\text { Science, }} \underline{232}, 1,620$ $1,623,1986$.

Arimoto, R., R.A. Duce, B.J. Ray, and C.K. Unni, Atmospheric trace elements at Enewetak Atoll, 2, Transport to the ocean by wet and dry deposition, J. Geophys. Res., 90, 2,391-2,408, 1985.

Arimoto, R., R.A. Duce, B.J. Ray, A.D. Hewitt, and J. Williams, Trace elements in the atmosphere of American Samoa: Concentrations and deposition to the tropical South Pacific, J. Geophys. Res., 22, 8,465-8,479, 1987.

Arimoto, R., B.J. Ray, R.A. Duce, A.D. Hewitt, R. Boldi, and A. Hudson, Concentrations, sources, and fluxes of trace elements in the remote marine atmosphere of New Zealand, J. Geophys. Res., 95, 22,389-22,405, 1990.

Atlas, E. (1990). Long-range transport of organic compounds, in The Long-Range Atmospheric Transport of Natural and Contaminant Substances, edited by A.H. Knap, pp. 105-135, Kluwer, Boston, Mass., 1990.

Atlas, E.L. and C.S. Giam, Global transport of organic pollutants; Ambient concentra-tions in the remote marine atmosphere, Science, 211, 163$165,1981$.

Atlas, E.L. and C.S. Giam, Sea-air exchange of high molecular weight synthetic organic compounds. in The Role of Air-Sea Exchange in Geochemical Cycling, edited by P. Buat-Menard, pp. 295-330, D. Reidel, Norwell, Mass., 1986.

Atlas, E.L. and C.S. Giam, Sea-air exchange of high molecular weight synthetic organic compounds-Results from the SEAREX Program, in Chemical Oceanography, vol 10. edited by J. P. Riley, R. Chester, and R.A. Duce, pp. 39-378, Academic Press, San Diego, Calif., 1989.

Atlas, E.L., R. Foster, and C.S. Giam, Air-sea exchange of high molecular weight organic pollutants: Laboratory studies, Environ. Sci. Technol., 16, 283-286, 1982.

Atlas, E.L., A. Velasco, K. Sullivan, and C.S. Giam, A radio-tracer study of air-water exchange of synthetic organic compounds, Chemosphere, $12,1,251-1,258,1983$.

Atlas, E.L., T. Bidleman, and C.S. Giam,
Atmospheric transport of PCB to the oceans, in PCB's and the Environment,Vol. I, edited by J.S. Waid, pp. 79-100, CRC Press Inc., Boca Raton, Florida, 1986a.

Atlas, E.L., K. Sullivan, and C.S. Giam, Widespread occurrence of polyhalogenated aromatic ethers in the marine atmosphere, Atmos. Environ., 20, 217-220, 1986b.

Atlas, E.L., M. Madero, and C.S. Giam, Synthetic organic compounds in rural air and rainfall, Water Air Soil Pollut., 38, 19-36, 1988.

Ayers, G.P., and J.L. Gras, Ammonia gas concentrations over the southern ocean, Nature, 284, 539-540, 1980.

Ayers, G.P., and J.L. Gras, The concentration of ammonia in southern ocean air, J. Geophys. Res., 88, 10,655-10,659, 1983.

Ayers, G.P., and J.P. Ivey, Precipitation composition at Cape Grim, 1977-1985, Tellus, Ser. B, 40, 297-307, 1988.

Ayers, G.P., J.P. Ivey, and H.S. Goodman, Sulfate and methanesulfonate in the maritime aerosol at Cape Grim, Tasmania, J. Atmos. Chem., 4, 173$185,1986$.

Bacci, E., D. Calamari, C. Gaggi, R. Fanelli, S. Focarki, and M. Morosini, Chlorinated hydrocarbons in lichen and moss samples from the Antarctic Peninsula, Chemosphere, 15, 747-754, 1986.

Ballschmiter, K., H. Buchert, S. Bihler, and M. Zell, Baseline studies of global pollution. IV, The pattern of pollution by organochlorine compounds in the North Atlantic as accumulated by fish, Fresnius Z. Anal. Chem., 306, 323-339, 1981.

Barber, R.T. and S.M. Warlen, Organochlorine insecticide residues in deep sea fish from $2500 \mathrm{~m}$ in the Atlantic Ocean, Environ. Sci. Technol., 13, 1,146-1,148, 1979.

Barrie, L.A., R.M. Hoff, and S.M. Daggupathy, The influence of mid-latitude pollution sources on haze in the Canadian Arctic, Atmos. Environ., 15, 1,407-1,419, 1981.

Berner, R.A., Burial of organic carbon and pyrite sulfur in the modern ocean, Am. J. Sci., 282, 451-473, 1986.

Berresheim, $H$. and W. Jaeschke, Study of metal aerosol system as a sink for atmospheric $\mathrm{SO}_{2}, \mathrm{~L}$ Atmos. Chem., 4, 311-334, 1986.

Berresheim, H., M.O. Andreae, G.P. Ayers, R.W. Gillett, J.T. Merrill, V.J. Davis and W.L. Chameides, Airborne measurements of dimethylsulfide, sulfur dioxide, and aerosol ions over the southern ocean south of Australia, J.Atmos. Chem., 10, 341-370, 1990.

Bidleman, T.F., Atmospheric processes, Environ. Sci, Technol., 22, 361-367, 1988.

Bidleman, T.F., and E.J. Christenson, Atmospheric removal processes for high molecular weight organochlorines, J. Geophys. Res., 84, 7,857$7,862,1979$.

Bidleman, T.F. and R. Leonard, Aerial transport of 
pesticides over the northern Indian Ocean and adjacent seas, Atmos. Environ., 16, 1,099-1,107, 1982.

Bidleman, T.F., E.J. Christensen, W.N. Billings, and R. Leonard, Atmospheric transport of organochlorines in the North Atlantic gyre, $\mathbf{L}$ Mar. Res., 39, 443-464, 1981.

Bidleman, T.F., W.N. Billings, and W.T. Foreman, Vapor-particle partitioning of semivolatile organic compounds: Estimates from field collections, Environ. Sci. Technol., 20, 1,038-1,043, 1986.

Bidleman, T.F., U. Wideqvist, B. Jansson, and R. Soderlund, Organochlorine pesticides and polychlorinated biphenyls in the atmosphere of southem Sweden, Atmos. Environ., 21, 641-654, 1987.

Bidleman, T.F., E.L. Atlas, R. Atkinson, B. Bonsang, K. Burns, W.C. Keene, A.H. Knap, J. Miller, J. Rudolf, and S.Tanabe, Transport of organic compounds in the atmosphere: Review and recommendations, in The Long-Range Atmospheric Transport of Natural and Contaminant Substances, edited by A.H. Knap, pp. 259-301, Kluwer, Boston, Mass., 1990.

Bottger, A., D.H. Ehhalt and G. Gravenhorst, Atmospharische Krieslaufe von Stickoxiden und Ammoniak, Ber. der Kernforschungsanlage Juelich, 1558, Ber. der Kernforschungsanlage Juelich, 1978.

Broecker, W.S. and T.-H. Peng, Tracers in the Sea, Lamont-Doherty Geological Observatory, Columbia University, Palisades, 690 pp., N.Y., 1982

Buat-Menard, P., The ocean as a sink for atmospheric particles, in The Role of Air-Sea Exchange in Geochemical Cycling, edited by P. BuatMenard, pp. 165-183, D. Reidel, Norwell, Mass., 1986.

Buat-Menard, P. and R.A. Duce, Precipitation scavenging of aerosol particles over remote marine regions, Nature, 321, 508-510, 1986.

Buijsman, E., W.A.H. Asman, T.B. Ridder, A.J. Frantzen, and R. Adolphs, Chemical composition of precipitation collected on a weather ship in the North Atlantic, Rep. R-85-5, Inst. for Meteorol. and Oceanogr., Univ. of Utrecht, Utrecht, Netherlands, 1985.

Burchfield, L.A., J.D. Akridge, and P.K. Kuroda, Temporal distributions of radio-strontium isotopes and radon daughters in rainwater during a thunderstorm, J. Geophys. Res., 88, 8,5798,584, 1983.

Burkhard, L.P., D.E. Armstrong, and A.W. Andren, Henry's law constants for the polychlorinated biphenyls, Environ. Sci. Technol., 19, 590596, 1985.

Burns, K.A., J.P. Villeneuve, and S.W. Fowler, Fluxes and residence times of hydrocarbons in the coastal Mediterranean: How important are the biota?, Estuarine Coastal Shelf Sci., 20, 313-330, 1985.
Burns, R.S. and R.W.F. Hardy, Nitrogen Fixation in Bacteria and Higher Plants, 189 pp., SpringerVerlag, New York, 1975.

Busenberg, E., and C.C. Langway, Jr., Levels of ammonium, sulfate, chloride, calcium, and sodium in snow and ice from southern Greenland, J. Geophys. Res., 84, 1,705-1,709, 1979.

Byrd, J.T., and M.O. Andreae, Concentrations and fluxes of tin in aerosols and rain, Atmos. Environ., 20, 931-939, 1986.

Callahan, M.A., et al., Water-related environmental fate of 129 priority pollutants, Rep.EPA-440/479-029a, 2 vols., Environ. Prot. Agency, Washington, D.C., 1979.

Caron, G., I.H. Suffet, and T. Belton, Effect of dissolved organic carbon on the environmental distribution of nonpolar organic compounds, Chemosphere, 14, 993-1,000, 1985.

Carroll, M.A., et. al., Aircraft measurements of $\mathrm{NO}_{\mathbf{x}}$ over the eastern Pacific and continental United States and implications for ozone production, $\mathrm{L}$ Geophys. Res., 95 10,205-10,233, 1990.

Carroll-Webb, S.A., and J.V. Walther, A surface complex reaction model for the $\mathrm{pH}$-dependence of corundum and kaolinite dissolution rates, Geochim. Cosmochim. Acta, 52, 2,609-2,623, 1988.

Chang, J.S., R.A. Brost, I.S.A. Isaksen, S. Madronich, P. Middleton, W.R. Stockwell, and C.J. Walcek, A three dimensional Eulerian acid deposition model: Physical concepts and formulation. J. Geophys. Res., 92, 14,681-14,700, 1988.

Chang. L.W., E.L. Atlas, and C.S. Giam, Chromatographic separation and analysis of chlorinated hydrocarbons and phthalate esters from ambient air samples, J. Int. Environ, Anal. Chem., 19, 145-153, 1985.

Chester, R., E. Joanna, K. Murphy, A.C. Saydam, and G.B. Sanders, The atmospheric distribution of lead over a number of marine regions, Mar. Chem., 13, 57-72, 1983.

Chester, R., K.J.T. Murphy, J. Townsend, and A. Thomas, The partitioning of elements in crust dominated marine aerosols, Chem. Geol., 54, 1$15,1986$.

Church, T.M., J.M. Tramontano, J.R. Scudlark, T.D. Jickells, J.J. Tokos, Jr., and A.H. Knap, The wet deposition of trace metals to the western Atlantic ocean at the mid-Atlantic coast and on Bermuda, Atmos. Environ., 18, 2,657-2,664, 1984.

Church, T.M., R. Arimoto, L.A. Barrie, F. Dehairs, F. Dulac, T.D. Jickells, L. Mart, W.J. Sturgess, and W.H. Zoller, The long-range transport of trace elements : A critical evaluation, in The Long-Range Atmospheric Transport of Natural and Contaminant Substances, edited by A.H. Knap, pp. 37-58, Kluwer, Boston, Mass., 1990.

Church, T.M., J. Tramontano, D.M. Whelpdale, 
M.O. Andreae, J.N. Galloway, W.C. Keene, A.H. Knap, and J. Tokos,Jr., Atmospheric and precipitation chemistry over the North Atlantic: Shipboard results from April - May 1984, L. Geophys, Res, in press, 1991.

Clegg, S.L., and P. Brimblecombe, Equilibrium partial pressures of strong acids over concentrated saline solutions, I, $\mathrm{HNO}_{3}$, Atmos. Environ., 22, 91-100, 1988.

Colson, J.G., Benzene hexachloride, in Encyclopedia of Chemical Technology, edited by R.E. Kirk and D.F. Othmer, pp. 808-818 , Wiley-Interscience, New York, 1979.

Crecelius, E.A., The solubility of coal fly ash and marine aerosols in seawater, Mar. Chem., 8, 245250, 1980.

Crutzen, P.J., Biomass burning: A large factor in the photochemistry and ecology of the tropics, paper presented at Chapman Conference on Global Biomass Burning: Atmospheric, Climatic and Biospheric Implications, AGU, Williamsburg, Va., March 19-23, 1990.

Dacey, J.W.H., S.G. Wakeham, and B.L. Howes, Henry's law constants for dimethylsulfide in freshwater and seawater, Geophys. Res. Lett., 11, 991-998, 1984.

Dana, M.T. and R.C. Easter, Statistical summary and analyses of event precipitation chemistry from the MAP 3S network, 1976-1983, Atmos. Environ., 21, 113-128, 1987.

Davis, D. D., J. D. Bradshaw, M. O. Rodgers, S. T. Sandholm, and S. Kesheng, Free tropospheric and boundary layer measurements of NO over the central and eastern North Pacific Ocean, L. Geophys. Res., 22, 2,049-2,070, 1987.

Dayan, U., Climatology of back trajectories from Israel based on synoptic analysis, L. Clim. Appl. Meteorol., 25, 591-595, 1986.

de Lappe, B.W., R.W. Risebrough, and W. Walker II, A large-volume sampling assembly for the determination of synthetic organic and petroleum compounds in the dissolved and particulate phases of seawater, Can. J. Fish. Aquat. Sci., 40, suppl. 2, 322-336, 1983.

Deacon, E.L., Gas transfer to and across an airwater interface, Tellus, 29, 363-374, 1977.

Delwiche, C.C., and G.E. Likens, Biogeochemical response to fossil fuel combustion products, in Global Cycles and Their Alterations by Man, edited by W. Stumm; pp. 73-88, Abakon Verlagsgesellschaft, Berlin, 1977.

Drummond, J.W., D.H. Ehhalt, and A. Volz, Measurements of nitric oxide between 0-12 km altitude and $67^{\circ} \mathrm{N}$ to $60^{\circ} \mathrm{S}$ latitude obtained during STRATOZ III, I. Geophys. Res., 23 , 15,83115,849, 1988.

Duce, R.A., Biogeochemical cycles and the air-sea exchange of aerosols, in The Major Biogeochemical Cycles and Their Interactions, SCOPE 21 , edited by B. Bolin and R.B. Cook, pp. 427459, John Wiley, New York, 1983
Duce, R.A., The impact of atmospheric nitrogen, phosphorus, and iron species on marine biological productivity, in The Role of Air-Sea Exchange in Geochemical Cycling, edited by P. Buat-Menard, pp. 497-529, D. Reidel, Norwell, Mass., 1986.

Duce, R.A., Chemical exchange at the air-coastal sea interface, in Ocean Margin Processes in Global Change, Dahlem Workshop Report PC 9, edited by R.F.C. Mantoura, J.-M. Martin and R. Wollast, pp. 91-109, John Wiley, New York, 1991.

Duce, R.A., and R.B. Gagosian, The input of atmospheric $n-C_{10}$ to $n-C_{30}$ alkanes to the ocean, $\mathrm{L}$ Geophys. Res., 87, 7,192-7,200, 1982.

Duce, R.A., et al., Trace metals in the marine atmosphere: Sources and fluxes, in Marine Pollutant Transfer, edited by H.L. Windom and R.A. Duce, pp. 77-119, Lexington Books, Lexington, Mass., 1976.

Duce, R.A., C.K. Unni, B.J. Ray, J.M. Prospero, and J.T. Merrill, Long-range atmospheric transport of soil dust from Asia to the tropical North Pacific: Temporal variability, Science, 209, 1,522-1,524, 1980.

Duce, R.A., R. Arimoto, B.J. Ray, C.K. Unni, and P.J. Harder, Atmospheric trace elements at Enewetak Atoll, $\mathrm{J}$. Geophys. Res., 88, 5,321$5,342,1983$.

Duinker, J. C., and F. Bouchertall, On the distribution of atmospheric polychlorinated biphenyl congeners between vapor phase, aerosols, and rain, Environ. Sci. Technol., 23, 57-62, 1989.

Dulac, F., P. Buat-Menard, M. Arnold, and U. Ezat, Atmospheric input of trace metals to the western Mediterranean Sea, 1, Factors controlling the variability of atmospheric concentrations, $\mathbf{L}$. Geophys. Res., 92, 8,437-8,453, 1987.

Ehhalt, D.H., and J.W. Drummond. (1983). The tropospheric cycle of $\mathrm{NO}_{\mathbf{x}}$, in Chemistry of the Unpolluted and Polluted Troposphere, edited by H.W. Georgii and W. Jaeschke, pp. 219-251, D. Reidel, Norwell, Mass., 1983.

Ehhalt, D.H., and J.W. Drummond, $\mathrm{NO}_{\mathrm{x}}$ sources and the tropospheric distribution of $\mathrm{NO}_{\mathrm{x}}$ during STRATOZ III, in Tropospheric Ozone, Regional and Global Scale Interaction, NATO ASI Ser., 227 , edited by I.S.A. Isaksen, pp. 217-237, D. Reidel, Norwell, Mass., 1988.

Eisenreich, S., Atmospheric Pollutants in Natural Waters, 512 pp., Butterworth, Stoneham, Mass., 1981.

Eisenreich, S., B.B. Looney, and J.D. Thornton, Airborne organic contaminants in the Great Lakes ecosystem, Environ. Sci. Technol., 15, 30-38, 1981 .

Elbaz-Poulichet, F., Transferts de plomb, de cadmium, et de cuivre des continents aux oceans par les fleuves et l'atmosphère, Ph.D. thesis, Univ. Pierre et Marie Curie, Paris, France, 1988.

Eliassen, A., and J. Saltbones, Modeling of longrange transport of sulfur over Europe: A two- 
year model run and some model experiements, Atmos. Environ., 17, 1,457-1,473, 1983.

Eliassen, A., O. Hov, T. Iverson, J. Saltbones, and D. Simpson, Estimates of airborne transboundary transport of sulfur and nitrogen over Europe, EMEP/MSC-W 1/88, 79 pp., 1988.

Erickson, D.J., J.T. Merrill, and R.A. Duce, Seasonal estimates of global atmospheric sea-salt distributions, I. Geophys. Res., 21, 1,067$1,072,1986$.

FAO (Food and Agriculture Organization), EAO Production Year Book, 245 pp., Rome, 1979.

Farmer, C.T., and T.L. Wade, Relationship of ambient atmospheric hydrocarbon $\left(\mathrm{C}_{12}-\mathrm{C}_{32}\right)$ concentrations to deposition, Water, Air. and Soil Pollut., 29, 439-452, 1986.

Fendinger, N.J., and D.E. Glotfelty, A laboratory method for the experimental determination of airwater Henry's law constants for several pesticides, Environ, Sci. Technol., 22, 1,289-1,293, 1988.

Fisher, D., J. Ceraso, T. Mathew, and M. Oppenheimer. Polluted Coastal Waters: The Role of Acid Rain, 101 pp., Environmental Defense Fund Report, New York, 1988.

Fitzgerald, W.F., Cycling of mercury between the atmosphere and oceans, in The Role of Air-Sea Exchange in Geochemical Cycling, edited by $P$. Buat-Menard, pp. 363-408, D. Reidel, Norwell, Mass., 1986.

Fitzgerald, W.J.F., G.A. Gill, and A.D. Hewitt, Air-sea exchange of mercury, in Trace Metals in Seawater, edited by C.S. Wong, et al., pp. 297315, Plenum, New York, 1983.

Foreman, W.T., and T.F. Bidleman, An experimental system for investigating vapor-particle partitioning of trace organic pollutants, Environ. Sci. Technol., 21, 869-875, 1987.

Galloway, J.N., The deposition of sulfur and nitrogen from the remote atmosphere: Background paper, in Biogeochemical Cycling of Sulfur and Nitrogen in the Remote Atmosphere, edited by J.N.Galloway, et al., pp. 143-173, D. Reidel, Norwell, Mass., 1985.

Galloway, J.N., and A. Gaudry, The composition of precipitation on Amsterdam Island, Indian Ocean, Atmos. Environ., 18, 2,649-2,656, 1984.

Galloway, J.N., and D.M. Whelpdale, WATOX-86 overview and western North Atlantic Ocean $S$ and N budgets, Global Biogeochem. Cycles, 1, 261$281,1987$.

Galloway, J.N., D.M. Whelpdale, and G.T. Wolff, The flux of $\mathbf{S}$ and $\mathrm{N}$ eastward from North America, Atmos, Environ., 12, 2,595-2,607, 1984.

Galloway, J.N., W.C. Keene, R.S. Artz, J.M. Miller, T.M. Church, and A.H. Knap, Processes controlling the concentrations of $\mathrm{SO}_{4}=, \mathrm{NO}_{3}^{-}$, $\mathrm{NH}_{4}^{+}, \mathrm{H}^{+}, \mathrm{HCOO}_{\mathrm{T}}$ and $\mathrm{CH}_{3} \mathrm{COO}_{\mathrm{T}}$ in precipitation on Bermuda, Tellus, Ser. B, 41, 427-433, 1989.
Geiger, R., World Maps, The Earth's Atmosphere, nr. 5, Mean Annual Precipitation, 1: 30.000,000, Justus Perthes, Darmstadt, Germany, 1965.

Georgii, H.W., and G. Gravenhorst, The ocean as a source or sink of reactive trace gases. Pure Appl. Geophys., 115, 503-511, 1977.

GESAMP (Group of Experts on the Scientific Aspects of Marine Pollution), Land/sea boundary flux of contaminants: Contributions from rivers, Rep. Stud. GESAMP, 32, 172 pp, 1987.

GESAMP, The atmospheric input of trace species to the world ocean, Rep. Stud. GESAMP, 38, 111 pp., 1989.

Giam, C.S., R.L. Richardson, M.K. Wong, and W.M. Sackett, Polychlorinated biphenyls in Antarctic biota, Antarct. J. U.S., 8, 303-305, 1974.

Gill, G.A., and W.F. Fitzgerald, Mercury in surface waters of the open ocean, Global Biogeochem. Cycles, 1, 199-212, 1987.

Gorzelska, K., and J.N. Galloway, Amine nitrogen in the atmospheric environment over the North Atlantic Ocean, Global Biogeochem. Cycles, 4, 309-334, 1990.

Graedel, T.E., C.J. Weschler, and M.L. Mandich, Influence of transition metal complexes on atmospheric droplet acidity, Nature, 317, 240-242, 1985.

Graham, W.F., and R.A. Duce, The atmospheric transport of phosphorus to the western North Atlantic, Atmos. Environ., 16, 1089-1097, 1982.

Gras, J. L., Ammonia and ammonium concentrations in the Antarctic atmosphere, Atmos. Environ., 17, 815-818, 1983.

Guicherit, R., and F.L. Schulting, The occurrence of organic chemicals in the atmosphere of the Netherlands, Sci. Total Environ., 43, 193-195, 1985.

Halter, B.C., Carbon dioxide and meteorology at Samoa, in Geophysical Monitoring for Climatic Change, Vol. 12, Summary Report 1983, edited by J. M. Harris and E. J. Nickerson, pp. 88-92, NOAA Air Resources Laboratory, Boulder, Colo., 1984.

Hameed, S., and J. Dignon, Changes in the geographical distributions of global emissions of $\mathrm{NO}_{\mathbf{x}}$ and $\mathrm{SO}_{\mathrm{x}}$ from fossil-fuel combustion between 1966 and 1980, Atmos. Environ., 22, 441-449, 1988.

Hargrave, B.T., W.P. Vas, P.E. Erickson, and B.R: Fowler, Supply of atmospheric organochlorines to food-webs in the Arctic Ocean. paper presented at Sixth International Symposium of the Commission on Atmospheric Chemistry and Global Pollution on Global Atmospheric Chemistry, International Association of Meteorology and Atmospheric Physics, Peterborough, Canada, Aug. 23-29, 1987.

Hartman, M.C., The total deposition of $\mathrm{Pb}, \mathrm{Cd}, \mathrm{Zn}$, ${ }^{210} \mathrm{~Pb}$ and atmospheric transport to the western Atlantic using 222-Rn and air mass trajectory 
analysis, M.S. Thesis, $123 \mathrm{pp}$., Univ. of Delaware, Newark, 1987.

Harvey, G.R., and W.G. Steinhauer, Atmospheric transport of polychlorobiphenyls to the North Atlantic, Atmos. Environ., 8, 777-782, 1974.

Hasse, L., Introductory meteorology and fluid dynamics, in Air-Sea Exchange of Gases and Particles, edited by P.S. Liss and W.G.N. Slinn, pp. 1-52, D. Reidel, Norwell, Mass., 1983.

Hastie, D.R., H.I. Schiff, D.M. Whelpdale, R.E. Peterson, W.H. Zoller, and D.L. Anderson, Nitrogen and sulphur over the western Atlantic Ocean, Atmos. Environ., 22, 2,381-2,391, 1988.

Herron, M.M., Impurity sources of $\mathrm{F}^{-}, \mathrm{Cl}^{-}, \mathrm{NO}_{3}^{-}$, and $\mathrm{SO}_{4}=$ in Greenland and Antarctic precipitation, J. Geophys. Res., 87, 3,052-3,060, 1982.

Hicks, B.B., and R.M. Williams, Transfer and deposition of particles to water surfaces, in Atmospheric Sulfur Deposition, edited by D.S. Shriner, C.R. Richmond, and S.E. Lindberg, pp. 237-244, Butterworth, Stoneham, Mass., 1980.

Hicks, B.B., M.L. Wesely, S.E. Lindberg, and S.M. Bromberg (Eds.), Proceedings of the NAPAP Workshop on Dry Deposition, 77 pp., Mar. 25-27, Harpers Ferry, W.Va., 1986.

Hodge, V., S.R. Johnson, and E.D. Goldberg, Influence of atmospherically transported aerosols on surface ocean water composition, Geochem. J., $12,7-20,1978$.

Hoff, R.M. and K.W. Chan, Atmospheric concentrations of chlordane at Mould Bay, N.W.T., Canada, Chemosphere, 15, 449-452, 1986.

Huebert, B.J., Nitric acid and aerosol nitrate measurements in the equatorial Pacific region, Geophys. Res. Lett., 7, 325-328, 1980.

Huebert, B.J., and A.L. Lazrus, Tropospheric gasphase and particulate nitrate measurements, $\mathbf{J}$. Geophys. Res., 85, 7,322-7,328, 1980a.

Huebert, B.J. and A.L. Lazrus, Bulk composition of aerosols in the remote troposphere, J.Geophys.

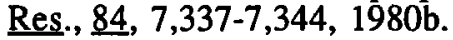

Hunter-Smith, R.J., P.W. Balls, and P.S. Liss, Henry's law constants and the air-sea exchange of various low molecular weight halocarbon gases, Tellus, Ser. B., 35, 170-176, 1983.

Jaeger, L., Monthly and areal patterns of mean global precipitation, in Variations in the Global Water Budget, edited by A. Street-Perrot, M. Beran, and R. Ratcliffe, pp. 129-140, D. Reidel, Norwell, Mass., 1983.

Jaehne, B., Zur parameterisierung des Gasaustausches mit Hilfe von Laborexperimenten, Ph.D. thesis, Univ. of Heidelberg, Heidelberg, Germany, 1980.

Jickells, T.D., A.H. Knap, and T.M. Church, Trace metals in Bermuda rainwater, J. Geophys. Res., 89, 1,423-1,428, 1984.

Jickells, T.D., T.M. Church, and W.G. Deuser, A comparison of atmospheric inputs and deep-ocean particle fluxes for the Sargasso Sea, Global Biogechem. Cycles, 1, 117-130, 1987.

Kawano, M., S. Tanabe, T. Inoue, and R. Tatsukawa, Chlordane compounds found in the marine atmosphere from the southern hemisphere, Trans. Tokyo Univ. Fish., 6, 59-66, 1985.

Kemp, K., Multivariate analysis of elements and $\mathrm{SO}_{2}$ measured at Danish EMEP stations, Tech. Rep. MST LUFT - A88, of Air Pollution Lab., Danish National Agency of Environmental Prot., Copenhagen, 1984.

Knap, A.H., K. Binkley, and W. Deuser, The flux of synthetic organic chemicals to the deep Sargasso Sea, Nature, 319, 572-574, 1986.

Knap, A.H., K. Binkley, and R. Artz, The occurrence and distribution of trace organic compounds in Bermuda precipitation. Atmos. Environ., 22, 1,411-1,423, 1988.

Knuth, R.H., E.O. Knutson, H.W. Feely, and H.L. Volchok, Size distribution of atmospheric $\mathrm{Pb}$ and $\mathrm{Pb}-210$ in rural New Jersey: Implications for wet and dry deposition, in Precipitation Scavenging. Dry Deposition and Resuspension, edited by H.R. Pruppacher, R.G. Semonin, and W.G.N. Slinn, pp 1,325-1,334, Elsevier, New York, 1983.

Lambert, G., G. Polian, J. Sanok, B. Ardouin, A. Buisson, A. Jegou, and J.C. LeRoulley, Cycle du radon et de ses dscendants: Application a l'etude des echanges troposphere -stratosphere, Ann. Geophys., 38, 477-531, 1983.

Levy, H., and W.J. Moxim, Examining the global impact of local/regional air pollution: The role of global transport chemistry models, paper presented at the 17th NATO/CCMS Meeting on Air Pollution Modeling, 1988.

Levy, H., and W.J. Moxim, Simulated global distribution and deposition of reactive nitrogen emitted by fossil fuel combustion, Tellus, Ser. B., 41, 256-271, 1989.

Ligocki, M.P., C. Leuenberger, and J.F. Pankow, Trace organic compounds in rain, II, Gas scavenging of neutral organic compounds, Atmos. Environ., 19, 1,609-1,617, 1985a.

Ligocki, M.P., C.L. Lewenberger, and J.F. Pankow, Trace organic compounds in rain, III, Particle scavenging of neutral organic compounds, Atmos. Environ., 19, 1,619-1,626, 1985b.

Lincoff, A.H. and J.M. Gossett, The determination of Henry's constant for volatile organics by equilibrium partitioning in closed systems, in Gas Transfer at Water Surfaces, edited by W. Brutsaert and G. Jirka, pp. 17-26, D. Reidel, Norwell, Mass., 1984.

Lindberg, S.E., and R.C. Harriss, Water and acid soluble trace metals in atmospheric particles, $J$. Geophys. Res., 88, 5,091-5,100, 1983.

Lindquist, O., Atmospheric mercury--A review, Tellus, Ser. B., 37, 136-159, 1985.

Liss, P.S., and L. Merlivat, Air-sea exchange rates: 
introduction and synthesis, in The Role of Air-Sea Exchange in Geochemical Cycling, edited by $P$. Buat-Menard, pp. 113-127, D Reidel, Norwell, Mass., 1986.

Liu, S.C., M. McFarland, D. Kley, O. Zafiriou, and B. Huebert, Tropospheric $\mathrm{NO}_{x}$ and $\mathrm{O}_{3}$ budgets in the equatorial Pacific, J. Geophys. Res., $\underline{88}$, 1,360-1,368, 1983.

Livingston, D.A., Chemical composition of rivers and lakes, in Data of Geochemistry, 6th ed., edited by M. Fleischer, U.S. Geological Sur. Prof. Paper 440-G, 61 pp., 1963.

Logan, J.A., Nitrogen oxides in the troposphere: Global and regional budgets, I. Geophys. Res., 88, 10,785-10,807, 1983.

Logan, J.A., M.J. Prather, S.C. Wofsy and M.B. McElroy, Tropospheric chemistry: A global perspective, J. Geophys. Res., 86, 7,210-7,254, 1981.

Losno, R., G. Bergametti, and P. Buat-Menard, The partitioning of zinc in Mediterranean rainwater, Geophys. Res. Lett., 15, 1,389-1,392, 1988.

Luke, W.T., and R.R. Dickerson, The flux of reactive nitrogen compounds from eastern North America to the western Atlantic Ocean, Global Biogeochem. Cycles, 1, 329-343, 1987.

Mackay, D., and W.Y. Shiu, Physical-chemical phenomena and molecular properties in Gas Transfer at Water Surfaces, edited by S.J. Brutsaert, and G.H. Jirka, pp. 3-16, D. Reidel, Norwell, Mass., 1984.

Mackay, D., and A.T.K. Yuen, Transfer rates of gaseous pollutants between the atmosphere and natural waters, in Atmospheric Pollutants in Natural Waters, edited by S.J. Eisenreich, pp. 5565, Butterworth, Stoneham, Mass., 1981.

Maring, H.B., and R.A. Duce, The impact of atmospheric aerosols on trace metal chemistry in open ocean surface seawater, I, Aluminum, Earth Planet. Sci. Lett., 84, 381-392, 1987.

Maring, H.B., and R.A. Duce, The impact of atmospheric aerosols on trace metal chemistry in open ocean surface seawater, II, Copper, J. Geophys. Res., 94, 1,039-1,045, 1989.

Maring, H.B., and R.A. Duce, The impact of atmospheric aerosols on trace metal chemistry in open ocean surface seawater, III, Lead, J. Geophys. Res., 95, 5,341-5,347, 1990.

Maring, H., D.M. Settle, P. Buat-Menard, F. Dulac, and C.C. Patterson, Stable lead isotope tracers of air mass trajectories in the Mediterranean region, Nature, 330, 154-156, 1987.

Maring, H., C. Patterson, and D. Settle, Atmospheric input fluxes of industrial and natural $\mathrm{Pb}$ from the Westerlies to the mid-North Pacific, in Chemical Oceanography, vol. 10, edited by J.P. Riley, R. Chester, and R.A. Duce, pp. 84-106, Academic, San Diego, Calif., 1989.

Martin, D., C. Mithieux, and B. Strauss, On the use of the synoptic vertical wind component in a transport trajectory model, Atmos. Environ., 21, 45-52, 1987.

Martin, J.H., and R.M. Gordon, Northeast Pacific iron distributions in relation to phytoplankton productivity, Deep Sea Res., 35, 177-196, 1988.

Martin, J.H., and S.E. Fitzwater, Iron deficiency limits phytoplankton growth in the north-east Pacific subarctic, Nature. 331, 341-343, 1988.

Masclet, P., P. Pistikopoulos, S. Beyne, and G. Mouvier, Long-range transport and gas/particle distribution of polycyclic aromatic hydrocarbons at a remote site in the Mediterranean Sea, Atmos. Environ., 22, 639-650, 1988.

McVeety, B.D., and R.A. Hites, Atmospheric deposition of polycyclic aromatic hydrocarbons to water surfaces: A mass balance approach, Atmos. Environ., 22, 511-536, 1988.

Merrill, J.T., Atmospheric pathways to the oceans, in The Role of Air-Sea Exchange in Geochemical Cycling, edited by P.Buat-Menard, pp. 35-63, D. Reidel, Norwell, Mass., 1986.

Merrill, J.T., R. Bleck, and M. Uematsu, Meteorological analysis of long range transport of mineral aerosols over the Pacific, L. Geophys. Res., 94, 8,584-8,598, 1989.

Meserve, J.M., The U.S. Navy Marine Climatic Atlas of the World, Naval Weather Service Detachment and National Climatic Center, Asheville, N. C., 1977.

Meybeck, M., Carbon, nitrogen and phosphorous transport by world rivers, Am. J. Sci., 282, 401$450,1982$.

Miller, J.M., The use of back air trajectories in interpreting atmospheric chemistry data: A review and bibliography, NOAA Tech. Memo. ERL ARL155, 28 pp., Air Resour. Lab., Silver Spring, Md., 1987.

Miller, J.M., D. Martin, and B. Strauss, A comparison of results from two trajectory models used to produce flow climatologies to the western Mediterranean, NOAA Tech. Memo. ERL ARL151, 11 pp., Air Resour. Lab., Silver Spring, Md., 1987.

Misanchuk, B.A., D.R. Hastie, and H.I. Schiff. The distribution of nitrogen oxides off the east coast of North America, Global Biogeochem. Cycles, 1, 345-355, 1987.

Moore, R.M., J.E. Milley, and A. Chatt, The potential for biological mobilization of trace elements from aeolian dust in the ocean and its importance in the case of iron, Oceanol. Acta, 7, 221-228, 1984.

Mopper, K., and R.G. Zika, Free amino acids in marine rains: Evidence for oxidation and potential role in nitrogen cycling. Nature, $\underline{325}, 246-249$, 1987.

Murphy, T.J., A. Schinsky, G. Paolucci, and G. Rzeszutko, Inputs of polychlorinated biphenyls 
from the atmosphere to lakes Huron and Michigan, in Atmospheric Pollutants in Natural Waters, edited by S.J. Eisenreich, pp. 445-458, Butterworth, Stoneham, Mass., 1981.

Murphy, T. J., M. D. Mullin, and J. A. Meyer, Equilibration of polychlorinated biphenyls and toxaphene with air and water. Environ. Sci. Technol., 21, 155-162, 1987.

National Atmospheric Deposition Program (NADP), NADP/National Trends Network annual data summary: Precipitation chemistry in the United States for 1984, NADP/NTN Coord. Off., Natl. Resource Ecol. Lab., Colo. State Univ., Fort Collins, 1986.

NADP, NADP/National Trends Network annual data summary: Precipitation chemistry in the United States for 1985, NADP/NTN Coord. Off., Natl. Resource Ecol. Lab., Colo. State Univ., Fort Collins, 1987a.

NADP, NADP/National Trends Network annual data summary: Precipitation chemistry in the United States for 1986, 363 pp., NADP/NTN Coord. Off., Natl. Resource Ecol. Lab., Colo. State Univ,, Fort Collins, 1987b.

Nagamoto, C, B. Kopceqicz, M. Zhou and F. Parungo, Wet and dry deposition of atmospheric aerosols to the ocean, paper presented at Symposium on the Role of the Oceans as a Source and Sink of Trace Substances That Influence Global Change, Amer. Meteorol. Soc., Anaheim, Calif., Feb. 1990.

National Academy of Sciences (NAS), The Tropospheric Transport of Pollutants and Other Substances to the Oceans, 243 pp., National Academy Press, Washington, D. C., 1978.

NAS, Global Tropospheric Chemistry: A Plan for Action, 194 pp., National Academy Press, Washington, D. C., 1984.

Nriagu, J.O., Natural sources of trace metals in the atmosphere: Global assessment, Nature. 338, 4749, 1988.

Nriagu, J.O., and J.M. Pacyna, Quantitative assessment of worldwide contamination of air, water and soils by trace metals, Nature, 333, 134139, 1988.

Oehme, M., and H. Stray, Quantitative determination of ultra-traces of chlorinated compounds in highvolume air samples from the Arctic using polyurethane foam as collection medium, Fresenius Z. Anal. Chem., 311, 665-673, 1982.

Ohta, K., and N. Handa, Organic components in size-separated aerosols from the Western North Pacific, J. Oceanogr. Soc. Jpn., 41, 25-32, 1985.

Olsson, M., and L. Reutergardh, DDT and PCB pollution trends in the Swedish aquatic environment, Ambio, 15, 101-107, 1986.

Oort, A.H., Global atmospheric circulation statistics, 1958-1973, NOAA Prof. Pap. 14, National
Oceanic and Atmos. Admin., Washington, D. C., 1983.

Pacyna, J.M., and M. Oehme, Long-range transport of some organic compounds to the Norwegian arctic, Atmos. Environ., 22, 243-257, 1988.

Pankow, J.F., Review and comparative analysis of the theories on partitioning between the gas and aerosol particulate phases in the atmosphere, Atmos. Environ., 21, 2,275-2,283, 1987.

Parungo, F., and J. Miller, Air chemistry studies over the Gulf of Mexico, NOAA Tech. Memo. ERL ESG-29, 254 pp., Environ. Res. Lab., Boulder, Colo., 1988.

Parungo, F.P., C.T. Nagamoto, J. Rosinski and P.L. Haagenson, A study of marine aerosols over the Pacific Ocean, J. Atmos.Chem., 4, 199-226, 1986.

Patterson, C.C., and D.M. Settle, Review of data on eolian fluxes of industrial and natural lead to the lands and seas in remote regions on a global scale, Mar. Chem., 22, 137-162, 1987.

Patterson, T.L., The cycle of atmospheric cadmium in the remote North Pacific, Ph.D. thesis, Univ. of R. I., Kingston, 1988.

Patton, G.W., D.A. Hinckley, M.D. Walla, T.F. Bidleman, and B.T. Hargrave, Airborne organochlorines in the Canadian high Arctic, Tellus. Ser. B., 41, 243-255, 1989.

Penner, J.E., C.S. Atherton, J. Dignon, S.J. Ghan, J.J. Walton and S. Hameed, Tropospheric nitrogen: A three-dimensional study of sources, distributions and deposition, J.Geophys. Res., 26, 959-990, 1991.

Petersen, G., H. Weber, and H. Grassl, Modeling the atmospheric transport of trace metals from Europe to the North Sea and Baltic Sea, paper presented at NATO Workshop on Control and Fate of Atmospheric Heavy Metals, Oslo, Norway, Sept. 12-16, 1988.

Prospero, J.M., Mineral and sea salt aerosol concentration in various ocean regions, J. Geophys. Res., 84, 725-731, 1979.

Prospero, J.M., Aeolian transport to the world ocean, in The Sea, vol. 7, The Oceanic Lithosphere., edited by C. Emiliani, pp. 801874, Wiley Interscience, New York, 1981.

Prospero, J.M., Mineral aerosol transport to the North Atlantic and North Pacific: The impact of African and Asian sources, in The Long-Range Atmospheric Transport of Natural and Contaminant Substances. edited by A.H. Knap, 59-86, Kluwer, Boston, Mass., 1990.

Prospero, J. M., and D. L. Savoie, Effect of continental sources on nitrate concentrations over the Pacific Ocean, Nature, 339, 687-689, 1989.

Prospero, J.M., D.L. Savoie, R.T. Nees, R.A. Duce, and J. Merrill, Particulate sulfate and nitrate in the boundary layer over the North Pacific 
Ocean, J. Geophys. Res., 90, 10,586-10,596, 1985.

Prospero, J.M., R.T. Nees, and M. Uematsu, Deposition rate of particulate and dissolved aluminum derived from Saharan dust in precipitation at Miami, Florida. J. Geophys. Res., 92, 14,723-14,731, 1987.

Prospero, J.M., M. Uematsu, and D.L. Savoie, Mineral aerosol transport to the Pacific Ocean, in Chemical Oceanography, vol. 10, edited by J.P. Riley, R. Chester, and R.A. Duce, pp. 188-218, Academic, San Diego, Calif., 1989.

Pszenny, A.A.P., Atmospheric deposition of nitrate to the ocean surface, Ph.D. thesis, Univ. of R. I., Kingston, 1987.

Quinn, P.K., R.J. Charlson, and W.H. Zoller, Ammonia, the dominant base in the remote marine troposphere: a review, Tellus, Ser. B., 39, 413425, 1997.

Quinn, P.K., R.J. Charlson, and T.S. Bates, Simultaneous observations of ammonia in the atmosphere and ocean, Nature, 335, 336-338, 1988.

Quinn, P.K., T.S. Bates, J.E. Johnson, D.S. Covert and R.J. Charlson, Interactions between the sulfur and reduced nitrogen cycles over the central Pacific Ocean, J. Geophys. Res., 95, $16,405-16,416,1990$.

Rahn, K.,The chemical composition of the atmospheric aerosol, technical report, Grad. Sch. of Oceanogr., Univ. R. I., Kingston, 265 pp, 1976.

Rapaport, R.A., and S.J. Eisenreich, Historical atmospheric inputs of high molecular weight chlorinated hydrocarbons to eastern North America, Environ. Sci. Technol., 22, 931-941, 1988.

Rapaport, R.A., N.R. Urban, P.D. Capel, J.E. Baker, B.B. Looney, S.J. Eisenreich, and E. Gorham, "New" DDT inputs to North America: Atmospheric deposition, Chemosphere, 14 , 1,167-1,173, 1985.

Ray, P.K., A.K. Prasad, and R. Nandan, Pesticides - Major environmental problem, Sci. Cult., 51, 363-371, 1985.

Reinhardt, K.H., and D. Wodarg, Transport of organochlorine compounds, in Proceedings of the NATO Advanced Workshop, Humidity Exchange Over the Sea, Main Experiment (HEXMAX) Analysis and Interpretation, technical report, Dep. of Atmos. Sci., Univ. of Wash., Seattle, 1988a.

Reinhardt, K.H., and D. Wodarg, Transport of selected organochlorine compounds over the sea, $\mathbf{J}$. Aerosol Sci., 19, 1,251-1,255, 1988b.

Rice, C.P., P.J. Samson, and G.R. Noguchi, Atmospheric transport of toxaphene to Lake Michigan, Environ. Sci. Technol., 20, 1,109$1,116,1986$.

Ridley, B.A., et al., Ratios of peroxyacetyl nitrate to active nitrogen observed during aircraft flights over the eastern Pacific Ocean and continental United States, J. Geophys. Res., 25, 10,17910,192, 1990.

Ridley, B.A., M.A. Carroll and G.L. Gregory, Measurements of nitric oxide in the boundary layer and free troposphere over the Pacific Ocean, J. Geophys. Res., 22, 2,025-2,047, 1987.

Risbo, T., H.B. Clausen, and K.L. Rasmussen, Supernovae and nitrate in the Greenland ice sheet. Nature, 294, 637-639, 1981.

Risebrough, R.W., and G.M. Carmignani, Chlorinated hydrocarbons in Antarctic birds, in Proceedings of the Colloquium. Conservation Problems in Antarctica, edited by B.C. Parker, pp. 63-78, Allen Press, Lawrence, Kansas, 1972.

Rodhe, H., The transport of sulfur and nitrogen through the remote atmosphere, in The Biogeochemical Cycling of Sulfur and Nitrogen in the Remote Atmosphere, edited by J.N. Galloway, et al., pp. 105-124, D. Reidel, Norwell, Mass., 1985.

Roether, W., Field measurements of gas exchange, in Dynamic Processes in the Chemistry of the Upper Ocean, edited by J.D. Burton, P.G. Brewer, and R. Chesselet, 117-128, Plenum, New York, 1986.

Rudolph, J., B. Vierkorn-Rudolph, and F.X. Meixner, Large-scale distribution of peroxyacetyl nitrate results from the STRATOZ III flights, J Geophys. Res., 92, 6,653-6,661, 1987.

Ryaboshapko, A.G., V.I. Lepeskin, E.D. Podgurskaya, and V.I. Medinets, Air pollution monitoring over the North Atlantic, in Proceedings of the International Symposium on Integrated Global Monitoring of the State of the Biosphere, 2, WMO/TD151, pp. 261-282, World Meteorol. Organ., Geneva, 1986.

Savoie, D., Nitrate and non-sea-salt sulfate aerosols over major regions of the world ocean: Concentration, sources, and fluxes, Ph.D. thesis, Univ. of Miami, Coral Gables, Fla., 1984.

Savoie, D.L., and J.M. Prospero, Particle size distribution of nitrate and sulfate in the marine atmosphere, Geophys. Res. Lett., 9, 1,207-1,210, 1982.

Savoie, D.L., and J.M. Prospero, Nitrate and nonseasalt sulfate concentrations at Bermuda, paper presented at the WATOX workshop, Bermuda Biological Station for Research, Ferry Reach, Bermuda, 1983.

Savoie, D. L., J.M. Prospero, and R.T. Nees, Nitrate, non-seasalt sulfate, and mineral aerosol over the northwestern Indian Ocean, J.Geophys. Res., 92, 933-942, 1984

Savoie, D.L., J.M. Prospero, J.T. Merrill, and M. Uematsu, Nitrate in the atmospheric boundary layer of the tropical South Pacific: Implications re- 
garding sources and transport, J. Atmos. Chem., $\underline{8}, 391-415,1989$ a.

Savoie, D. L., J.M. Prospero, and E.S. Saltzman, Nitrate, non-seasalt sulfate, and methanesulfonate over the Pacific Ocean, in Chemical Oceanography, vol. 10, edited by J.P. Riley, R. Chester, and R.A. Duce, pp. 220-250, Academic, San Diego, Calif., $1989 \mathrm{~b}$.

Schaug, J., J.E. Hansen, K. Nodop, B. Ottar, and J.M. Pacyna, Co-operative program-me on monitoring and evaluation of the long range transmission of air pollutants in Europe (EMEP), summary report Chem. Coord. Cent. for the Third Phase of EMEP, 1987.

Schneider, J.K., R.B. Gagosian, J.K. Cochran, and T.W. Trull, Particle size distributions of n-alkanes and $210 \mathrm{~Pb}$ in aerosols off the coast of Peru, Nature, 304, 429-432, 1983.

Scudlark, J.R., and T.M. Church, The atmospheric deposition of arsenic and association with acid deposition, Atmos. Environ., 22, 937-963, 1988.

Seiler, W., and P.J. Crutzen, Estimates of gross and net fluxes of carbon between the biosphere and the atmosphere from biomass burning, Clim. Change, 2, 207-247, 1980.

Sericano, J.L., E.L. Atlas, T.L. Wade, and J.M. Brooks, NOAA's Status and Trends Mussel Watch Program: Chlorinated pesticides and PCBs in oysters (Crassostrea virginica) and sediments from the Gulf of Mexico, 1986-1987, Mar. Environ. Res., 19, 161-203, 1990.

Settle, D.M., and C.C. Patterson, Magnitudes and sources of precipitation and dry deposition fluxes of industrial and natural leads to the North Pacific at Enewetak, J. Geophys. Res., 87, 8,857-8,869, 1982.

Settle, D.M., C.C. Patterson, K.K. Turekian, and J.K. Cochran, Lead precipitation fluxes at tropical oceanic sites determined from ${ }^{210} \mathrm{~Pb}$ measurements, J. Geophys. Res., 87, 1,239-1,245, 1982.

Shen, G.T., and E.A. Boyle, Lead in corals: Reconstruction of historic industrial fluxes to the surface of the ocean, Earth Planet. Sci. Lett., $\underline{326}$, 278-280, 1987.

Sicre, M.A., J.C. Marty, A. Saliot, X. Aparicio, J. Grimalt, and J. Albaiges, Aliphatic and aromatic hydrocarbons in the different sized aerosols over the Mediterranean Sea: Occurrence and origin, Atmos. Environ., 12, 2,247-2,259, 1987.

Singh, H.B., L.J. Salas, and W. Viezee, Global distribution of peroxyacetyl nitrate, Nature, 321, 588-591, 1986.

Singh, H.B., et al., Peroxyacetyl nitrate measurements during CITE 2: Atmospheric distribution and precursor relationships, J. Geophys. Res., 95. 10,163-10,178, 1990.

Slater, R.M., and D.J. Spedding, Transport of dieldrin between air and water, Arch. Environ. Contam. Toxicol., 10, 25-30, 1981.
Slinn, S.A., and W.G.N. Slinn, Predictions for particle deposition on natural waters, Atmos. Environ., 14, 1,013-1,016, 1980.

Slinn, W.G.N., L. Hasse, B.B. Hicks, A.W. Hogan, D. Lal, P.S. Liss, K.O. Munnich, G.A. Sehmel, and O. Vittori, Some aspects of the transfer of atmospheric trace constituents past the airsea interface, Atmos. Environ., 12, 2,055-2,087, 1978.

Slutz, R., S.J. Lubker, J.D. Hiscox, S.D. Woodruff, R.L. Jenne, D.H. Joseph, P.M. Steurer, and J.D. Elms, Comprehensive oceanatmosphere data set, Release 1, Clim. Res. Program, Environ. Res. Lab., Natl. Atmos. and Oceanic Admin., Boulder, Colo., 1985.

Smith, J.H., D.C. Bomberger, Jr., and D.L. Haynes, Volatilization rates of intermediate and low volatility chemicals from water, Chemosphere, 10, 281-289, 1981.

Soderlund R., and B.H. Svensson, The global nitrogen cycle, in Nitrogen, Phosphorus and Sulfur-Global Cycles, SCOPE 7. Ecol. Bull. Swedish National Science Research Council, Stockholm, edited by B.H. Svensson and R. Soderlund, pp. 22-74, 1976.

Sovocool, G.W., R.G. Lewis, R.L. Harless, N.K. Wilson, and R.D. Zehr, Analysis of technical chlordane by gas chromatography/mass spectrometry, Anal. Chem., 49, 734-740, 1977.

Statham, P.J., and R. Chester, Dissolution in sea and rainwater of manganese in atmospheric particulates, Geochim. Cosmochim. Acta, 51, 2,433$2,437,1988$.

Stedman, D.H., and R.E. Shetter, The global budget of atmospheric nitrogen species, in Trace Atmospheric Constituents. Properties. Transformations, and Fates, edited by S.E. Schwartz, pp. 411-454, John Wiley, New York, 1983.

Subramanian, A., S. Tanabe, Y. Fujise, and R. Tatsukawa, Organochlorine residues in Dall's and True's porpoises collected from northwestern Pacific and adjacent waters, Mem. Natl. Inst. Polar Res. 44, Spec. Issue, 167-173, 1986.

Subramanian, A., S. Tanabe, H. Tanaka, $H$. Hidaka, and R. Tatsukawa, Gain and loss rates and biological half-life of PCBs and DDE in the bodies of Adelie penguins, Environ. Pollut., 43, 39-46, 1987.

Suntio, L.R., W.Y. Shiu, D. Mackay, J.N. Seiber, and D. Glotfelty, A critical review of Henry's law constants for pesticides, Rev. Environ. Contam. Toxicol., 103, 1-59, 1987.

Swackhamer, D.L., and D.E. Armstrong, Estimation of the atmospheric and non-atmospheric contributions and losses of polychlorinated biphenyls for Lake Michigan on the basis of sediment records of remote lakes, Environ. Sci. Technol., 20, 879 883, 1986.

Talbot, R.W., R.C. Harriss, E.V. Browell, G.L. Gregory, D.I. Sebacher and S.M. Beck, Distribution and geochemistry of aerosols in the 
tropical North Atlantic troposphere: Relationship to Saharan dust, J. Geophys. Res., 91, 5,1735,182, 1986.

Talbot, R.W., A.S. Vijgen and R.C. Harriss, Measuring tropospheric $\mathrm{HNO}_{3}$ : Problems and prospects for nylon filter and mist chamber techniques, J. Geophys. Res., 25, 7,553-7,561, 1990.

Tanabe, S., PCB problems in future: Foresight from current knowledge, Environ. Pollut., 50, 5-28, 1988.

Tanabe, S., and R. Tatsukawa, Chlorinated hydrocarbons in the North Pacific and Indian oceans, $\mathrm{J}$ Oceanogr. Soc. Jpn., 36, 217-226, 1980.

Tanabe, S., and R. Tatsukawa, Chlorinated hydrocarbons in the southern ocean, in Mem, of Natl. Inst. of Polar Res. Spec. Issue Jpn., 27 Proceedings of BIOMASS Colloquium in 1982, pp. 64-76, 1983.

Tanabe, S., and R. Tatsukawa, Distribution, behavior, and load of PCB's in the oceans, in PCB's and the Environment, Vol. I. edited by J.S. Waid, CRC Press, Boca Raton, Fla., 1986.

Tanabe, S., M. Kawano, and R. Tatsukawa, Chlorinated hydrocarbons in the Antarctic, western Pacific and eastern Indian oceans, Trans. Tokyo Univ. Fish., 5, 97-109, 1982a,

Tanabe, S., R. Tatsukawa, M. Kawano, and H. Hidaka, Global distribution and atmospheric transport of chlorinated hydrocarbons: $\mathrm{HCH}$ (BHC) isomers and DDT compounds in the western Pacific, eastern Indian and Antarctic oceans, J. Oceanogr. Soc. Jpn., 38, 137-148, 1982 b.

Tanabe, S., H. Hidaka, and R. Tatsukawa, PCBs and chlorinated hydrocarbon pesticides in antarctic atmosphere and hydrosphere, Chemosphere, 12, 277-288, 1983a.

Tanabe, S., T. Mori, R. Tatsukawa, and N. Miyazaki, Global pollution of marine mammals by PCB's, DDT's, and HCH's (BHCs), Chemosphere, 12, 1,269-1,275, 1983b.

Tateya, S., S. Tanabe, and R. Tatsukawa, PCBs on the globe: possible trend of future levels in the open ocean environment, in Toxic Contaminants in Large Lakes, vol. 3, edited by N.W. Schmidke, pp. 237-281, Lewis, Chelsea, Mich, 1988.

Tatsukawa, R., and S. Tanabem, Fate and bioaccumulation of persistent organochlorine compounds in the marine environment, in Oceanic Processes in Marine Pollution, edited by D.J. Baumgartner and I.W. Duedall, pp. 39-52, Krieger, Malibar, Fla., 1990.

Taylor, G.S., M.B. Baker, and R.J. Charlson, Heteorgeneous interactions of the $\mathbf{C}, \mathrm{N}$, and $S$ cycles in the atmosphere: The role of aerosols and clouds, in The Maior Biogeochemical Cycles and Their Interactions, SCOPE 21, edited by B. Bolin and R. B. Cook, pp. 115-142, John Wiley, New York, 1983.
Taylor, S.R., and S.M. McLennan, The Continental Crust: Its Composition and Evolution, $312 \mathrm{pp}$., Blackwells, Oxford, England, 1985.

Tsunogai, S., and T. Kondo, Sporadic transport and deposition of continental aerosols to the Pacific Ocean, J. Geophys. Res., 87, 8,870-8,874, 1982.

Tsunogai, S., T. Suzuki, T. Kurata, and M. Uematsu, Seasonal and areal variation of continental aerosol in the surface air over the western North Pacific region, J. Oceanogr. Soc. Jpn., 41, 427-434, 1985.

Tsunogai, S., T. Kurata, T. Suzuki, and K. Yokota, Seasonal variation of atmospheric ${ }^{210} \mathrm{~Pb}$ and $\mathrm{Al}$ in the western North Pacific, J.Atmos. Chem., 1, 389-407, 1988.

Turekian, K.K., Y. Nozaki, and L.K. Bennington, Geochemistry of atmospheric radon products, Annu. Rev. Earth Planet. Sci., 5, 227-255, 1977.

Turekian, K.K., L.K. Benninger, and E.P. Dion, ${ }^{7} \mathrm{Be}$ and ${ }^{210} \mathrm{~Pb}$ total deposition fluxes at New Haven, Connecticut, and at Bermuda, $\mathrm{J}$. Geophys. Res., 88, 5,411-5,415, $198 \overline{3}$.

Turekian, K.K., W.C. Graustein, and J.K. Cochran, Lead-210 in the SEAREX Program: An aerosol tracer across the Pacific, in Chemical Oceanography, vol. 10, edited by J.P. Riley, R. Chester, and R.A. Duce, 51-81, Academic, San Diego, Calif., 1989.

Unified Deposition Data Base Committee (UDDBC), $A$ unified wet deposition data base for eastem North America: Addendum with results for sulfates and nitrates (1980-1983), $406 \mathrm{pp}$., Ontario Ministry of the Environment, Toronto, Ont., Canada, 1986.

Uematsu, M., R.A. Duce, J.M. Prospero, L. Chen, J.T. Merrill, and R.L. McDonald, Transport of mineral aerosol from Asia over the North Pacific Ocean, J. Geophys. Res., 88, 5,343-5,332, 1983.

Uematsu, M., R.A. Duce, and J.M. Prospero, Deposition of atmospheric mineral particles in the North Pacific Ocean, J.Atmos. Chem., 3, 123138. 1985.

Van Bennekom, A.J., and W. Salomons, Pathways of organic nutrients and organic matter from land to ocean through rivers, in River Input to the Ocean Svstem edited by J.D. Burton, D. Eisma, and J.M. Martin, pp. 33-51, UNESCO-UNEP, SCOR Workshop, Rome 1979, 1981.

Van Neste, A., R.A. Duce, and C. Lee, Methylamines in the marine atmosphere, Geophys. Res. Lett., 14, 711-714, 1987.

Veron, A., Dynamique du transfert du plomb dans l'ocean Atlantique nord-est depuis l'atmosphere jusqu'au sediment, These Docteur en Sciences, Univ. Paris-Sud, France, 1988.

Vet, R.J., W.B. Sukloff, M.E. Still, and R. Gilbert., Canadian Air and Precipitation Network 
(CAPMoN) precipitation chemistry data summary 1983-1984, Report AORB-86-001-M. 544 pp., Atmo. Environ. Serv., Downsview, Ont., Canada, 1986.

Villeneuve, J.-P., and C. Cattini, Input of chlorinated hydrocarbons through wet and dry deposition to the western Mediterranean, Chemosphere, $15,115-120,1986$.

Volkening, J., and K.G. Heumann, Heavy metals in the near-surface aerosol over the Atlantic Ocean from $60^{\circ}$ South to $54^{\circ}$ North, J. Geophys. Res., 95, 20,623-20,632, 1990.

Volkening, J., H. Baumann, and K.G. Heumann, Atmospheric distribution of particulate lead over the Atlantic Ocean from Europe to Antarctica, Atmos. Environ., 22, 1,169-1,174, 1988.

Wade, T.L., E.L. Atlas, J.M. Brooks, M.C. Kennicutt II, R.G. Fox, J. Sericano, B. GarciaRomero, and D. Defreitas, NOAA Gulf of Mexico Status and Trends Program: Trace organic contaminant distribution in sediments and oysters, Estuaries, 11, 171-178, 1988.

Wagenbach, D., U. Gärlach, K. Maser, and K.O. Münnich, Coastal Antarctic aerosol: The seasonal pattern and its chemical composition and radionuclide content, Tellus, Ser. B., 40, 426-436, 1988.

Walsh, P.R., and R.A. Duce, The solubilization of anthropogenic atmospheric vanadium in seawater, Geophys. Res. Lett., 3, 375-378, 1976.

Walton, J.J., M.C. MacCracken, and S.J. Ghan, A global scale Lagrangian trace species model of transport, transformation, and removal processes, J. Geophys. Res., 23, 8,339-8,354, 1988.

Wanninkhof, R., J.R. Ledwell, and W.S. Broecker, Gas exchange - wind speed relation measured with sulfur hexafluoride on a lake, Science, 227 . 1,224-1,226, 1985.

Warneck, P., Chemistry of the Natural Atmosphere, 757 pp., Academic, San Diego, Calif., 1988.

Watson, A.J., R.C. Upstill-Goddard, and P.S. Liss, Air-sea gas exchange in rough and stormy seas measured by a dual-tracer technique, Nature, 349 , 145-147, 1991.

Weisel, C.P., R.A. Duce, J.L. Fasching, and R.W. Heaton, Estimates of the transport of trace metals from the ocean to the atmosphere, J. Geophys. Res., 89, 11,607-11,618, 1984.

Wells, D.E., and S.J. Johnstone, The occurrence of organochlorine residues in rainwaters, Water Air Soil Pollut., 2, 271-280, 1978.

Whelpdale, D.M., and J.L. Moody, Large-scale meteorological regimes and transport processes, in The Long-Range Atmospheric Transport of Natural and Contaminant Substances, edited by A.H. Knap, pp. 3-36, Kluwer, Boston, Mass., 1990.

Whelpdale, D.M., W.C. Keene, A.D.A. Hansen, and J. Boatman, Aircraft measurements of sulfur, nitrogen, and carbon species during WATOX-86, Global Biogeochem. Cycles, 1, 357-368, 1987.

Whitehouse, B., The effects of dissolved organic matter on the aqueous partitioning of polynuclear aromatic hydrocarbons, Estuarine Coastal, and Shelf Sci., 20, 393-402, 1985.

Wolff, G.T., M.S. Ruthkosky, D.P. Stroup, P.E. Korsog, M.A. Ferman, G.J. Wendel, and D.H. Stedman, Measurements of $\mathrm{SO}_{\mathbf{x}}, \mathrm{NO}_{\mathbf{x}}$, and aerosol species on Bermuda, Atmos. Environ., 20, 1,229-1,239, 1986a.

Wolff, G.T., N.A. Kelly, M.A. Ferman, M.S. Ruthkosky, D.P. Stroup, and P.E. Korsog, Measurements of sulfur oxides, nitrogen oxides, haze, and fine particles at a rural site on the Atlantic coast, $\mathbf{J}$. Air Pollut. Control Assoc., 36, 585-591, 1986 b.

Wollast, R., Interaction between major biogeochemical cycles in marine ecosystems, in Some Perspectives of the Maior Biogeochemical Cycles, edited by G.E. Likens, pp. 125-142, John Wiley, New York, 1981.

Wollast, R., Interactions in estuaries and coastal waters, in The Major Biogeochemical Cycles and Their Interactions. SCOPE 21, edited by B. Bolin and R.B. Cook, pp. 385-407, John Wiley, New York, 1983.

Wollast, R., and L. Chou, Kinetic study of the dissolution of albite with a continuous flow-trough fluidized bed reactor, in The Chemistry of Weathering, edited by J.I. Drever, pp. 75-96, D. Reidel, Norwell, Mass., 1985.

Yamasaki, H., K. Kuwata, and H. Miyamoto, Effects of temperature on aspects of airborne polycyclic aromatic hydrocarbons, Environ. Sci. Technol., 16, 189-194, 1982.

Zafiriou, O.C., and M. McFarland, Nitric oxide from nitrite photolysis from the central equatorial Pacific, J. Geophys. Res., 86, 3,173-3,182, 1981.

Zafiriou, O.C., R.B. Gagosian, E.T. Peltzer, J.B. Alford, and T. Loder, Air-to-sea fluxes of lipids at Enewetak Atoll, L. Geophys. Res., 20, 2,4092,423, 1985.

Zhuang, G., R.A. Duce, and D.R. Kester, The solubility of atmospheric iron in surface seawater of the open ocean, J. Geophys. Res., 25, 16,20716,216, 1990.

R. Arimoto, R.A. Duce, W. Ellis, L. Hanson, J.T. Merrill, and J.J. Tokos, Jr., Graduate School of Oceanography, University of Rhode Island, Narragansett, RI 02881.

E.L. Atlas, National Center for Atmospheric

Research, Boulder, CO 80307.

P. Buat-Menard, Centre des Faibles

Radioactivites, B.P. 1, 91190 Gif-sur-Yvette, France. 
T.M. Church, College of Marine Studies, University of Delaware, Newark, DE 19711. J.N. Galloway, Department of Environmental Sciences, University of Virginia, Charlottesville, VA 22903.

B.B. Hicks and J.M. Miller, Air Resources Laboratory, NOAA, Silver Spring, MD 20910. T.D. Jickells and P.S. Liss, School of Environmental Sciences, University of East Anglia, Norwich NR4 7TJ, England.

A.H. Knap, Bermuda Biological Station for Research, Ferry Reach 1-15, Bermuda.

J.M. Prospero, Rosenstiel School for Marine and Atmospheric Sciences, University of Miami, Miami, FL 33149.

K.H. Reinhardt, GKSDS Research Center, MaxPlanckstrasse, D-2054 Geesthacht, Federal Republic of Germany.
B. Schneider, Institut fur Meereskunde, Universitat Kiel, D-2300 Kiel, Federal Republic of Germany.

A. Soudine, World Meteorological Organization, C.P. 5, CH-1211 Geneve 20, Switzerland.

S. Tsunogai, Department of Chemistry, Hokkaido University, Hakodate, Japan.

R. Wollast, Laboratoire d'Oceanographie, Universite Libre de Bruxelles, 2050 Bruxelles, Belgium.

M. Zhou, National Research Center for Marine Environment Forecasts, Beijing 100081, People's Republic of China.

(Received September 6, 1990; revised June 14, 1991; accepted July 2, 1991.) 